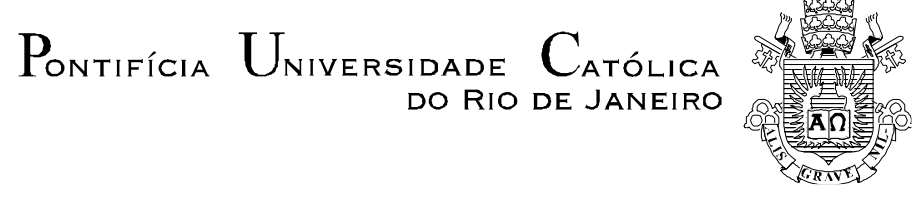

Lorena Hernandez Mastrapa

\title{
MELHORIAS EM UM MÉTODO HEURÍSTICO PARA A SOLUÇÃO DO PROBLEMA DE DESENHO DE REDE DE TRANSPORTE PÚBLICO URBANO
}

Dissertação de Mestrado

Dissertação apresentada como requisito parcial para obtenção do grau de Mestre pelo Programa de Pós-graduação em Transporte e Logística do Departamento de Engenharia Industrial da PUC-Rio.

Orientador: Prof. José Eugenio Leal

Co-Orientador: Profa. Luciana Pessoa

Rio de Janeiro

Agosto de 2017 


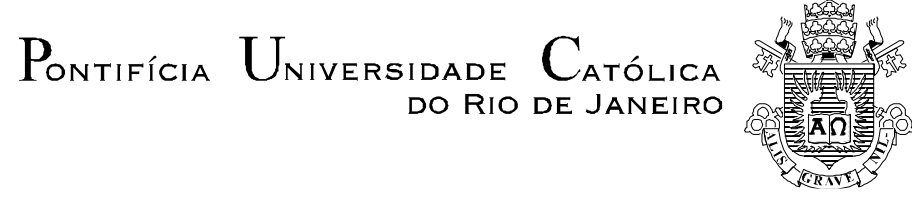

Lorena Hernández Mastrapa

\section{MELHORIAS EM UM MÉTODO HEURÍSTICO PARA A SOLUÇÃO DO PROBLEMA DE DESENHO DE REDE DE TRANSPORTE PÚBLICO URBANO}

Dissertação apresentada como requisito parcial para obtenção do grau de Mestre pelo Programa de Pós-Graduação em Engenharia de Produção da PUC-Rio. Aprovada pela Comissão Examinadora abaixo assinada.

Prof. José Eugenio Leal Orientador

Departamento de Engenharia Industrial - PUC-Rio

Prof. Luciana de Souza Pessôa Presidente e Co-orientadora Departamento de Engenharia Industrial - PUC-Rio

Prof. Orivalde Soares da Silva Júnior Departamento de Engenharia Industrial - PUC-Rio

Prof. Vânia Barcellos Gouvêa Campos Instituto Militar de Engenharia - IME

Prof. Márcio da Silveira Carvalho Coordenador Setorial do Centro

Técnico Científico - PUC-Rio

Rio de Janeiro, 10 de agosto de 2017 
Todos os direitos reservados. É proibida a reprodução total ou parcial do trabalho sem autorização da universidade, da autora e do orientador.

\section{Lorena Hernández Mastrapa}

Graduou-se em Engenharia Industrial na Universidade de Holguín “Oscar Lucero Moya”, Cuba em 2013.

Ficha Catalográfica

Hernández Mastrapa, Lorena

Melhorias em um método heurístico para a solução do problema de desenho de rede de transporte público urbano / Lorena Hernández Mastrapa; orientador: José Eugenio Leal ; coorientadora: Luciana de Souza Pessôa. - 2017.

114 f. ; $30 \mathrm{~cm}$

Dissertação (mestrado)-Pontifícia Universidade Católica do Rio de Janeiro, Departamento de Engenharia Industrial, 2017.

Inclui bibliografia

1. Engenharia Industrial - Teses. 2. Problema de desenho de redes de ônibus urbano. 3. Métodos heurísticos. 4. Otimização de redes de transporte público urbano. I. Leal, José Eugenio. II. Pessôa, Luciana de Souza. III. Pontifícia Universidade Católica do Rio de Janeiro. Departamento de Engenharia Industrial. IV. Título.

CDD: 658.5 


\section{Agradecimentos}

A Deus, por ter permitido que eu alcançasse mais um sonho.

Aos meus pais, pelo apoio incondicional.

A meu esposo, pela compreensão, pela força, por ser meu melhor amigo e parceiro.

A minha prima Gretell, pela ajuda infinita.

Aos meus orientadores, sem os quais não tivesse conseguido.

À CAPES e a PUC-Rio, pelos auxílios concedidos, sem os quais não tivesse sido possível realizar esse trabalho. 


\section{Resumo}

Mastrapa, Lorena Hernández; Leal, Jose Eugenio; Pessoa, Luciana. Melhorias em um método heurístico para a solução do Problema de Desenho de Rede de Transporte Público Urbano. Rio de Janeiro, 2017. 114p. Dissertação de Mestrado - Departamento de Engenharia Industrial, Pontifícia Universidade Católica do Rio de Janeiro.

Atualmente mais da metade da população mundial mora em cidades. O deslocamento na região urbana, mediante a utilização de transporte público se dificulta devido ao planejamento deficiente das rotas e redes de transporte, longos tempos de viagem, aumento do custo das passagens, dos tempos de espera, etc. Como consequência, a busca de operações mais eficientes no sistema de transporte público urbano tem aumentado visando atender as necessidades de transporte de forma mais sustentável. Após a revisão da literatura relacionada ao problema de desenho de rede de transporte público urbano, foi escolhido o método proposto por Aquino, (1980), aplicável para redes de ônibus urbanos. Por médio da modernização do programa do método escolhido e as melhorias nele, o número de rotas que define a rede conectada diminuiu. O número de transbordos na rede foi minimizado até zera-lo com um menor conjunto de rotas. Análise de indicadores e de rentabilidade das rotas que minimizam o número de transbordo na rede, permite ao planejador ter uma visão geral do comportamento dessas rotas possibilitando tomar decisões mantendo os requerimentos iniciais e o objetivo de estudo. O programa do método desenvolvido, adaptado a uma linguagem moderna, $\mathrm{C}++$, oferece, tanto ao meio acadêmico quanto ao profissional, uma ferramenta de fácil aplicação para dar solução ao Problema de Desenho de Rede de Transporte Público Urbano. Contribuindo potencialmente ao incremento da eficiência do processo de planejamento e, portanto, à redução de não conformidades do serviço de transporte resultando em economia dos custos para as empresas prestadoras deste serviço.

\section{Palavras chave}

Problema de Desenho de Redes de Ônibus Urbano; Métodos Heurísticos; Otimização de Redes de Transporte Público Urbano. 


\section{Abstract}

Mastrapa, Lorena Hernández; Leal, Jose Eugenio; Pessoa, Luciana (Advisor). Improvement in heuristic method for the solution of the Urban Public Transport Network Design Problem. Rio de Janeiro, 2017. 114p. MsC Thesis - Departament of Industrial Engineering, Pontifícia Universidade Católica do Rio de Janeiro.

Nowadays, more than half of the world's population lives in cities. Displacement in the urban area through the use of public transportation is hampered by poor planning of transport routes and networks, long travel times, increased ticket costs and waiting times, etc. As a consequence, the search for more efficient operations in the urban public transport system has increased in order to meet the transport needs in a more sustainable way. After the literature review related to the urban public transport network design problem, the method proposed by Aquino (1980), applicable to urban bus networks, was chosen. By means of the program's modernization of the chosen method and the improvements in it, the number of routes defining the connected network has decreased. The overflow number on the network has been minimized to zero with a smaller set of routes. Analysis of indicators and profitability of the routes that minimize the number of transfer in the network, allows the planner to have an overview of the behavior of these routes allowing to make decisions keeping the initial requirements and the objective of study. The developed method program, adapted to a modern language, $\mathrm{C}++$, offers both an academic and a professional environment an easy application tool to solve the Urban Public Transport Network Design Problem. Potentially contributing to the increase of the efficiency of the planning process and, therefore, to the reduction of nonconformities of the transport service, resulting in cost savings for the companies that provide this service.

\section{Keywords}

Transit Network Design Problem; Heuristic Method; Urban Public Transport Network Optimization. 


\section{Sumario}

1. Introdução 12

1. 1 Caracterização do problema 12

1. 2 Justificativa 15

$\begin{array}{ll}1.3 \text { Objetivos } & 16\end{array}$

$\begin{array}{ll}1.4 \text { Estrutura da dissertação } & 16\end{array}$

2. Análise da literatura referente ao Problema de Desenho de Rede de $\begin{array}{lr}\text { Transporte Público Urbano (PDRTPU) } & 18\end{array}$

2. 1 Sistema de transporte público urbano 18

2. 1.1 Processo de Planejamento do Sistema de Transporte Público Urbano 19

2. 2 Definição do Problema de Desenho de Rede de Transporte Urbano 21

2. 2.1 Classificação do PDRTU 22

2. 2.1 Análise de modelos do PDRTPU 24

2.3 Métodos de solução para o PDRTPU $\quad 27$

2. 3.1 Análise dos métodos heurísticos de construção de solução para o PDRTPU 28

3. Formulação do PDRTPU 37

3. 1 Delimitação do problema 37

3. 1.1 Critérios avaliados no estudo 38

3. 2 Representação do problema 39

3. 2.1 Hipóteses do problema 41

3.3 Descrição da rede 43

4. Proposta da estratégia para a resolução do PDRTPU 46

4. 1 Definição da estratégia de solução do PDRTPU 46

4. 2 Descrição do método e das adequações aplicadas 49 
4. 2.1 Geração do conjunto de rotas candidatas

4. 2.2 Geração de uma rede inicial conectada

4. 2.3 Definição de um conjunto de rotas em ordem de minimização de transbordos

5. Análise dos resultados

65

5. 1 Dados usados na aplicação do algoritmo modificado 65

5.2 Geração do conjunto de rotas candidatas $\quad 70$

5.3 Geração de uma rede inicial conectada 76

5. 3.1 Definição de um conjunto de rotas em ordem de minimização de transbordos

78

5. 3.2 Avaliação das rotas que minimizam os transbordos na rede

79

6. Considerações finais

84

6. 1 Conclusões

84

6.2 Recomendações

85

7. Referências bibliográficas

86

8. Anexos

96 


\section{Lista de figuras}

Figura 1. População urbana e rural mundial de 1950 até 2050.Tomado de Nações Unidas (2014b)...................................................................... 12

Figura 2. Exemplo de um mapa do processo de solução do PDRTU. Adaptado de Farahani, et al. (2013) e Ibarra -Rojas, et al. (2015)..............22

Figura 3. Exemplo de rede de transporte............................................... 44

Figura 4. Fluxograma da função principal proposta por Aquino, (1980)........48

Figura 5. Pseudocódigo da função para a geração do conjunto de rotas candidatas G por Aquino, (1980). Algoritmo Floyd-Warsahall, (1962). .50

Figura 6. Pseudocódigo da função que gera o conjunto de rotas candidatas G modificado. Dijkstra, (1959).

Figura 7. Pseudocódigo da função que elimina as rotas que retrocedem sobre elas mesmas do conjunto $\mathrm{G}^{*}$ por Aquino, (1980).

Figura 8. Pseudocódigo da função que elimina as rotas que retrocedem sobre elas mesmas do conjunto $\mathrm{G}^{\star}$ modificado. .53

Figura 9. Pseudocódigo da função que junta linhas complementares. .54

Figura 10. Pseudocódigo da função que elimina as rotas inseridas em outras no conjunto de rotas candidatas $G^{*}$ por Aquino, (1980). .55

Figura 11. Pseudocódigo da função que elimina as rotas inseridas em outras no conjunto de rotas candidatas $\mathrm{G}^{*}$ modificado. .55

Figura 12.Pseudocódigo da função que gera o conjunto de rotas candidatas F, por Aquino, (1980). 
Figura 13. Pseudocódigo da função que gera o conjunto de rotas candidatas F, por Aquino, (1980).

Figura 14. Pseudocódigo da função que gera o conjunto de rotas candidatas $\mathrm{F}$ modificado. .58

Figura 15. Pseudocódigo original da rotina para criar o conjunto de rotas que definem a rede conectada. 60

Figura 16. Pseudocódigo da função que cria a rede conectada modificada. 60 Figura 17. Fluxograma da função principal modificada. 67

Figura 18. Rede de teste 68

Figura 19.Trajetória das rotas que definem a rede conectada. .77 Figura 20.Trajetória das rotas que definem a rede conectada pelo método modificado. 


\section{Lista de tabelas}

Tabela 1. Análise de métodos heurísticos pesquisados para a solução de PDRTPU. Adaptado de Baaj e Mahmassani, (1994)...................................33

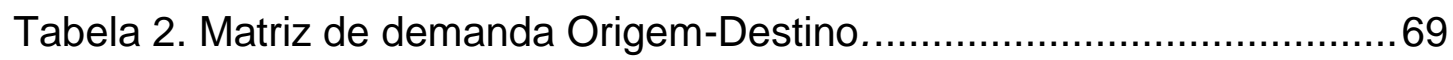

Tabela 3.Valores de distância e tempos de viagem de ida (I) e volta (V) nos arcos.

Tabela 4.Conjunto de rotas do geradas para o conjunto G. Obtidas pelo algoritmo de Floyd-Warshall e pelo Algoritmo Dijkstra.

Tabela 5.Conjunto de rotas do geradas para o conjunto $\mathrm{G}^{*}$. Segundo o método original e o modificado.

Tabela 6. Conjunto de rotas do geradas para o conjunto F. Segundo o método original e o modificado. .75

Tabela 7. Conjunto de rotas que definem a rede conectada. Segundo o método original e o modificado.

Tabela 8. Conjunto de rotas candidatas em ordem de minimização de transbordos. Segundo o método original e o modificado.

Tabela 9. Indicadores que avaliam o conjunto de rotas que minimizam o número de transbordos na rede.

Tabela 10. Comparação entre o desempenho das rotas criadas pelo método Aquino (1980) e o modificado 


\section{1.}

\section{Introdução}

Neste capítulo serão expostas as motivações que impulsionaram a presente pesquisa, apresentando o problema a ser resolvido, os objetivos, justificativa do estudo e a estrutura desta dissertação.

\section{1}

\section{Caracterização do problema}

O crescimento das cidades em termos de superfície e população é uma das tendências globais mais importantes desde o século passado. O ano 2007 marcou uma etapa histórica no mundo. Nesse ano o percentual da população urbanizada excedeu pela primeira vez a população rural, crescendo para mais de $50 \%$ da população mundial, segundo o relatório das Nações Unidas (2014a). Com mais de 7,2 bilhões de pessoas no mundo, enquanto este documento está sendo escrito (2017), existem mais de 3.8 bilhões de pessoas que moram nas cidades. Além disso, este fenômeno tem uma rápida velocidade; tendo em conta o período de tempo de 1950 a 2050, enquanto a população mundial cresce anualmente em média 1,30\%, a população urbana cresce em média 2,16\% ao ano (Nações Unidas, 2014b). A figura 1 mostra a evolução da população mundial (total, urbana e rural) de 1950 a 2050 (projetada).

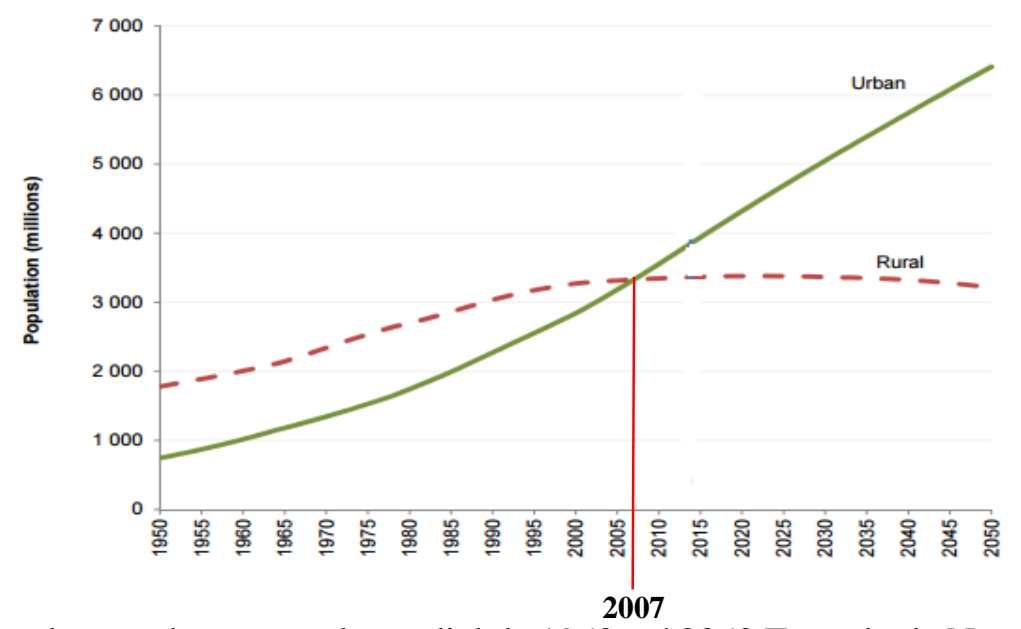

Figura 1. População urbana e rural mundial de 1950 até 2050.Tomado de Nações Unidas (2014b). 
Um impacto desta rápida urbanização é o crescimento das cidades em todo o mundo. Em especial, o surgimento de megacidades e megaregiões está se tornando mais frequente, onde a população está atingindo níveis consideravelmente altos.

As cidades de São Paulo e Rio de Janeiro ocupam, respectivamente, o quarto e o decimo nono lugar na lista das trinta cidades com maior população do mundo, colocando o Brasil entre os quatro países com maior população urbana, antecedido por Índia, China e Japão (2014a). Segundo o relatório das Nações Unidas (2014a) essas cidades brasileiras colocam o Brasil nos primeiros lugares no ranking das 30 cidades com maior população urbana.

A questão da mobilidade urbana ainda é tratada no Brasil como uma questão de provisão de serviços de transporte. As iniciativas de planejamento se caracterizaram, no país, por uma sucessão de planos viários e de transporte público, frequentemente sem articulação. Além disto, padecem de falta de continuidade, uma vez que as administrações locais raramente preservam o que foi proposto por seus antecessores, sobretudo quando é de linhas políticas distintas (IPEA, 2016).

Todo este planejamento dos transportes urbanos no Brasil acontece em um espaço onde os recursos são limitados, consequentemente gerando desperdícios financeiros, agravados pela falta de controle social e quando se observa que as questões ambientais não são devidamente consideradas (IPEA, 2016).

O planejamento do transporte rodoviário que tem criado estratégias de construção de grandes vias expressas, a priorização do transporte individual em detrimento do coletivo e a desarticulação entre o planejamento urbano e de transportes deram origem a graves problemas de mobilidade hoje encontrados nas cidades brasileiras, (IPEA, 2016). Isso prova que na dissociação entre planejamento urbano e de transportes ainda existe uma brecha que precisa ser superada.

O agravamento dos problemas de mobilidade, resultantes deste modo fragmentado de ver a cidade e seus sistemas de transportes, levou ao desenvolvimento de um novo paradigma para a mobilidade urbana, que tem recebido diferentes denominações: transporte sustentável, mobilidade sustentável, transporte humano, 
mobilidade cidadã, entre outros (Brasil, 2005). Aqui o foco está na melhoria da qualidade de vida das pessoas, resultado de cidades mais acessíveis, com menos desigualdades sociais e que respeitem o meio ambiente. Isto se dá necessariamente no contexto de um tratamento sistêmico e integrado da mobilidade.

No entanto, as cidades são sistemas complexos que estão evoluindo constantemente, e o planejamento para um futuro sustentável não é uma tarefa fácil. Em particular o domínio do transporte terá de sofrer grandes mudanças estruturais e comportamentais para se adaptar ao futuro. Este trabalho enquadra-se, portanto, no tema do transporte urbano sustentável, pois está focalizado num método que visa tornar os sistemas de transporte urbano mais sustentáveis através da promoção do transporte público.

Dentre os modos de transporte público que garantem o deslocamento das pessoas nas regiões urbanas predomina o ônibus devido às características de: grande flexibilidade para conectar pontos de origem e destino dispersos nas zonas urbanas; custos de implantação relativamente baixos; adaptabilidade da oferta a incrementos da demanda até limites de densidade de trafego que exigem modalidade de atendimento em massa (Aquino, 1980).

A maior deficiência, do ponto de vista da mobilidade urbana do Brasil, é a ausência de uma rede metropolitana integrada de transportes que atenda a demanda da cidade aportando benefícios para toda a população de forma tal que permita deslocar as pessoas de forma econômica, rápida, confortável e saudável, ou seja, um transporte público sustentável.

Um sistema cientificamente projetado pode reduzir o total de ônibus requeridos para transportar um determinado volume de passageiros, levando a um uso mais eficiente e econômico da frota disponível. Tal sistema gera ainda outros benefícios, como: redução em congestionamentos e redução da sobrecarga do ônibus com resultante aumento da segurança, conforto e velocidade. 


\section{2}

\section{Justificativa}

Segundo Krempi (2004) muitas cidades brasileiras não possuem serviço de transporte público urbano de boa qualidade o que termina prejudicando a acessibilidade dos moradores a diferentes áreas da região. Os mais prejudicados são aqueles que moram nas periferias das cidades, pois devido as grandes distancias e ao precário serviço de transportes, acabam despendendo mais tempo de viagem.

Observa-se que uma das variáveis a ter em conta nas estratégias de planejamento de transporte urbano é o tempo de viagem, tendo como premissa fundamental que os usuários desejam chegar aos seus destinos da mais forma rápida. O tempo total de viagem é decomposto em tempo de saída de / para as paradas, espera, viajem no veículo e transbordos (Ortúzar e Willumsen, 2001; Raveau et al, 2011; Cepeda et al, 2006; Schmöcker et al, 2011).

É evidente que uma das variáveis que influencia no tempo de viagem é o transbordo entre linhas de ônibus, entenda-se como o ato o efeito dos passageiros passarem de uma linha de ônibus para outra. A existência do transbordo pode reduzir a sobreposição entre linhas, e consequentemente que as estradas estejam menos sobrecarregadas pelo trânsito de veículos. Ao mesmo tempo um número elevado de transbordos reduz o nível de serviço oferecido com o aumento de custos de viagem, e do tempo de percurso (Barra, 2011).

Assim, torna-se necessária a avaliação dos sistemas integrados de transporte urbano por ônibus, no sentido de analisar os impactos causados pelos transbordos nas estações de transferência. Estes podem ser avaliados tanto quantitativamente, apresentando relações diretas entre os custos do sistema como um todo, quanto qualitativamente, avaliando preferências e opiniões dos usuários de sistemas já implantados (Barra, 2011).

A partir de uma busca bibliográfica feita foi possível perceber que ainda não existe uma literatura ampla de estudos dedicados à análise da variável transbordo, entre as linhas de ônibus urbanos. Além disso, métodos como o proposto por Aquino (1980) 
podem ser aproveitados na atualidade, apartando-lhes melhorias e modernização ao desenvolvimento destes métodos, com o intuito de aproveitar estas ferramentas já propostas não publicadas e com potencial de oferecer boas soluções ao PDRTPU. A presente pesquisa se justifica por um estudo que visa planejar uma rede interurbana que seja conectada por várias linhas de ônibus com o número mínimo de transbordos visando fornecer um software que facilite o planejamento e a tomada de decisão no transporte público urbano.

\section{3}

\section{Objetivos}

O objetivo principal deste estudo é oferecer uma ferramenta computacional básica para resolver o PDRTPU, a partir da implementação computacional do método proposto por Aquino (1980).

Adicionalmente os objetivos específicos são:

1. Analisar o estado da arte do Problema de Desenho de Rede de Transporte Público Urbano (PDRTPU), assim como os métodos de solução mais usados para este problema.

2. Formular o PDRTPU, segundo as características do problema objeto de estudo.

3. Identificar as principais estruturas do programa desenvolvido por Aquino e propor melhorias visando simplificar alguns aspectos, melhorar sua legibilidade e obter melhores resultados finais.

4. Disponibilizar para o meio acadêmico e profissional uma versão mais moderna do programa de solução do PDRTPU, em C++.

\section{4}

\section{Estrutura da dissertação}

Este documento está estruturado como é descrito a seguir. Após esta introdução, no capítulo 2 é feita uma revisão da literatura que estuda o PDRTPU como parte do 
planejamento do Sistema de transporte e que aplica os diferentes métodos de solução para o problema. Em seguida, no capítulo 3, é formulado o PDRTPU de acordo com as características do problema e as hipóteses estabelecidas. No capítulo 4, é descrito o método implementado segundo as condições definidas no capítulo anterior, assim como a descrição das modificações feitas com o objetivo de introduzir melhorias nos resultados obtidos após sua aplicação. Uma análise comparativa entre os resultados obtidos com a aplicação das mudanças feitas ao método e os resultados obtidos originalmente é detalhada no capítulo 5. A seguir são dispostas as conclusões do trabalho que estabelecem especialmente o caminho para futuras pesquisas que potencializem o desenvolvimento dos métodos de solução do PDRTPU. Finalmente são apresentados os anexos que complementam o presente estudo. 


\section{2.}

\section{Análise da literatura referente ao Problema de Desenho de Rede de Transporte Público Urbano (PDRTPU)}

\section{1}

\section{Sistema de transporte público urbano}

O transporte público é considerado de vital importância no desenvolvimento urbano sustentável, uma vez que deve permitir movimentos mais eficientes em toda a cidade. No entanto, os sistemas de transportes públicos muitas vezes têm dificuldades em fornecer um bom nível de serviço a um custo acessível para a administração pública e para o usuário (Ibarra-Rojas et al., 2015).

Estes sistemas variam um pouco ao redor do mundo. Muitas vezes uma rede com vários modos oferece oportunidades de integração entre estes serviços. Enquanto algumas cidades oferecem integração tarifária em toda a cidade, em outros, todos os serviços competem como alternativas independentes. Enquanto algumas cidades dependem das operações de empresas privadas, outras mantêm essa responsabilidade dentro de uma agência pública. Tudo isso evidencia que planejar, operar e controlar um sistema de transporte público, é muito desafiador (Ibarra-Rojas et al., 2015).

Usuários e não-usuários interagem na cidade em um espaço cada vez mais limitado: o congestionamento rodoviário e a limitada capacidade veicular implicam que a decisão de cada viajante afetará a experiência de muitos outros. O contexto urbano em que toda essa atividade acontece é muito dinâmico e muitas vezes imprevisível, de modo que elementos-chave como a demanda e os tempos de viagem seguem padrões inerentemente estocásticos dependentes do tempo (Ibarra-Rojas et al., 2015).

Nas últimas décadas foram desenvolvidas novas tecnologias destinadas a melhorar a informação disponível para o planejamento e controle do funcionamento 
dos sistemas de transportes públicos, como: Sistemas Automatizados de Coleta de Tarifas (AFC); Sistemas de Contador Automático de Passageiros (APC); Sistemas Automatizados de Localização de Veículos (AVL), e Sistemas de Posicionamento Geográfico (GPS), entre outros. Estas ferramentas estão, cada vez mais, sendo instaladas em sistemas de transporte público. Seu uso permitiu uma melhor compreensão do impacto das decisões e um melhor desempenho. A grande quantidade de dados que estes sistemas fornecem tornou-se um ativo importante que poderia ser explorado de forma mais intensa (Ibarra-Rojas et al., 2015).

Cada um dos níveis de decisão - estratégicos, táticos e operacionais -, bem como decisões em tempo real, afetam a eficiência do sistema, que é um elemento importante na obtenção de um sistema de transporte público sustentável em áreas urbanas segundo Ibarra-Rojas, et al. (2015). De fato, o funcionamento eficiente dos sistemas de transporte além de influenciar nos níveis de poluentes, consumo de combustível e ruído, podem incentivar a interação entre os indivíduos e reduzir a segregação das comunidades através do estabelecimento de canais de comunicação entre eles. Devido a esses benefícios potenciais, o desenvolvimento de ferramentas eficientes para o planejamento de sistemas de transporte, campo onde se concentra o presente estudo, continua a ser uma área de pesquisa desafiadora que exige a consideração cuidadosa de diferentes características no contexto de diferentes cidades.

\section{1.1}

\section{Processo de Planejamento do Sistema de Transporte Público Urbano}

O processo de planejamento abrange todas as decisões que devem ser tomadas antes da operação do sistema, e é conhecido como o Problema de Planejamento de Rede de Transporte (PPRT). Devido à sua complexidade, o PPRT é comumente dividido nos seguintes subproblemas que abrangem decisões táticas, estratégicas e operacionais (Desaulniers e Hickman, 2007; Ceder, 2007).

- Desenho da Rede de Transporte: Define os desenhos de linhas e as características operacionais associadas, como tipos de material circulante e espaço entre paradas, a fim de otimizar funções objetivo específicas, como a minimização da 
soma ponderada dos custos dos operadores e dos usuários. O presente estudo está focado na resolução desse subproblema para o ônibus público urbano especificamente. - Definição de Frequência: caracteriza os períodos de operação com base nos padrões de demanda (pico da manhã, pico não matutino, pico da tarde e assim por diante) e determina o número de viagens por hora necessárias para satisfazer a demanda de passageiros em cada período de planejamento.

- Programação de horários do transporte público: Define os horários de chegada e partida dos ônibus em todas as paradas ao longo da rede de transporte público, a fim de atingir diferentes objetivos, tais como: atender a uma dada frequência, satisfazer padrões de demanda específicos, maximizar o número de transferências oportunas de passageiros e minimizar os tempos de espera. Em alguns casos, o número de viagens é dado, enquanto outros problemas também podem determinar o número de viagens com base na capacidade do veículo e padrões de demanda.

- Programação de Veículos: Determina a atribuição de veículos para cobrir todas as viagens planejadas, de forma que os custos operacionais baseados no uso do veículo sejam minimizados.

- Programação da tripulação: Define tarefas diárias que cobrem todas as viagens programadas e minimizar o custo dos salários do motorista e eventual cobrador. As soluções devem satisfazer regulamentações específicas do trabalho para motoristas e cobradores, como duração mínima / máxima de trabalho, tempo de trabalho máximo sem descanso e descanso diário.

Todos estes subproblemas do PPRT tem uma interdependência entre eles. Por exemplo, frequências diferentes podem implicar diferentes horários de veículos e taxas de condução que influenciam fortemente os custos operacionais. Portanto, seria desejável uma abordagem integrada considerando todas as decisões para a solução PPRT. 


\section{2}

\section{Definição do Problema de Desenho de Rede de Transporte Urbano}

Segundo Dantzig et al., (1979), o PDRTU refere-se à construção de novas vias ou a expansão da capacidade das vias existentes. Esta definição é bastante comum na literatura para o catálogo de problemas gerais de desenho de rede.

Friesz, (1985), define que o PDRTU visa determinar as localizações ótimas de instalações a serem adicionadas a uma rede de transporte, ou determinar as melhorias de capacidade de instalações existentes em uma rede. Nesta definição, as instalações podem ser representadas por nós ou por links.

Magnanti e Wong, (1984) afirmaram que o PDRTU lida com uma hierarquia completa de processos de tomada de decisão no planejamento de transporte, incluindo decisões estratégicas, táticas e operacionais. As decisões estratégicas são decisões em longo prazo relacionadas com as infraestruturas das redes de transporte, incluindo as redes de transporte público e rodoviárias; as decisões tácticas são aquelas relativas à utilização eficaz das infraestruturas e recursos das redes de transporte urbano existentes, tomadas entre um prazo mediano e curto; e decisões operacionais são decisões de curto prazo, que são principalmente relacionadas ao controle de fluxo de tráfego, gerenciamento de demanda ou problemas de programação. 
Exemplo de um mapa do processo de solução do PDRTU é apresentado na seguinte

figura.

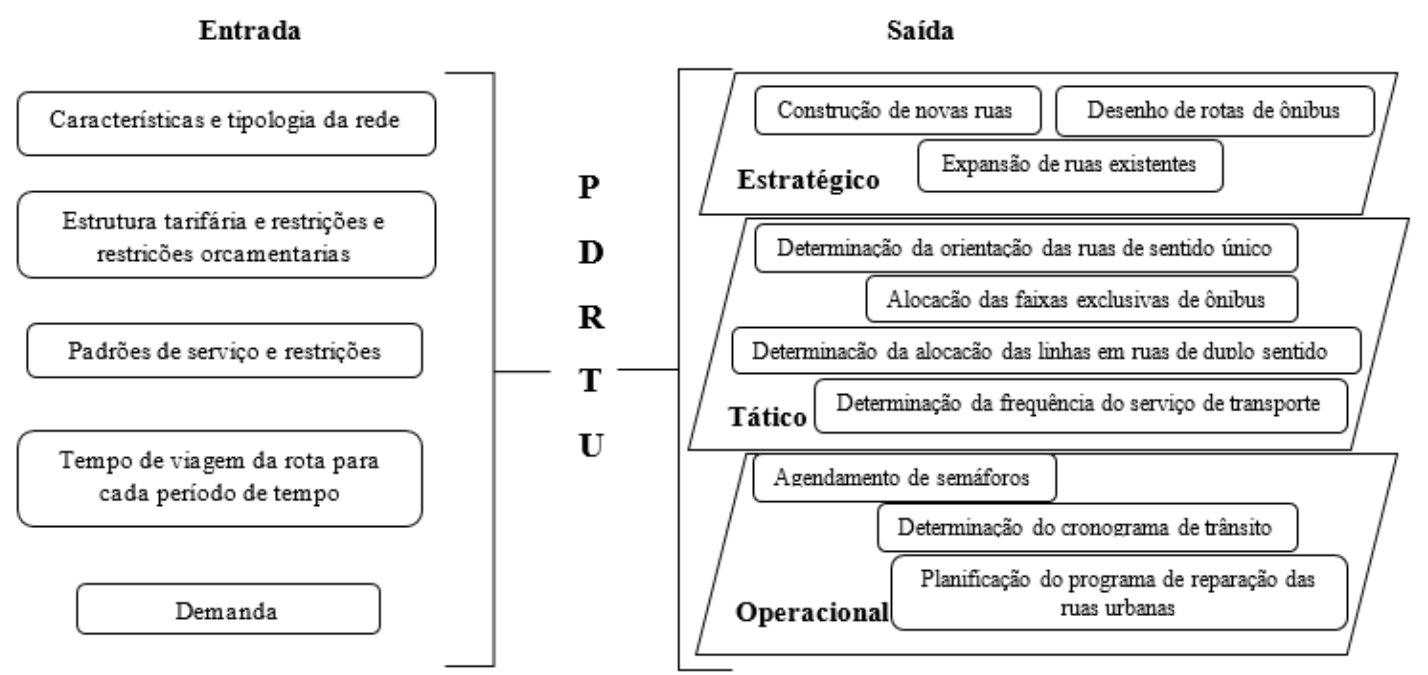

Figura 2. Exemplo de um mapa do processo de solução do PDRTU. Adaptado de Farahani, et al. (2013) e Ibarra-Rojas, et al. (2015).

Esse exemplo de mapa é uma representação que complementa o dito anteriormente sobre a complexidade e a interdependência dos subproblemas que compõem o PDRTU. É importante destacar que a resolução de cada subproblema influi sobre os outros subproblemas e no PDRTU como um todo. Além disso os pontos de entradas podem ser comuns para todos os subproblemas que compõem o PDRTU. Devido à complexidade e abrangência do problema muitos estudos são dedicados a resolver um subproblema só com o intuito de propor algumas soluções de carácter estratégico, como é o caso do presente estudo.

\section{2.1}

\section{Classificação do PDRTU}

O PDRTU pode ser classificado em problemas que surgem de uma variedade de políticas e decisões de projeto de rede possíveis. Tradicionalmente, o PDRTU é considerado separadamente em dois grupos principais. O primeiro grupo considera principalmente redes de rua e não distingue o fluxo de veículos de transporte público e outros veículos particulares, é por isso que os problemas desse grupo são chamados de 
Problemas de Desenho de Redes de Estradas. Eles geralmente supõem que todos os fluxos de tráfego são homogêneos. O segundo grupo considera principalmente a topologia das redes de transporte público, bem como a frequência de serviço e os horários, reconhecendo-se como Problemas de Programação de Redes de Transporte Público (Farahani, et al., 2013; Ibarra-Rojas, et al. 2015).

Com base na natureza das decisões consideradas, os Problemas de Desenho de Redes de Transporte Urbano podem ser ainda classificados em três grupos:

(1) Problema de Desenho Discreto de Rede, que lida com decisões discretas de desenho;

(2) Problema de Desenho Contínuo de Rede, que se preocupa apenas com as decisões de projeto contínuo, tais como a expansão da rede de rodovias, a construção de novas estradas, capacidade das ruas, agendamento de semáforos e determinação de portagens para algumas ruas específicas; e

(3) Problema de Desenho Misto de Rede, que contém uma combinação de decisões contínuas e discretas (Ibarra-Rojas, et al. (2015)).

Segundo Farahani, et al. (2013) os Problemas de Programação de Redes de Transporte Público podem ser classificados em cinco tipos com base na origem das decisões:

(1) Problema de Desenho da Rede de Transporte Público, que atende exclusivamente o desenho de rotas das linhas do Transporte Público, incluindo as origens e destinos das rotas de Transporte Público e a sequência dos links visitados.

(2) Problema de Desenho de Rede de Transporte Público e Configuração de Frequência determina a frequência do serviço de cada linha de ônibus, além do desenho da rota.

(3) Problema de configuração das frequências da rede de Transporte Público trata puramente da definição da frequência dada à estrutura da rota.

(4) Problema do Horário da Rede de Transporte Público trata das questões relacionadas com o horário, atendendo à frequência e às rotas do serviço.

(5) Problema de Programação da Rede de Transporte Público considera tanto a frequência como as decisões de horário dada a estrutura da rota. 
Na realidade, existem múltiplos modos e suas demandas estão inter-relacionadas. O Problema de Desenho de Rede Multi-Modal é uma outra categoria, que engloba pelo menos dois modos diferentes para o PDRTU. O fluxo de trânsito nesta categoria pode abranger automóveis, táxis, vans, ônibus, bicicletas, motocicletas, metrô etc. As decisões consideradas no Problema de Desenho de Rede Multi-Modal podem ser decisões relativas a um único modo (exemplo: estrada, Transporte Público, etc.) ou combinações de várias decisões.

O presente trabalho se enquadra no segundo grupo do PDRTU, referido as redes de transporte público, por tanto a continuação o problema objeto de estudo é referenciado como PDRTPU, Problema de Desenho de Redes de Transporte Público Urbano.

\section{2.1}

\section{Análise de modelos do PDRTPU}

A análise e modelagem do PDRTPU envolvem duas questões importantes: a formulação de políticas para a melhoria da rede, com base na política de transporte para a concepção da rede e, a previsão dos comportamentos dos usuários da rede em resposta às políticas de projeto formuladas (Farahani, et al., 2013).

O PDRTPU pode ser modelado como um problema de otimização discreta para determinar o conjunto de linhas para uma dada matriz Origem-Destino e os tempos de viagem previstos por link na rede. Uma alternativa a esta abordagem é representar o PDRTPU através da análise de modelos que representam abordagens de aproximação contínua, onde a demanda de passageiros é representada como uma função contínua sobre um espaço geográfico em vez de uma matriz Origem-Destino (Clarens e Hurdle, 1975, Daganzo, 2010, Ouyang et al. (2014). A solução de uma aproximação contínua é baseada em uma representação idealizada da cidade que considera estruturas de grade específicas como retangulares, circulares, hub-e-spokes, e assim por diante (IbarraRojas, et al. (2015)).

Segundo Kepaptsoglou e Karlaftis (2009), as abordagens analíticas desenvolvem relações entre os componentes da rede de transporte público representada com 
estruturas idealizadas. Os primeiros estudos se concentraram na determinação do espaçamento entre linhas, espaçamento de parada e frequência de linha, assumindo que a demanda é uniformemente distribuída ao longo da área de serviço (Holryod, 1967; Byrne e Vuchic, 1972). Outras abordagens foram desenvolvidas para considerar a demanda dependente do tempo (Salzborn, 1972), demanda dependente do espaço (Byrne, 1975, Black, 1979) e demanda dependente do tempo e do espaço (Hurdle, 1973).

Concluindo que os termos essenciais e comuns para modelar o PDRTPU incluem: (1) os objetivos do problema; (2) parâmetros de problema tais como, estrutura da rede rodoviária, padrões e características da demanda de viagens dos passageiros, estratégias de operação que possam melhorar a capacidade e o desempenho do sistema de Transporte Público, bem como as limitações do problema; (3) técnicas de solução que podem ser exatas ou heurísticas, (Kepaptsoglou e Karlaftis, 2009).

O problema pode ser formulado como um problema de dois níveis ou um problema líder-seguidor. O problema de nível superior é o problema líder, o problema de projeto, ou o problema do tomador de decisão, (por exemplo, o governo), que planeja ou gerencia a rede de transporte. Este problema de nível superior está relacionado com a discussão de políticas na prática e inclui uma meta mensurável (por exemplo, reduzir o tempo total de viagem), restrições (por exemplo, restrições políticas, físicas e ambientais) e as decisões de projeto a serem tomadas. Este problema de nível superior supõe que o líder pode prever o comportamento dos viajantes. O problema de nível mais baixo é o problema dos seguidores ou o problema dos viajantes que decidem se viajam e, em caso afirmativo, seus modos de viagem e rotas. A estrutura de dois níveis permite ao tomador de decisão considerar a reação dos viajantes e melhorar a rede para influenciar a escolha de viagem dos viajantes, mas não tem controle direto sobre sua escolha. Esta estrutura não permite aos viajantes prever a decisão do líder, mas apenas lhes permite determinar a sua escolha depois de conhecer a decisão do líder (Farahani, et al., 2013).

Ben-Ayed et al. (1988) estudaram problemas de dois níveis e concluíram que mesmo um problema de dois níveis com problemas de nível superior e de nível inferior 
também é NP-complexo. Outra característica é a não convexidade de dois níveis. Mesmo se ambos os problemas de nível superior e inferior podem ser convexos, a convexidade do problema de dois níveis não pode ser garantida (Luo et al., 1996).

Kepaptsoglou e Karlaftis (2009) resumiram os objetivos práticos da PDRTPU como:

- Maximização do benefício do usuário em Transporte Público, que inclui a minimização de custos como viagens, acesso, espera e transferências; Maximização da cobertura de serviços, enquanto os benefícios do sistema são representados pela máxima utilização e qualidade de serviço.

- Minimização de custos de operador de transporte com minimização de tamanho de frota, maximização de lucro, minimização de comprimento de percurso, minimização de horas de operação de veículo e minimização de consumo de combustível como proxies.

- Total maximização do bem-estar que é representado pela minimização dos custos de passageiros e operadores.

- Maximização da capacidade individual da rota de Transporte Público e da capacidade do veículo.

- Conservação de energia - proteção do ambiente contra emissões e ruído.

- Otimização de parâmetros individuais, como número máximo permitido de rotas de Transporte Público, comprimentos de rotas de Transporte Público, bem como o fator de carga, que pode ser entendido como a taxa de ocupação dos ônibus.

$\mathrm{Na}$ prática, algumas das restrições da vida real da PDRTPU podem ser brevemente resumidas da seguinte forma (Baaj e Mahmassani (1995), Pattnaik, et al. (1998), Tom e Mohan (2003), Mauttone e Urquhart (2009), Yan et al. (2013) e Buba e Lee (2016)):

- Cobertura da procura - mede a percentagem de passageiros que viajam direta ou indiretamente da origem até ao destino com, no máximo, duas transferências.

- Comprimento da rota - implica que o comprimento da rota de Transporte Público não deve ser maior que um valor máximo permitido por causa da dificuldade na 
manutenção da programação. Da mesma forma, o comprimento da rota não deve ser inferior a um valor mínimo para garantir a conectividade ou a qualidade do serviço.

- Número máximo de rotas - em consideração aos recursos dos operadores e ao desejo de maximizar o lucro.

- Frequência - exige que a frequência de serviço na rota de Transporte Público resultante seja limitada, pois excedendo o valor máximo operacionalmente implementável, a manutenção da programação se torna difícil. Da mesma forma, é impossível fornecer uma frequência de serviço muito baixa em um ambiente urbano, o que será entendido pelos passageiros como ausência de serviço.

- Fator de carga - reflete a tolerância para o número de passageiros em pé.

- Tamanho da frota - impõe condições adicionais para as frequências e os recursos dos operadores.

- Confiabilidade do tempo de viagem - um parâmetro que reflete o grau de estabilidade de serviço oferecido pelo sistema de Transporte Público.

Como mencionado por Chakroborty (2003), é difícil formular um PDRTPU como um problema matemático, uma vez que é inerentemente discreto e conceitos como transferências e continuidade de rota são difíceis de representar. Baaj e Mahmassani (1991) discutiram a complexidade do problema decorrente de sua natureza combinatória, não-linear, não-convexidade e multiobjetivo. Eles também descreveram as dificuldades na formulação como um modelo matemático e indefinição de layouts de rotas espaciais aceitáveis. Uma terceira abordagem modela as decisões de atribuição de passageiros no PDRTU usando restrições não-lineares ou funções objetivas não-lineares, levando a problemas não convexos que podem ser resolvidos através de algoritmos heurísticos (Ibarra-Rojas,2015).

\section{3}

\section{Métodos de solução para o PDRTPU}

Uma das abordagens para iniciar a solução do PDRTPU é decompô-lo em estágios para gerar as linhas e logo atribuir o fluxo nelas. Por exemplo, Marwah et al. 
(1984) atribuem a demanda às linhas da rede em uma primeira fase e então projetam um conjunto de linhas de ônibus potenciais para selecionar as que minimizam o número de transferências. Outro exemplo é o de Van Nes et al. (1988), onde um procedimento heurístico começa com um dado conjunto de linhas de potencial: é selecionado o que tem o maior número de viagens diretas e a frequência nessa linha é aumentada até atingir o limite orçamentário e o limite de tamanho da frota. Baaj e Mahmassani (1991, 1992, 1995) propuseram decomposições semelhantes para resolver a PDRTPU com o objetivo de maximizar o número de viagens diretas e minimizar os tempos de transferência.

As formulações matemáticas para o projeto de rede de Transporte Público são geralmente intratáveis por abordagens exatas. No entanto, é possível resolvê-los de forma exata, como casos de projeto de linha única (Guan et al., 2003), simplificações que reduzem o tamanho da rede de Transporte Público (Lownes e Machemehl, 2010) e para pequenos casos (Wan e Lo, 2003). As heurísticas e meta-heurísticas avançadas são implementadas, na maioria das vezes, para resolver problemas de PDRTPU, algumas vezes, formuladas com modelos de dois níveis para considerar decisões de atribuição de Transporte Público (Ibarra-Rojas, et al., 2015).

\section{3.1}

\section{Análise dos métodos heurísticos de construção de solução para o PDRTPU}

Nesta seção será feita uma revisão de artigos que propõem métodos de otimização para o desenho de redes de transporte. Os trabalhos iniciais, nos anos 1960 e 1970, em que se dá atenção especial a objetivos exclusivos, tais como a minimização de tempos de transferência, algoritmos de desenho são abordados em Axhausen e Smith (1984).

Lampkin e Saalmans, (1967), propõem um método num estudo de caso de reestruturação de uma rede. Nele busca-se uma estrutura de rotas que permita ao sistema de uma empresa de transporte municipal operar no ponto de equilíbrio entre 
receita e despesa e ao mesmo tempo assegurar um bom nível de serviço aos usuários. A função objetivo, chamada de fluxo corrigido, permite avaliar primeiramente os quatro melhores nós para formar um esqueleto, e depois para definir a inserção dos melhores nós a conformar a rota. O melhor nó a ser inserido na rota esqueleto será aquele que quando incluído causa maior incremento na função objetivo.

Silman, et al., (1974) fazem uma proposta muito parecida com o método descrito anteriormente, onde tem como objetivo modificar um sistema de rotas, através de variações em alguns critérios. Estabelecem a função objetivo: Medida desejável do sistema de rotas (seleção da melhor rota do conjunto de rotas desejáveis). Calculam as frequências ótimas para as rotas de cada conjunto tomado em conta, a taxa e ocupação dos ônibus e o tamanho da frota. Uma vez que a rota ou várias rotas são determinadas, é possível compara-las tendo em conta os seguintes fatores: $f$ requência da rota $r$ $\left(f_{r}\right)$; tempo total na realização (ou percorrido) da rota $\mathrm{r}\left(\theta_{r}\right)$; número de ônibus requeridos para operar a rota, $n_{r}=f_{r} * \theta_{r}$, onde o total de ônibus na frota é N. Este parâmetro pode variar entre períodos.

Hsu e Surti (1977), tiveram como objetivo de estudo, apresentar uma abordagem de decomposição para o desenho de redes de ônibus onde a tarefa do desenho de rede é realizada através da otimização de uma série de subproblemas baseado numa descrição funcional de rotas. Para selecionar o melhor alinhamento para as rotas individuais são desenvolvidos algoritmos para o que ele define como quatro tipos de rotas (rota de atividade, rota corredor, rota residencial e rota de transferência).

Dubois, et al., (1979) fez um estudo com o intuito de modificar a rede de ônibus interurbana, a modo de ajusta-la com a demanda existente, através de um procedimento de análise e decisão multicritério. Para procurar de forma eficiente à linha que maximiza a diminuição do número de conexões, avalia-se para cada zona os números de viagens indiretos que comecem ou terminem nela. A rota a ser adicionada é escolhida de entre aquelas que nas zonas transversais tem um nível de serviço ruim. Para cada rota candidata, avalia-se a soma dos desvios da linha do tempo mínimo, o número de conexões que seriam eliminados com a sua inserção, além da taxa de rentabilidade. A rotina é concluída quando a soma dos desvios da linha nos tempos de 
viagem e o número de conexões são suficientemente baixos, tendo em conta que o número de veículos necessários não aumente muito.

Hobeika e Cho, (1979) apresentam um método para determinar a estrutura de um sistema de rotas de ônibus. Um algoritmo heurístico divide as paradas de ônibus existentes em uma área urbana em setores e busca uma maneira de vincular as paradas ao tentar minimizar a distância total percorrida por todos os ônibus. O processo de otimização está sujeito a restrições de capacidade e distância. As rotas desenvolvidas são melhoradas iterativamente. Em cada iteração, um modelo de escolha desagregada é usado para examinar o comportamento dos passageiros. O equilíbrio entre a oferta e a demanda é atingido quando a proporção de passageiros que utilizam os ônibus não pode ser aumentada através da melhoria da rede de ônibus.

Aquino (1980) desenvolveu um método computacional baseando-se no método de Dubois, et al., (1979). Faz-se um aprofundamento do conjunto de rotas com tamanhos considerados razoáveis e que são gerados por um conjunto de caminhos referidos como "os mais longos caminhos mínimos", ou seja, caminhos mínimos incorporando vários pares O-D e que possuam maior comprimento.

Marwah et al. (1984) desenvolvem um método para a concepção simultânea de rotas e frequências. Em primeiro lugar, os fluxos de passageiros são atribuídos à rede rodoviária. Em seguida, é gerado um grande conjunto de rotas que satisfazem determinadas restrições. Finalmente, as rotas que minimizam o número de transferências de todo o sistema são selecionadas. As heurísticas são utilizadas para a concentração de fluxos na rede rodoviária e para a geração inicial de rotas. A programação linear é utilizada para a seleção de rotas ótimas e para a atribuição de frequências.

Baaj e Mahmassani (1991, 1992, 1994) desenvolvem métodos de projeto de redes de Transporte Público baseados na inteligência artificial. Os métodos discutidos são desenvolvidos por uma formulação típica do problema de projeto de rede como um problema de programação com frequência mínima, fator de carga e restrições de tamanho de frota. O primeiro trabalho (1991) usa fluxogramas para apresentar uma 
descrição quantitativa de um processo de projeto de três estágios para uma rede de rotas. Na primeira etapa, é gerado um grande conjunto de rotas; A segunda fase envolve análise de rede e uma determinação de frequências; A terceira etapa é a melhoria da rede. O segundo artigo (1992) focaliza num método de representar a rede de transporte usando listas e matrizes para tornar o procedimento de solução eficiente. O terceiro artigo (1994) concentra-se na fase de criação de um conjunto inicial de rotas, baseado num conjunto de esqueletos básicos. Este conjunto é criado pelos caminhos mais curtos entre nós com alta demanda de passageiros. Os esqueletos são expandidos, usando um conjunto de variações para a inserção de nós.

Wan e Lo (2002) desenvolvem um modelo de desenho de rede com uma consideração explícita das transferências intermodais e entre rotas. O modelo tem duas fases separadas. Primeiro, os pontos que devem ser conectados a um serviço direto são determinados por um algoritmo heurístico. Este algoritmo utiliza uma abordagem de representação de rede chamada State Augmented Multi-Model (SAM), que envolve a inserção de links imaginários na rede rodoviária real onde um serviço direto é fornecido. Posteriormente, um sistema de rotas de ônibus real é construído como um problema de programação linear inteira mista.

Cepeda et al.(2006) abordam um modelo de escolha de rotas com base a frequência para redes de trânsito congestionadas, que leva em consideração as conseqüências do congestionamento nos fluxos previstos, bem como sobre os tempos esperados de espera e de viagem. A formulação usada para o modelo lida com tempos de viagem dependentes do fluxo e é uma generalização dos modelos de equilíbrio de rede de trânsito baseados numa estratégia nomeada hyperpath.

Bagloee e Ceder (2011) propõem uma metodologia heurística para o projeto de uma rede de trânsito de rotas de tamanho real, levando em consideração as principais preocupações das autoridades de trânsito, tais como restrições orçamentárias, padrões de nível de serviço e a atratividade das rotas de trânsito. Além disso, esta abordagem considera outros aspectos importantes do problema, incluindo categorização de paradas, as classes de veículos de trânsito, planejamento hierárquico, capacidade do sistema e a integração entre análise de roteamento e análise de frequência. O processo desenvolvido começa com a construção de um conjunto de paradas potenciais por um critério de agrupamento. Então, pelo uso da teoria da 
gravidade de Newton e um procedimento especial de caminho mais curto, um conjunto de rotas candidatas é formado.

Cipriani et al. (2012) apresentam um procedimento para resolver o problema do desenho da rede de ônibus com demanda elástica em uma grande área urbana e sua aplicação em um contexto real. O procedimento de solução consiste em um conjunto de heurísticas, que inclui uma primeira rotina para geração de rotas baseada no processo de concentração de fluxo e um algoritmo genético para encontrar um conjunto de rotas subótimas com as frequências associadas. Os critérios de projeto são direcionados para desenvolver uma rede de ônibus intensiva, em vez de extensa, para melhorar a eficiência, a integração entre rotas diretas e pontos de transferência efetivos que afetam fortemente a qualidade do serviço e o número de passageiros. Os desempenhos do sistema de transporte são estimados em uma rede multimodal levando em consideração a elasticidade da demanda.

Chew et al. (2016) tem como objetivos minimizar os custos de passageiros e operadores, onde a qualidade dos conjuntos de rotas é avaliada por um conjunto de parâmetros. O algoritmo proposto emprega um procedimento de adição de nós que ajuda a converter uma solução inviável em uma solução viável, utilizando um conjunto de critérios de viabilidade para reduzir a possibilidade de produzir uma rede inviável.

A continuação, na Tabela 1, apresenta algumas características de uma pequena amostra dos estudos feitos para dar solução ao PDRTPU sobre a base de métodos heurísticos. Segundo as características analisadas, a maioria destes métodos se preocupa com a minimização de custos, tanto do usuário quanto do sistema. Entendese por sistema a empresa que oferece o serviço de transporte. Como estes métodos são desenhados para redes medianas ou grandes, são desenhados mais de um caminho ou rota para atender toda a rede, tendo em conta que o número de transferências não seja excessivo. Porém a maioria deles define como variáveis de controle as rotas e as frequências em alguns casos. 
Tabela 1.Análise de métodos heurísticos pesquisados para a solução de PDRTPU. Adaptado de Baaj e Mahmassani, (1994).

\begin{tabular}{|c|c|c|c|c|c|c|c|}
\hline Ano & Autor & Objetivo & $\begin{array}{l}\text { Análise da } \\
\text { demanda }\end{array}$ & $\begin{array}{l}\text { Otimização do } \\
\text { usuário ou sistema }\end{array}$ & $\begin{array}{l}\text { Tipos de caminhos } \\
\text { atribuidos }\end{array}$ & $\begin{array}{l}\text { Considera } \\
\text { transferências }\end{array}$ & $\begin{array}{l}\text { Variáveis } \\
\text { de controle }\end{array}$ \\
\hline 1967 & $\begin{array}{l}\text { Lampkin e } \\
\text { Saalmans }\end{array}$ & $\begin{array}{ll}\text { Min } & \text { Tempo } \\
\text { generalizado } & \end{array}$ & Fixa & Usuário e sistema & Multiple & Sim & $\begin{array}{l}\text { Rotas e } \\
\text { frequencias }\end{array}$ \\
\hline 1974 & $\begin{array}{l}\text { Silman, et } \\
\text { al. }\end{array}$ & Min Custo generalizado & Fixa & Usuário & Multiple & Sim & $\begin{array}{l}\text { Rotas e } \\
\text { frequencias }\end{array}$ \\
\hline 1979 & $\begin{array}{l}\text { Dubois, et } \\
\text { al. }\end{array}$ & $\begin{array}{ll}\text { Min } & \text { Tempo } \\
\text { generalizado } & \end{array}$ & Fixa & Usuário & Multiple & Sim & Rotas \\
\hline 1980 & Aquino & $\begin{array}{l}\text { Min Tempo de viagem e } \\
\text { número de transbordos }\end{array}$ & Fixa & Usuário e Sistema & Multiple & Sim & $\begin{array}{l}\text { Rotas e } \\
\text { frequencias }\end{array}$ \\
\hline 1986 & $\begin{array}{ll}\text { Ceder } & \text { e } \\
\text { Wilsom }\end{array}$ & $\begin{array}{cc}\text { Min } & \text { Tempo } \\
\text { generalizado } & \end{array}$ & Fixa & Usuário & Multiple & Sim & Rotas \\
\hline 1994 & $\begin{array}{lr}\text { Baaj } & \mathrm{e} \\
\text { Mahmassani }\end{array}$ & $\begin{array}{l}\text { Função objetivo não } \\
\text { explícita }\end{array}$ & Fixa & Usuário e Sistema & Multiple & Sim & $\begin{array}{l}\text { Rotas e } \\
\text { frequencias }\end{array}$ \\
\hline 2002 & Wan e Lo & $\begin{array}{l}\text { Minimizar a soma dos } \\
\text { custos de operação das } \\
\text { linhas de tránsito }\end{array}$ & Fixa & Sistema & Multiple & Sim & Rotas \\
\hline 2006 & $\begin{array}{l}\text { Cepeda et } \\
\text { al. }\end{array}$ & $\begin{array}{l}\text { Minimizar o equilibrio } \\
\text { da rede congestionada }\end{array}$ & Fixa & Sistema & Multiple & Não & Rotas \\
\hline 2011 & $\begin{array}{l}\text { Bagloee e } \\
\text { Ceder }\end{array}$ & $\begin{array}{l}\text { Maximizar o tempo total } \\
\text { economizado em relação }\end{array}$ & Variavel & Sistema & Multiple & Sim & $\begin{array}{l}\text { Rotas e } \\
\text { frequencias }\end{array}$ \\
\hline
\end{tabular}




\begin{tabular}{|c|c|c|c|c|c|c|c|}
\hline & & $\begin{array}{l}\text { ao cenário do plano sem } \\
\text { trânsito }\end{array}$ & & & & & \\
\hline 2012 & $\begin{array}{l}\text { Cipriani et } \\
\text { al. }\end{array}$ & $\begin{array}{l}\text { Minimizar os custos } \\
\text { totais (de operação, do } \\
\text { usuário e externos) }\end{array}$ & Variavel & Usuário e Sistema & Multiple & Sim & Rotas \\
\hline 2016 & Chew et al. & $\begin{array}{l}\text { Minimizar o tempo de } \\
\text { viagem dos usuarios e o } \\
\text { cumprimento das rotas } \\
\text { na rede }\end{array}$ & Variavel & Usuário e Sistema & Multiple & Sim & Rotas \\
\hline
\end{tabular}




\section{3.1.1}

\section{Seleção do método heurístico a estudar na presente pesquisa}

Ainda aprofundando nos métodos analisados na Tabela 1; de forma geral o método criado por Aquino, (1980) tem muitas semelhanças com os métodos descritos anteriormente. Porém o que os une neste estudo é a maior semelhança, ou seja, eles foram criados para a construção da solução do problema de desenho de redes de transporte público para cidades médias ou grandes. Além disso, são problemas multiobjetivos, com um nível de complexidade alto, não convexos e por tanto o método de solução utilizado é a heurística. Aquino, (1980) tem em conta para o primeiro passo como é feito nos outros métodos a geração de um conjunto de rotas candidatas. Não tomando o critério seguido por Lampkin e Saalmans, (1967) e Silman, et al., (1974) de criar especificamente um esqueleto inicial de rotas, mas sim conjunto de rotas candidatas onde estejam os mais longos caminhos mínimos, sendo muito semelhante ao proposto por Dubois, et al., (1979) e como sugerido por Baaj e Mahmassani (1994).

Todos estes métodos têm dedicado pelo menos uma fase para a determinação e análise da validade das restrições, as quais variam em função da abordagem pelas que foram criadas e segundo as informações e dados fornecidos. Outro ponto em comum é a fase dedicada à geração de uma rede tal que seja possível o deslocamento por ônibus entre qualquer par de zonas na área de estudo. Embora alguns estudos como o de Lampkin, e Saalmans, (1967), Silman, et al. (1974) tenham feito uma abordagem onde asseguram a conexão entre as zonas homogêneas ou as que conformaram o esqueleto inicial de rotas, isto pode levar a um grande número de transbordos para o usuário que precise conectar rotas diferentes a estas.

Porém, o estudo feito por Aquino, (1980) tenta ligar qualquer par de zonas da rede, evitando que o usuário precise fazer transbordos na conexão de zonas, característica abordada de forma similar em Dubois et al. (1979), Ceder e Wilsom 
(1986), Bagloee e Ceder(2011), Cepeda et al.(2006), Cipriani et al.(2012) e Chew et al.(2016) onde as rotas candidatas são as que atendem o maior número de terminais. $\mathrm{Na}$ comparação entre estes métodos, pode-se perceber que alguns não estão desenhados para se focar na minimização de transbordos, sendo que em algumas fases esta análise é feita de maneira implícita.

Como se pode observar na análise feita, Aquino (1980) aproveita ajustando-se ao objetivo do estudo, muitas caraterísticas e modos de abordagem dos demais métodos e em outras, contribui com uma melhor abordagem. Porém a iniciativa de Aquino (1980) resultou em um método simples e eficiente em uma rede de teste de 45 nós. Em Dubois et al. (1979), assim como em Lampikn e Saalmans, (1964), Silman et al. e Hsu e Surti, (1977), e Ceder e Wilsom (1986), falta detalhamento na análise e implementações em computador que gerassem resultados quantitativos da melhoria do sistema de transportes afetados; já nos métodos de Baaj e Mahmassani (1994) e Wan e Lo (2002) existe uma análise computacional.

Porém o método de Aquino (1980) conseguiu implementar o método de de Floyd complementando os demais métodos da análise para dar a solução ao PDRTPU. Gera um conjunto de rotas candidatas que posteriormente são analisadas até chegar ao menor número de rotas que sejam capazes de conectar à rede toda minimizando o número de transbordos.

As vantagens do método de Aquino (1980) são principalmente: a eliminação da necessidade de definição antecipada de nós terminais; a adoção de critérios bem definidos para a seleção de rotas candidatas; definição e avaliação de parâmetros para medir a rentabilidade das rotas candidatas; e ser totalmente informatizado. Esse método tem grande valor do ponto de vista histórico, sendo que na atualidade não existe um software dedicado a realizar o desenho de rotas de ônibus urbanos no Brasil, mas para sua aplicação seria necessário incrementos consideráveis no modelo. 


\section{3.}

\section{Formulação do PDRTPU}

Este capítulo define uma série de aspectos essenciais a serem abordados na formulação do problema objeto de estudo.

\section{1}

\section{Delimitação do problema}

Quando o problema se trata de transporte público, existe um grande número de variáveis que interagem nele, tais como a organização de uma estrutura de rotas, as tarifas, a escolha de frequências para operá-las, a demanda nos diferentes pontos da rota, a programação dos ônibus e do pessoal de serviço. Devido a esse grande número de variáveis e de restrições que o problema encerra, gera-se um problema de grande dimensão e de complexo relacionamento entre essas variáveis através das restrições e dos vários critérios existentes. Estes fatores têm uma influência importante na hora de gerar soluções, uma delas é que ainda não existe método de pesquisa operacional capaz de proporcionar uma solução ótima do problema, como foi visto na seção anterior.

Na prática o problema deve ser estudado por componentes, de forma separada, dividindo-o em subproblemas, como foi mostrado na seção 2.2.1, onde segundo as classificações do PDRTPU fornecidas por Farahani, et al. (2013) o problema objeto de estudo está contido dentro do subgrupo dos Problemas de Programação de Redes de Transito. Segundo a natureza das decisões consideradas pode ser considerado como Problema de Desenho Misto de Rede, que contém uma combinação de decisões contínuas e discretas. E segundo a origem das decisões o problema objeto de estudo encaixa dentro do subgrupo de Problemas de Desenho da Rede de Transporte Público, que atende exclusivamente o desenho de rotas das linhas do Transporte Público, incluindo as origens e destinos das rotas de Transporte Público e a sequência dos links visitados. 
O problema em questão é analisado considerando a definição das frequências como adaptadas à demanda. É evidente que para chegar à solução global do problema, vários ajustes serão necessários entre os resultados desses diversos subproblemas.

\section{1.1}

\section{Critérios avaliados no estudo}

A eficiência do transporte público, do ponto de vista dos passageiros, inclui um tempo de viagem reduzido desde a origem até ao destino com um número mínimo de transferências, idealmente sem transferências. Isto é porque o tempo de espera na transferência aumentará o tempo de viagem dos passageiros, além do desconforto associado. É por isso que as rotas de maior demanda devem ser sem transbordos. E aquelas que necessitarem de transbordo, devem ser criadas a modo de facilita-lo.

Otimizar a rede de Transporte Público é uma tarefa difícil, devido à complexidade das características do tempo de viagem de Transporte Público que incluem o tempo de viagem do veículo, o tempo de espera, o tempo de transferência, e as penalidades de transferência. É um desafio para a PDRTPU contribuir para a construção de um sistema de transporte eficiente. Isso sem esquecer as expectativas de um sistema eficiente de transporte público de outros pontos de vista, como o governo local e a comunidade. Portanto, a definição de eficiência pode ser diferente de acordo com vários pontos de vista, mas é importante que a rede de rotas avaliada possua características atraentes tanto para os usuários como as empresas que operam em elas.

Do ponto de vista dos operadores, o custo decorrente na exploração do transporte público é uma consideração importante. Os operadores visam minimizar o custo na operação do serviço. Por tanto os operadores tentarão minimizar o comprimento total das rotas, de modo a reduzir esses custos. Assim, fica claro que o comprimento da rota total de um sistema de transporte público é um aspecto importante para o custo do operador. Ao mesmo tempo as empresas preferem rotas não muito curtas, pois rotas 
curtas atendem a um número potencialmente menor de destinos e criam situações desfavoráveis tanto administrativa quanto operacionalmente.

De acordo com Chakroborty e Dwivedi, (2002), o objetivo da PDRTPU é atender a demanda de Transporte Público de forma eficiente. Um conjunto de rota eficiente é aquele que satisfaz o seguinte.

(1) O conjunto de rotas deve satisfazer a demanda de Transporte Público dos passageiros com a percentagem de procura satisfeita, sem transferências tão elevada quanto possível.

(2) O conjunto de rotas deve oferecer um tempo médio de viagem por Transporte Público tão baixo quanto possível.

Contudo, estabelecendo um equilíbrio entre usuário e operadores foram consideradas as seguintes características comuns e básicas na escolha tanto para o usuário quanto para as empresas operadoras nas rotas:

$>$ Minimização do tempo de percurso: facilita a criação de rotas não muito longas para que os usuários possam chegar aos seus destinos no menor tempo possível.

$>$ Minimização do número de transbordos: permite que as viagens que tem uma alta demanda sejam realizadas sem transbordos

$>\quad$ Maximização da Rentabilidade: essa é a característica mais geral, geralmente é avaliada segundo os interesses das empresas que prestam serviços na rede.

\section{2}

\section{Representação do problema}

Para fins de simplicidade, neste estudo, a rede de Transporte Público é considerada simétrica, onde o tempo de viagem e a distância nos arcos e a demanda entre dois nós são os mesmos independentemente da direção de viagem. A representação do problema é a seguinte. 
A rede é representada por um grafo não-direcionado $G(N, A)$ onde os nós em $N$ $=\left\{n_{1}, \ldots, n_{n}\right\}$ representam interseções na rede viária ou os pontos de demanda das diferentes zonas que compõe a rede em estudo, e as arestas em $A=\left\{a_{1}, \ldots, a_{m}\right\}$ representam as ligações da rede. Uma rota pode então ser representada por um caminho na rede de Transporte Público, $\lambda_{l}=\left(\mathrm{n}_{1}, \mathrm{n}_{2}, \ldots, \mathrm{n}_{\mathrm{p}}\right)$, onde $\mathrm{n}_{\mathrm{i}} \in N$. Portanto, a solução para o PDRTPU é especificada por um conjunto de rotas $\mathrm{R}=\left\{\lambda_{I}: 1 \leq l \leq \mathrm{z}\right\}$, onde $\mathrm{z} \in \mathbb{Z}^{+}$. Será usado o termo rota para designar uma linha componente da rede de ônibus.

Com o intuito de responder as exigências tanto dos usuários quanto dos operadores foi criado o seguinte modelo de PDRTPU, onde as funções objetivo são as seguintes:

- Minimizar o tempo total de viagem efetuado por todos os passageiros (TTP) que viajam da sua origem até ao respectivo destino.

Minimizar TTP $=\sum d_{i j} * t_{i j} \quad \forall i j \in N^{2}$

Onde dij é a demanda de viagens entre o nó $i$ e o nó $j$ e $t_{i j}$ é o menor tempo de viagem entre o nó $i$ e o nó $j$.

- Minimizar o número de transbordos (NT) feitos pelos usuários desde o ponto de origem até o destino.

Minimizar NT $=\sum d_{i j} * t r_{i j} \quad \forall i j \in T I$

Sendo:

TI: conjunto de trajetos indiretos;

$\operatorname{tr}_{\mathrm{ij}}$ : número de transbordos sobre o trajeto $\mathrm{ij}$.

Ambas funções objetivos estão sujeitas às seguintes restrições.

$$
\operatorname{VSK}_{\lambda} \geq \mathrm{r} \quad \forall \lambda \in F
$$

Onde:

F: conjunto de rotas candidatas;

r: taxa compatível com a rentabilidade de uma rota; 
$\mathrm{VSK}_{\lambda}$ : Número de Passageiros por quilometro $=\mathrm{U}_{\lambda} / \mathrm{l}_{\lambda}$

$\mathrm{U}_{\AA}$ : Demanda potencial da rota;

$1_{2}:$ comprimento da rota;

\section{2.1}

\section{Hipóteses do problema}

A seguir são expostas as seguintes hipóteses assumidas para a resolução do problema

1) Cada rota no conjunto de percurso é livre de nós repetidos. Isso é para evitar retornos e/ou ciclos na rota.

2) Todos os nós de demanda devem ser incluídos no conjunto de rotas para formar um conjunto completo de percursos.

3) As rotas no conjunto de percursos estão conectadas entre si.

4) A mesma rota não pode ser repetida nem total nem parcialmente.

5) As matrizes de demanda, tempo de viagem e distância são simétricas. É assumido também que um veículo viajará nos dois sentidos ao longo da mesma rota, invertendo sua direção toda vez que atingir um nó terminal.

6) São admitidos os seguintes parâmetros:

1. Demanda ao longo da rota;

2. Capacidade dos veículos (CAP);

3. Velocidade média na rota $\left(\mathrm{VM}_{\lambda}\right)$;

4. Intervalo de tempo em que as demandas devem ser atendidas (delta);

5. Taxa de ocupação imposta (t);

6. Comprimento da rota $\left(1_{2}\right)$;

7) Presume-se que existam veículos com capacidade suficiente para atender a demanda e que o tempo total de viagem consista apenas do tempo em trânsito no veículo e os tempos de transbordos não serão computados. Porém aqueles trajetos indiretos serão 
taxados mediante uma penalidade uniforme $(\mathrm{p})$ pretendendo reduzir o número de transbordos na rede.

8) Supondo que existe o número suficiente de veículos com uma capacidade (CAP) para atender a demanda potencial num intervalo de tempo (delta), o número de ônibus necessários (NUMBUS) para o transporte de passageiros na rota de comprimento $1_{\lambda}$, será calculado da seguinte forma.

$\mathrm{NUMBUS}_{\lambda}=\mathrm{TTV} * \mathrm{~F}_{\lambda}$

Sendo: TTV: tempo total de viagem

$\mathrm{F}_{\lambda}$ : Frequência na rota ג

Tendo:

$\mathrm{TTV}=\left(2 * 1_{\lambda}\right) / \mathrm{VM}_{\lambda}$

Observação: Assume-se que a distância de ida é igual à de volta, é por isso que se estabelece como distância total: $2 * 1_{\lambda}$.

$\mathrm{F}_{\lambda}=\mathrm{NP}_{\lambda} /$ delta

Onde:

$\mathrm{VM}_{\lambda}$ : Velocidade média dos veículos sobre a rota $\lambda ;$

$\mathrm{NP}_{\lambda}$ : Número máximo de passageiros na rota $\lambda$;

Levando as funções 3.5 e 3.6 em 3.4, obtemos uma fórmula de NUMBUS onde, $\operatorname{NUMBUS}(\lambda)=\left(2 * 1_{\lambda} * \mathrm{NP} \lambda\right) /\left(\mathrm{VM}_{\lambda} *\right.$ delta $)$

Para determinar $\mathrm{NP}_{\lambda}$, é determinada a carga máxima da rota e para isso é calculada a carga em cada trecho i. A carga em cada trecho i, após a parada i, pode ser calculada como o número de passageiros que estão na linha até a parada i, menos o número de passageiros com destino à parada mais o número de passageiros que partem de i para todas as paradas após i.

O número de passageiros $\left(\mathrm{Chega}_{\mathrm{i}}\right)$ na linha até a parada i pode ser calculado como:

$$
\operatorname{Chega}_{i}=\sum_{k=1}^{i-1} \sum_{j=i}^{n} D_{k j}
$$


O número de passageiros $\left(\mathrm{Sai}_{\mathrm{i}}\right)$ que se destinam a parada i é dado por:

$S a i_{i}=\sum_{k=1}^{i-1} D_{k i}$

E o número de passageiros (Entrai) que partem da parada i para todos os destinos após i é:

$\operatorname{Entra}_{i}=\sum_{k=i+1}^{n} D_{i k}$

A carga na parada $\mathrm{i}, \mathrm{C}_{\mathrm{i}}$, é dada por:

$C_{i}=$ Chega $_{i}+$ Entra $_{i}-$ Sai $_{i}$

A carga máxima em um sentido será então: $\operatorname{Maximo}_{i}\left(\vec{C}_{i}\right)$ e no sentido contrário

$\operatorname{Maximo}_{i}\left(\bar{C}_{i}\right)$

A carga máxima na linha pode ser dada por:

$\mathrm{C}_{\lambda}=\max \left(\overrightarrow{C_{l}}, \overleftarrow{C_{l}}\right)$

$N P_{\lambda}=\left(\frac{C_{\lambda}}{t * C A P}\right)$

$N U M B U S_{\lambda}=\left(\frac{2 * l}{V M_{\lambda}} * N P_{\lambda}\right)^{+}$

Ou seja o inteiro maior do valor encontrado na expressão 3.15 dentro do intervalo de tempo delta.

\section{3}

\section{Descrição da rede}

A rede onde será desenvolvido o estudo será dividida por zonas. As zonas são áreas básicas, assumidas de tal forma que tenham uma uniformidade razoável com respeito ao uso de solo. $\mathrm{O}$ tamanho da zona deve ser considerado de forma tal que o 
usuário possa caminhar de qualquer ponto até o nó centroide. Os nós centroides representarão a cada uma das zonas.

A rede de transporte utilizada no estudo se estrutura por nós, arcos e rotas.

Os nós podem ser:

- Nós intermediários: simbolizam as interseções viárias de rotas;

- Nós centroides: representam cada zona e a ele se atribui a demanda da zona.

Os arcos são aqueles que unem pares de nós, e se classificam em:

- Arcos artificiais, ou conectores: representam a conexão dos centroides artificiais na rede;

- Arcos não artificiais: simbolizam vias ou trechos de vias mais importantes.

A cada arco é associado o comprimento e o tempo de viagem.

As rotas são as sequencias de nós que são conectados por arcos de um mesmo modo de transporte.

A rede é não orientada e os parâmetros dos arcos representam a média dos dois sentidos de tráfego. Na figura 3 é apresentado um exemplo de rede de transporte.

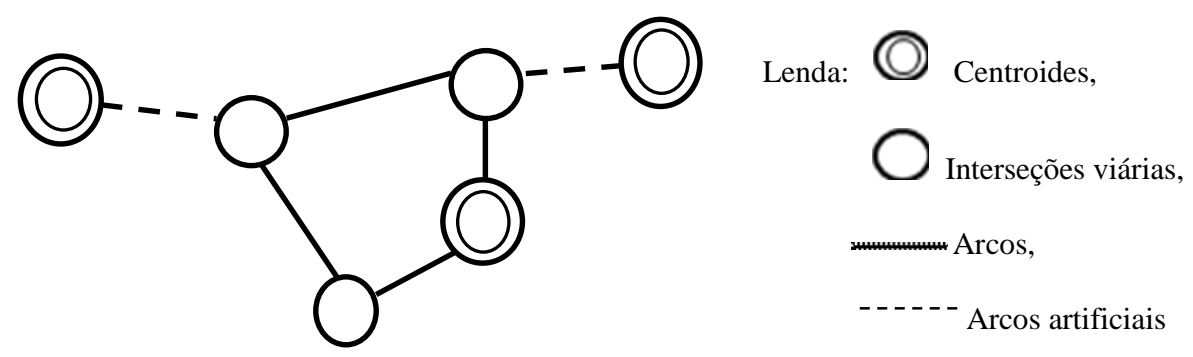

Figura 3. Exemplo de rede de transporte. 
Para o período do estudo, estabelecido de uma hora, a distribuição das viagens entre as zonas se considera como conhecida e é representada através de uma matriz Origem-Destino (O-D). Destacando que esta matriz é independente do conjunto de rotas. A demanda com origem ou destino de qualquer parte da zona é assumida como gerada no centroide que representa à zona. 
4.

\section{Proposta da estratégia para a resolução do PDRTPU}

Neste capítulo é apresentada uma estratégia para a solução do problema proposto no presente estudo. A partir da análise da literatura, foram detectados alguns métodos afins com as características do problema objeto de estudo. O mais viável na aplicação do presente estudo é o método proposto por Aquino (1980), por ser aplicável numa rede de grande porte, analisar a rentabilidade das rotas através de vários parâmetros e finalmente construir uma rede aceitável tanto para o usuário quanto para a empresa operadora. O método constrói uma rede a partir da conexão das rotas mais rentáveis que minimizam o número de transbordos. Esta estratégia foi implementada na linguagem Fortran, na sua versão inicial, proposta por Aquino, (1980) e em C++ na sua versão com melhorias, apresentada na presente pesquisa.

\section{1}

\section{Definição da estratégia de solução do PDRTPU}

Tendo em conta seu nível de complexidade o problema objeto de estudo, foi dividido em subproblemas. A estratégia proposta está dividida nas seguintes fases que resolvem progressivamente cada um destes subproblemas até resolver o PDRTPU completamente.

Fase 1. Geração do conjunto de rotas candidatas;

Fase 2. Geração de uma rede tal que seja possível o deslocamento por ônibus entre qualquer par de centroides na área em estudo;

Fase 3. Avaliação dos parâmetros das rotas;

Fase 4. Definição de uma lista de rotas em ordem de minimização de transbordos.

No fluxograma, na figura 4, é explícita a implementação do método escolhido, através da integração das fases referidas anteriormente. Nele G significa o primeiro 
conjunto de rotas candidatas para criar uma rede de rotas, determinadas a partir de algoritmos que determinem os caminhos mais curtos. $G^{*}$ é o segundo conjunto de rotas candidatas definidas como uma variante das linhas pertencentes

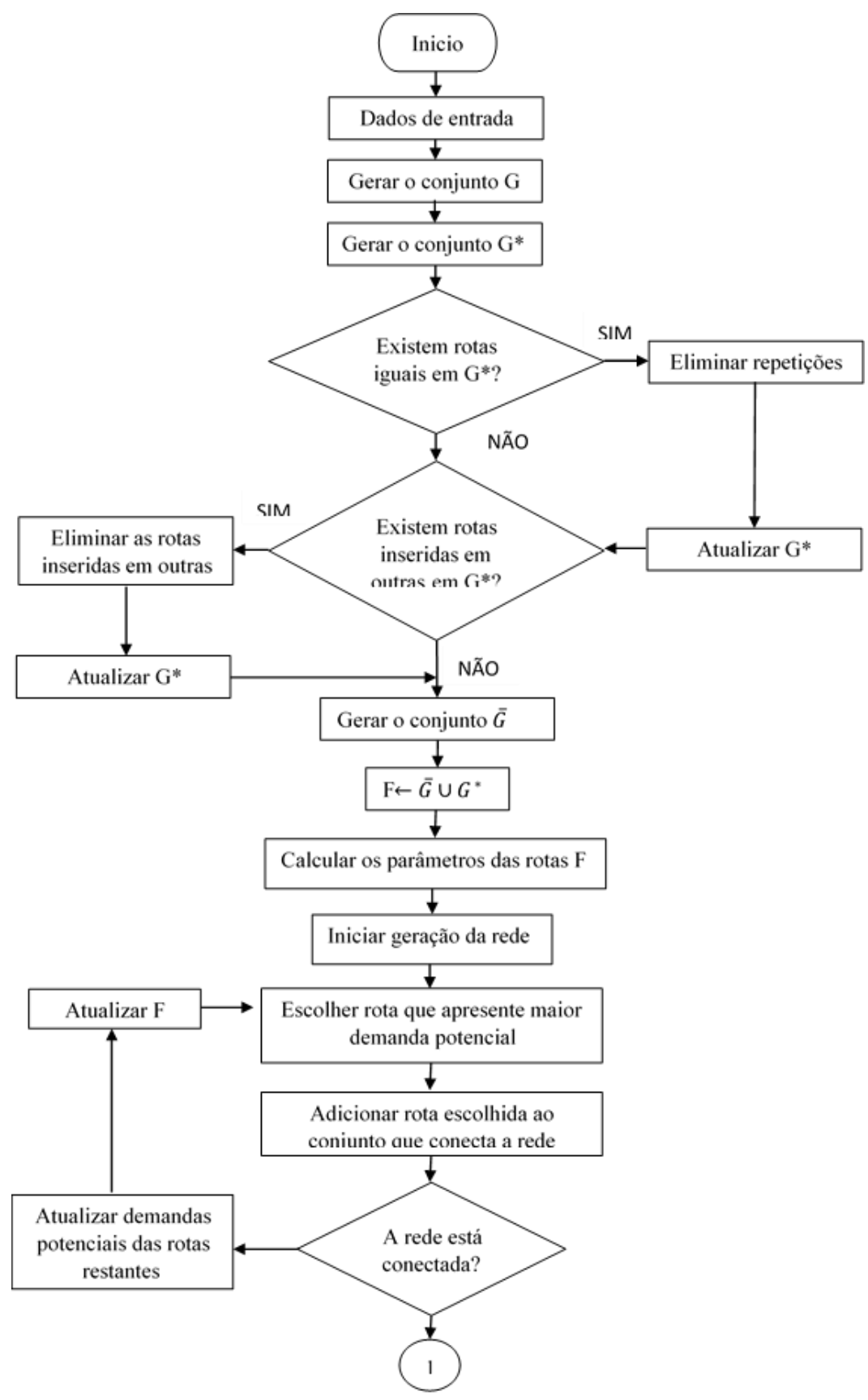




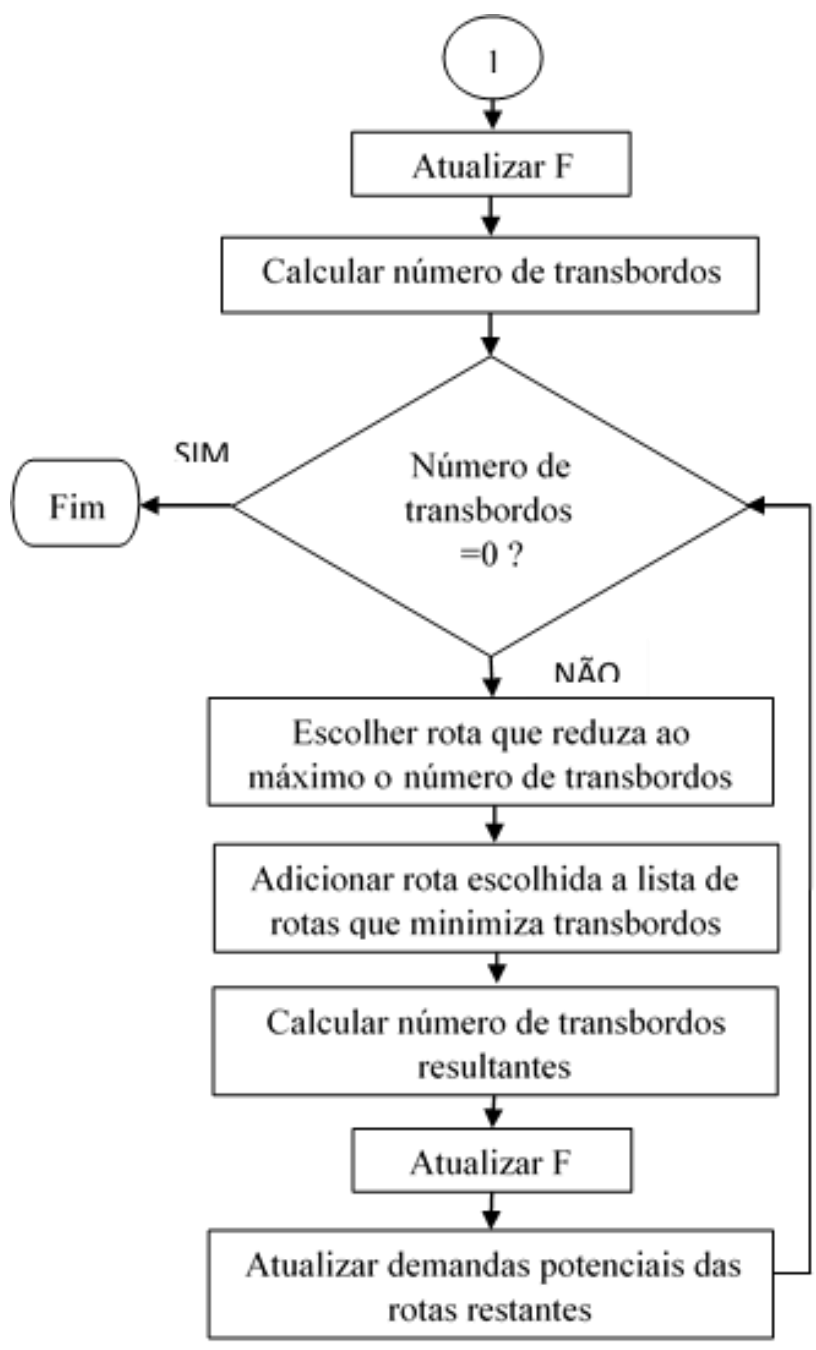

Figura 4. Fluxograma da função principal proposta por Aquino, (1980).

ao conjunto $\mathrm{G}$, com os caminhos com desvios com relação aos caminhos mínimos. Os comprimentos destes caminhos serão menores ou iguais a $(1+\mu)$ vezes o cumprimento da rota original, sendo $\mu$ um parâmetro da estratégia de resolução a ser determinado pelo planejador.

$\mathrm{O}$ conjunto $\mathrm{F}$ é a união do conjunto $\mathrm{G}^{*}$ e as rotas contidas em $\mathrm{G}$ que não estejam em $\mathrm{G}^{*}$, ficando com os mais longos caminhos mínimos, sendo estes caminhos, os que conectam a maior quantidade de nós centroides com a menor trajetória entre eles. No anexo 1 encontra-se o pseudocódigo que descreve a função principal. 


\section{2}

\section{Descrição do método e das adequações aplicadas}

No método selecionado foram feitas várias adequações a fim de melhorar seu desempenho e moderniza-lo. Elas serão detalhadas a seguir assim como as rotinas de cada uma das fases que o integram.

\section{2.1}

\section{Geração do conjunto de rotas candidatas}

O objetivo dessa primeira fase, correspondente à linha 2 do pseudocódigo do programa, descrito na figura 4, é começar a gerar um conjunto de rotas que minimize o tempo de trajeto, o número de transbordos e sejam rentáveis. Para isto é preciso a geração de rotas que não sejam muito curtas, ou seja, suficientemente longas como para atender a vários centroides da rede. Os caminhos que parecem atender a estas exigências são os mais longos caminhos mínimos, definidos no conjunto F. Este conjunto de rotas é capaz de cobrir toda a rede, havendo um serviço direto entre qualquer par de zonas pelo caminho mínimo, atendendo a cada par origem-destino da demanda.

Para chegar à geração do conjunto de rotas candidatas $\mathrm{F}$, foi primeiramente gerado um conjunto de caminhos mínimos nomeado conjunto G. A geração do conjunto G é determinada com o Algoritmo de caminhos mínimos de Floyd- Warshall, (1962). Na sua versão originalmente implementada por Aquino trabalha-se com duas matrizes. Uma guarda o valor do caminho mínimo entre i e j, neste caso a matriz de tipo float, $\operatorname{tmin}(i, j)$. A outra matriz guarda para cada nó i de origem o primeiro sucessor no caminho de i para cada $\mathrm{j}$, refere-se à matriz de tipo inteira $i c u(i, j)$.

O algoritmo usa a matriz icu $(i, j)$ que guarda para cada nó i de origem o primeiro sucessor no caminho de i para cada j. Aqui, para retraçar o caminho mínimo deve-se 
ver o primeiro sucessor k de i no caminho entre i e j, encontrado na posição $(i, j)$. Logo vai-se a linha k e mantendo a coluna encontra-se o primeiro sucessor de k no caminho até $\mathrm{j}$, na posição $(k, j)$. Assim por diante até alcançar j, ou seja, encontrar j na coluna $\mathrm{j}$ da linha k. Na figura 5 é apresentado o pseudocódigo do algoritmo antes referenciado.

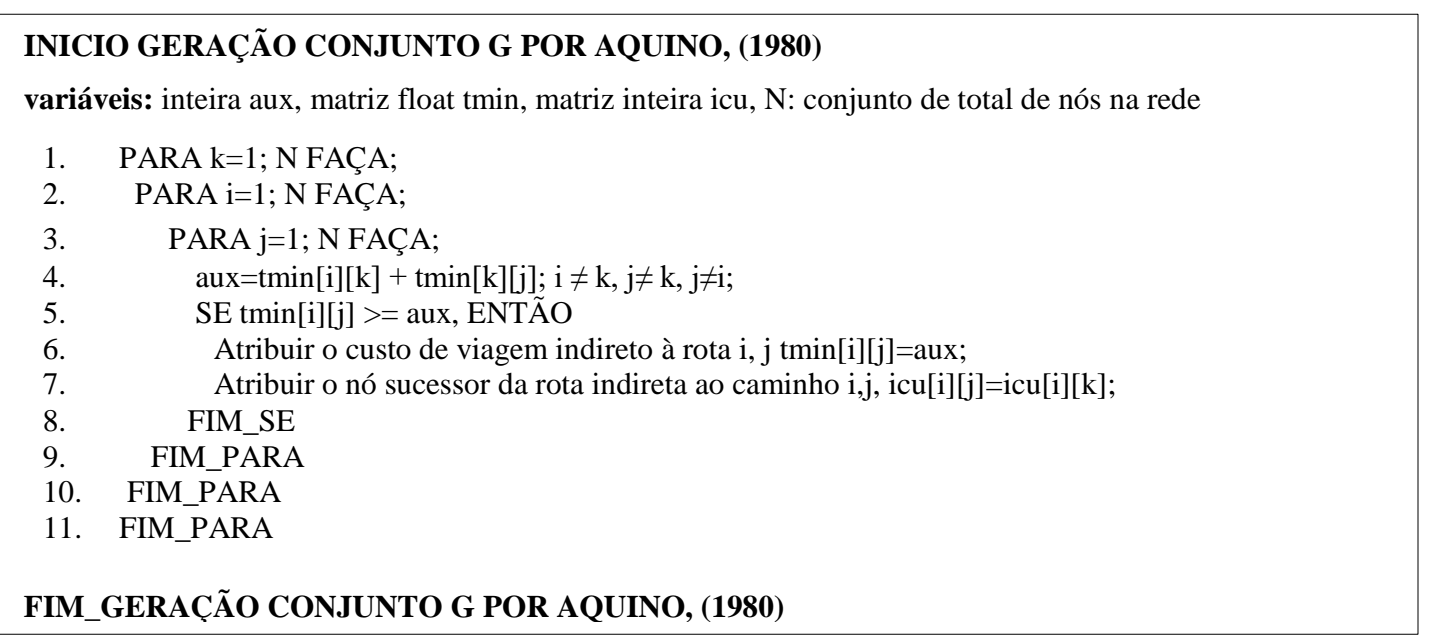

Figura 5. Pseudocódigo da função para a geração do conjunto de rotas candidatas $\mathrm{G}$ por Aquino, (1980). Algoritmo Floyd-Warsahall, (1962).

Este algoritmo foi substituído pelo algoritmo de Dijkstra, (1959), mostrado na figura 6. Esta é a primeira modificação no programa de Aquino, (1980). Esta adequação foi feita visando à possibilidade de aplicação para redes de grande porte, pois para um maior número de arestas e vértices esse último algoritmo tem melhor desempenho. Além do mais o algoritmo Dijkstra tem um tempo computacional de O ([E+V] log V) onde $\mathrm{E}$ é o número de arestas e $\mathrm{V}$ é o número de vértices, sendo menor do que o algoritmo de Floyd-Warshall de $\mathrm{O}\left(\mathrm{V}^{3}\right)$.

Na rotina original só é tomado o sucessor no caminho de i para j, o que não contraria o princípio da árvore de caminho mínimo. Na árvore um nó pode ter mais de um sucessor, desde uma origem, mas para um destino específico, só pode ter um sucessor. Tendo em vista isto, o Algoritmo Dijkstra foi adaptado para ser aplicado de cada destino para todas as origens. 
Para obter a matriz de sucessores $i c u(i, j)$, na implementação do Dijkstra, é conveniente fazer a rota mínima dos destinos para cada origem. Lembra-se que só interessam os caminhos mínimos entre cada par de centroides e não entre todos os nós da rede. Para fazer a rota mínima do destino para cada origem trabalhou-se com a estrutura de lista de predecessores (backward star). Para criar esta estrutura toma-se a lista de arcos ordenados pelos nós de destino. Faz-se uma rotina para criar os ponteiros de cada nó. O trabalho será feito com a lista de ponteiros e depois com a lista de nós de origem de cada arco e de custos nos arcos. Para fazer a rota mínima apenas entre pares de centroides, cria-se, além de um conjunto de nós temporários, como na versão tradicional do Dijkstra, um conjunto de centroides temporários. A cada vez que um centroide é selecionado como o menor temporário e é eliminado da lista. Quando ela estiver vazia, o procedimento termina. Essa é uma clara vantagem do algoritmo de Dijkstra frente ao de Floyd.

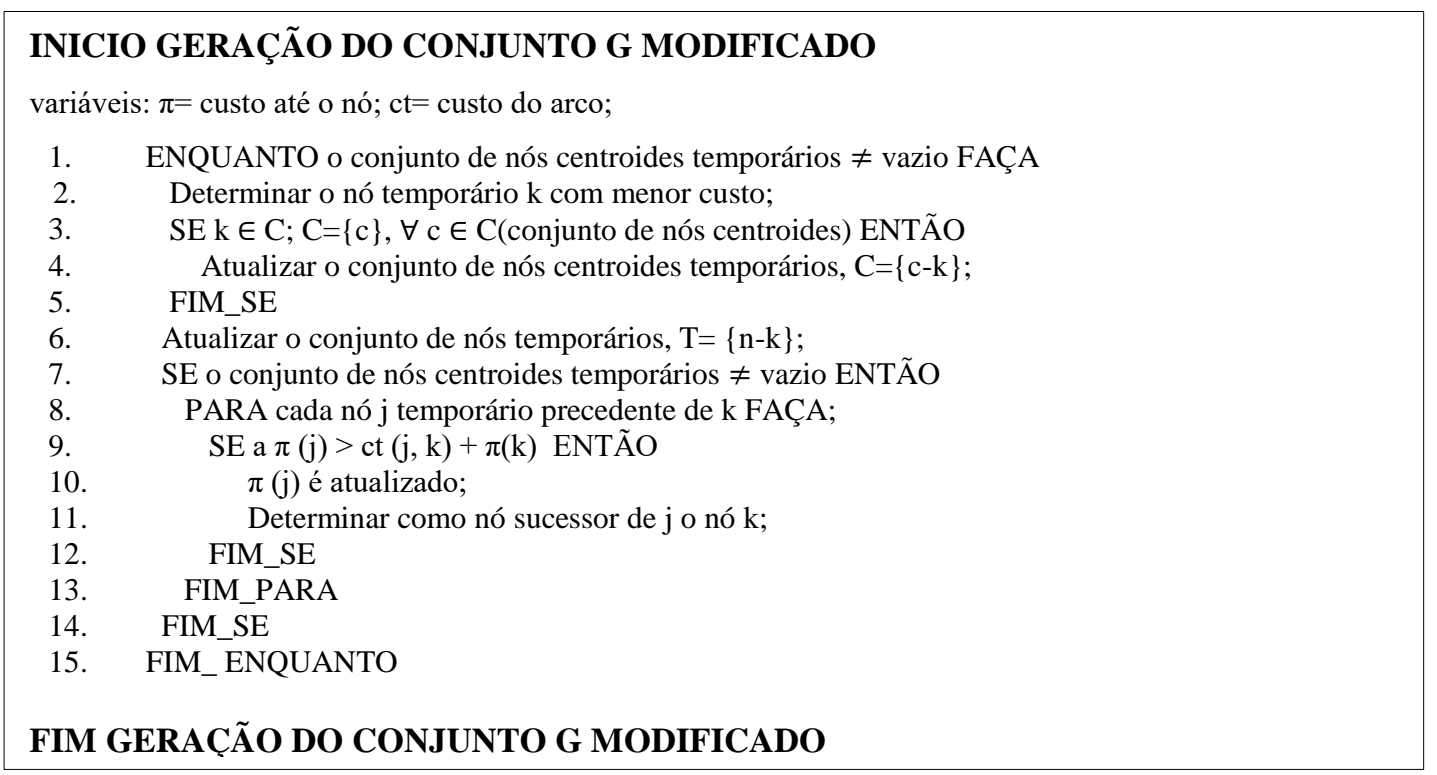

Figura 6. Pseudocódigo da função que gera o conjunto de rotas candidatas G modificado. Dijkstra, (1959).

No entanto o conjunto $\mathrm{G}$ obtido inicialmente conduz geralmente ao uso de uma frota muito grande, com a possibilidade de criar rotas muito curtas, contrariando o 
objetivo de rentabilidade dessas rotas. É por isso que é adotada a seguinte estratégia. Para cada um dos caminhos pertencentes ao conjunto $G$, são investigados os caminhos vizinhos que possuam os mesmos nós terminais. Seus comprimentos serão menores ou iguais a $(1+\mu)$ vezes o comprimento da rota original, sendo $\mu$ um parâmetro da estratégia de resolução a ser determinado pelo planejador.

Estas novas rotas são obtidas inserindo em cada rota $\mathrm{\lambda} \in \mathrm{G}$, nós centroides $\mathrm{k}$ ainda não contidos na rota e que a distância entre os nós terminais da rota original via $\mathrm{k}$ atenda ao limite estabelecido. Cria-se um novo conjunto de caminhos mínimos mais longos G*, como referenciado na linha 3 do pseudocódigo do programa principal na figura 4.

Esse novo conjunto é depurado mediante a eliminação das seguintes rotas:

$>$ Rotas que retrocedem sobre elas mesmas;

$>$ Rotas repetidas;

Rotas inseridas em outras;

Uma segunda melhoria no programa foi realizada para a eliminação das rotas repetidas no conjunto $\mathrm{G}^{*}$, como referenciado na linha 5 do pseudocódigo do programa. Com isto se simplifica a programação alcançando os mesmos resultados do programa original.

Para eliminar as rotas que retrocedem sobre elas mesmas, basta verificar a existência de nós repetidos numa mesma rota. Para isso foi criada uma variável inteira que conta o número de nós repetidos, apresentada na linha 1 no pseudocódigo da rotina modificada na figura 8. Após a análise para todas as rotas, essa variável é verificada, para cada rota e caso seja maior que zero, ou seja, a rota tem pelo menos um nó repetido, começa o processo para zerar essa (s) rota (s) na matriz lige, onde são armazenadas as rotas do conjunto $\mathrm{G}^{*}$, sendo que cada linha da matriz contém os nós de uma rota do conjunto. Posteriormente é atualizada a variável que conta o número nlige de rotas que pertencem $\mathrm{G}^{*}$, como é descrito a partir da linha 8 da figura em questão. Esta adaptação 
foi feita para conseguir fazer essa análise para todas as rotas criadas anteriormente, sendo que, no programa original apresentado na figura 7, a análise era feita dentro do mesmo loop onde eram verificados os nós repetidos dessas rotas, impedindo que a totalidade das rotas fossem verificadas numa mesma iteração, como é mostrado na figura 8. No Anexo 2 encontra-se a continuação do pseudocódigo que elimina as repetições do conjunto de rotas $\mathrm{G}^{*}$ após as modificações feitas.

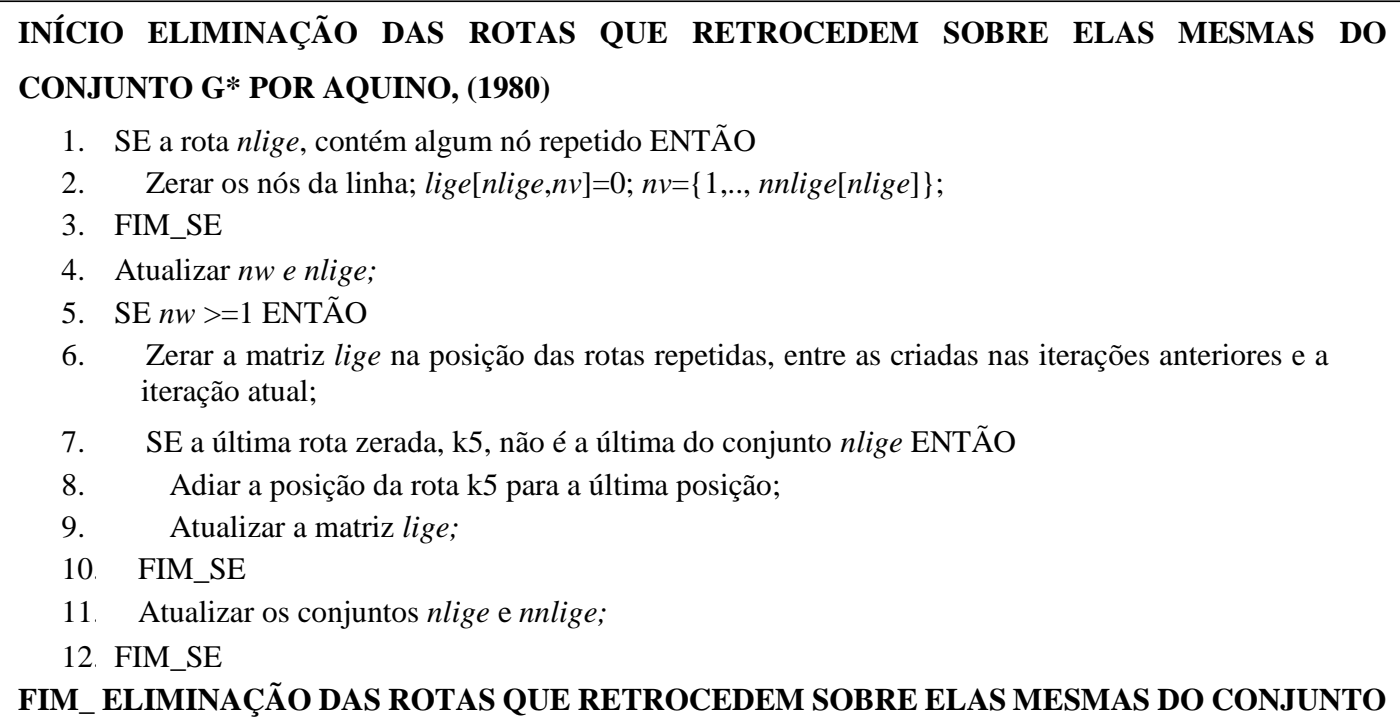

1. SE a rota $n l i g e$, contém algum nó repetido ENTÃO

2. Zerar os nós da linha; lige $[$ nlige,$n v]=0 ; n v=\{1, . .$, nnlige $[$ nlige $]\}$;

3. FIM_SE

4. Atualizar $n w$ e nlige;

5. SE $n w>=1$ ENTÃO

6. Zerar a matriz lige na posição das rotas repetidas, entre as criadas nas iterações anteriores e a iteração atual;

7. SE a última rota zerada, $\mathrm{k} 5$, não é a última do conjunto nlige ENTÃO

8. Adiar a posição da rota $\mathrm{k} 5$ para a última posição;

9. Atualizar a matriz lige;

10. FIM_SE

11. Atualizar os conjuntos nlige e nnlige;

12. FIM_SE

FIM_ELIMINAÇÃO DAS ROTAS QUE RETROCEDEM SOBRE ELAS MESMAS DO CONJUNTO

Figura 7. Pseudocódigo da função que elimina as rotas que retrocedem sobre elas mesmas do conjunto $\mathrm{G}^{*}$ por Aquino, (1980).

\section{INÍCío ELIMINAÇÃo dAS ROTAS QUE RETROCEDEM SOBRE ELAS MESMAS DO CONJUNTO G* MODIFICADO}

1. Inicializar variável inteira contadora do número de nós repetidos na rota, cont $=0$;

2. SE a rota nlige, contém algum nó repetido ENTÃo

3. Aumentar variável contadora das rotas repetidas, $\operatorname{cont}=$ cont +1 ;

4. FIM_SE

5. SE cont $>0$ ENTÃO

6. A linha correspondente a rota nlige, na matriz lige será zerada, lige $[$ nlige,$n v]=0 ; n v=\{1, \ldots$, nnlige[nlige $]\}$;

7. Atualizar variável que armazena o número de rotas criadas na iteração atual, $n w=n w-1$;

8. Atualizar variável que armazena o número total de rotas do conjunto $\mathrm{G}^{*}$, nlige $=$ nlige -1 ;

9. FIM_SE

FIM ELIMINAC̣ÃO DAS ROTAS QUE RETROCEDEM SOBRE ELAS MESMAS DO CONJUNTO

Figura 8. Pseudocódigo da função que elimina as rotas que retrocedem sobre elas mesmas do conjunto $\mathrm{G}^{*}$ modificado. 
Após a geração destas rotas, com o intuito de criar rotas ainda mais longas e que ainda atendam a condição de caminho mínimo, foi introduzida outra modificação importante. Foi adicionada uma nova função que permitisse juntar aquelas linhas do conjunto $\mathrm{G}^{*}$ que tivessem o nó final em comum com o nó inicial de outra linha, mas apenas esses nós em comum entre elas. Ou seja, duas rotas que podem ser unidas, tornam-se uma rota. A rotina desta função é apresentada na figura 9.

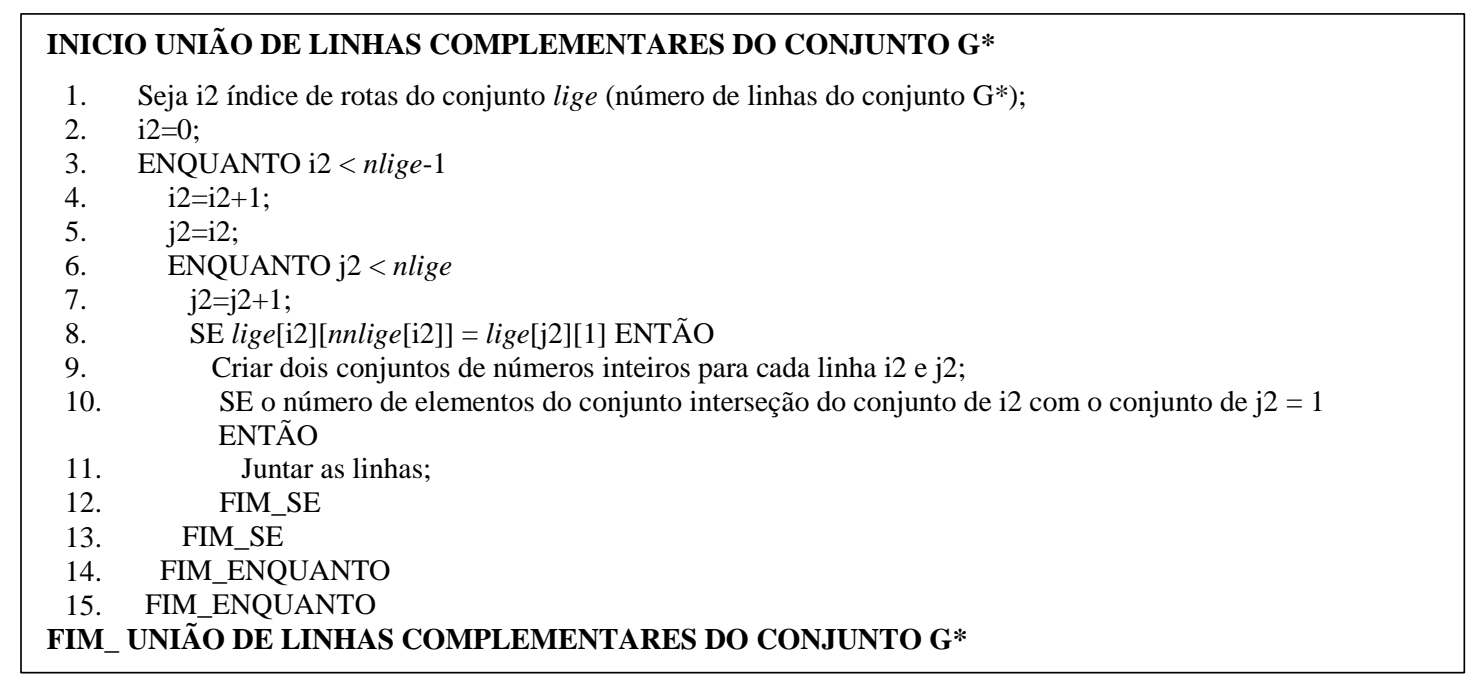

Figura 9. Pseudocódigo da função que junta linhas complementares.

Para a eliminação das rotas inseridas em outras como referenciado na linha 8 do pseudocódigo do programa na figura 4, foram feitas as seguintes melhorias. Foram feitas adaptações com o intuito de facilitar e resumir sua execução, como descrito na figura 10. Foram declaradas, ao invés de variáveis inteiras, variáveis tipo strings para armazenar as rotas do conjunto $\mathrm{G}^{*}$ e sua forma inversa. Isso possibilitou uma simplificação do procedimento para a eliminação das rotas repetidas e aquelas que estavam inseridas dentro de outras. Rotinas simples permitem comparar strings sem ter que correr explicitamente cada elemento da lista. Na figura 10 é descrita esta função em sua forma original, proposta por Aquino, (1980). 


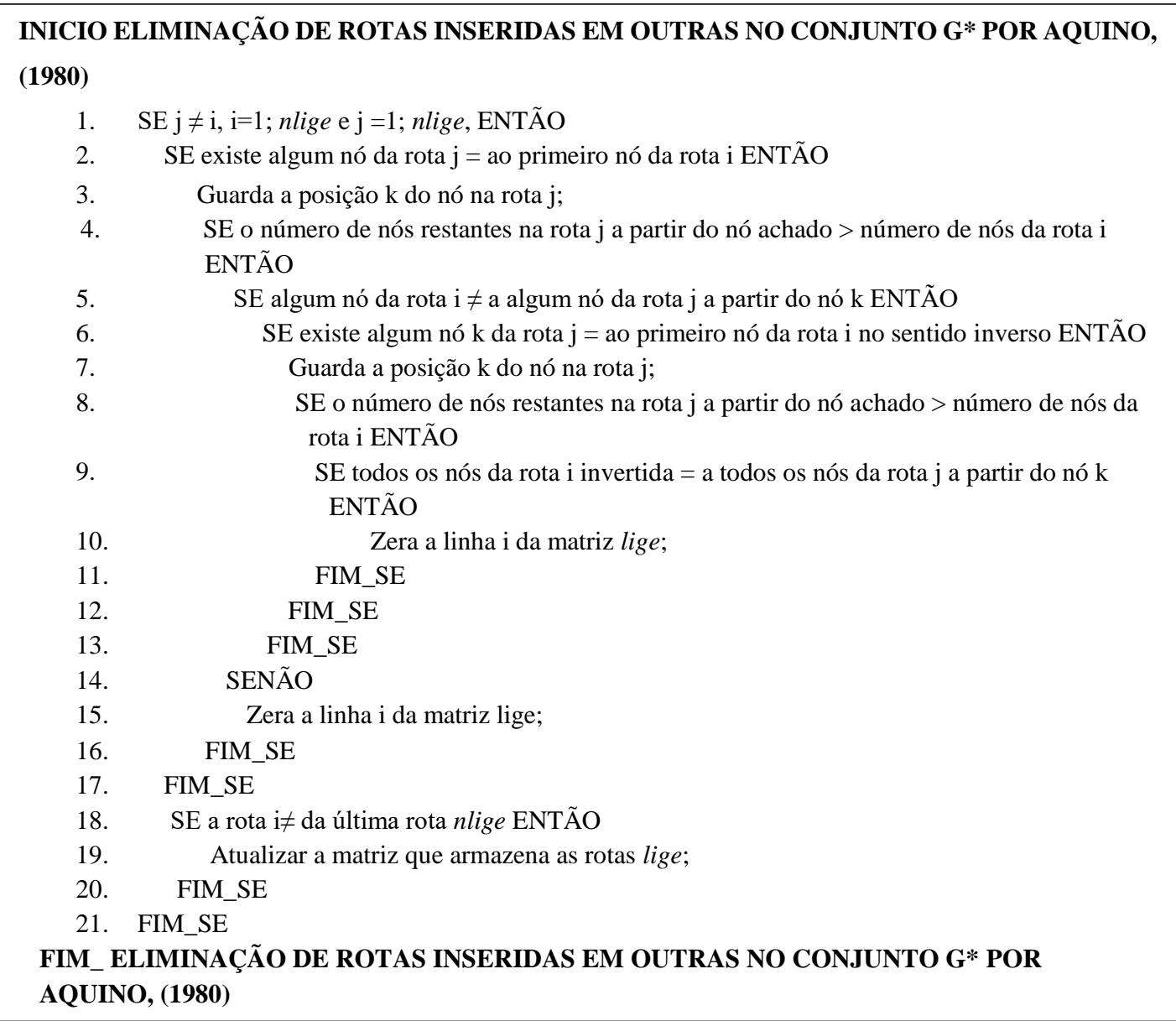

Figura 10. Pseudocódigo da função que elimina as rotas inseridas em outras no conjunto de rotas candidatas $\mathrm{G}^{*}$ por Aquino, (1980). 


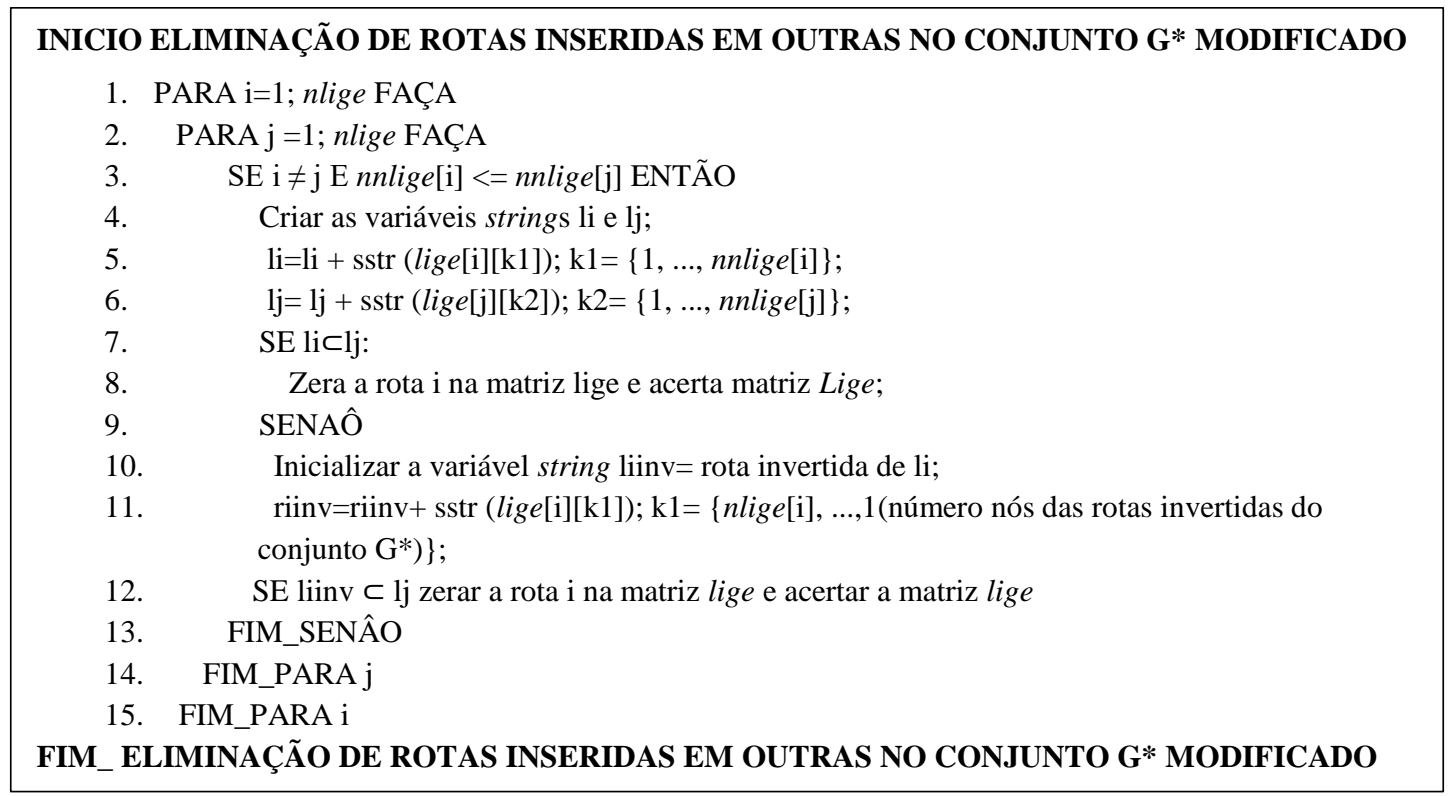

Figura 11. Pseudocódigo da função para a eliminação de rotas inseridas em outras e que retrocedem sobre elas mesmas no conjunto $G^{*}$ modificado.

Tendo essas rotas resultantes que formarão o conjunto $G^{*}$, elimina-se do conjunto $\mathrm{G}$ as rotas inseridas em $\mathrm{G}^{*}$ e o conjunto resultante define-se como $\overline{\boldsymbol{G}}$, gerando com isso o conjunto final de rotas candidatas $(\mathrm{F})$, como descrito nas linhas 12 e 13 do pseudocódigo referente à figura 4.

Em seguida, na criação da função para determinar o conjunto $\mathrm{F}$, descrita em sua forma original, proposta por Aquino, (1980) na figura 12, foram feitas modificações similares a essa função, como é apresentado na figura 13. A análise é muito parecida com a função que acerta o conjunto $\mathrm{G}^{*}$. Desta vez foram adequadas as variáveis de tipo strings, descrito a partir da linha 2 da figura correspondente à modificação, para as rotas do conjunto $\mathrm{G}^{*}$, já acertadas, e as do conjunto $\overline{\boldsymbol{G}}$ assim 


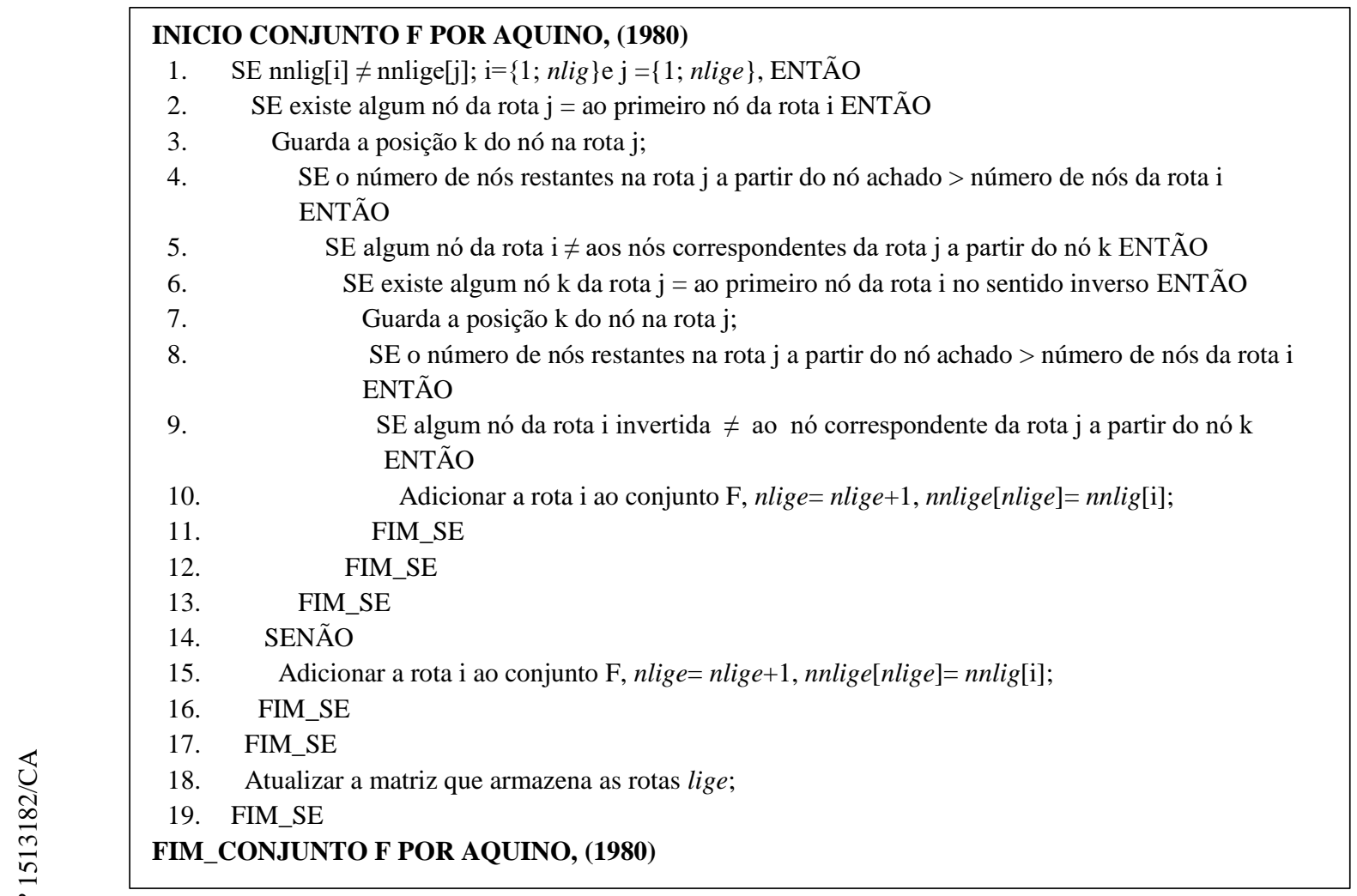

Figura 12.Pseudocódigo da função que gera o conjunto de rotas candidatas F, por Aquino, (1980).

como para suas inversas, comprovando que cada uma das rotas inclusas no conjunto $\mathrm{F}$ sejam únicas nos sentidos indo e voltando, além de que não exista nenhuma inclusa dentro da outra, o que possibilita reunir finalmente os maiores caminhos mínimos de ambos conjuntos, $\mathrm{G}_{\text {e }} \mathrm{G}^{*}$, no conjunto $\mathrm{F}$. 


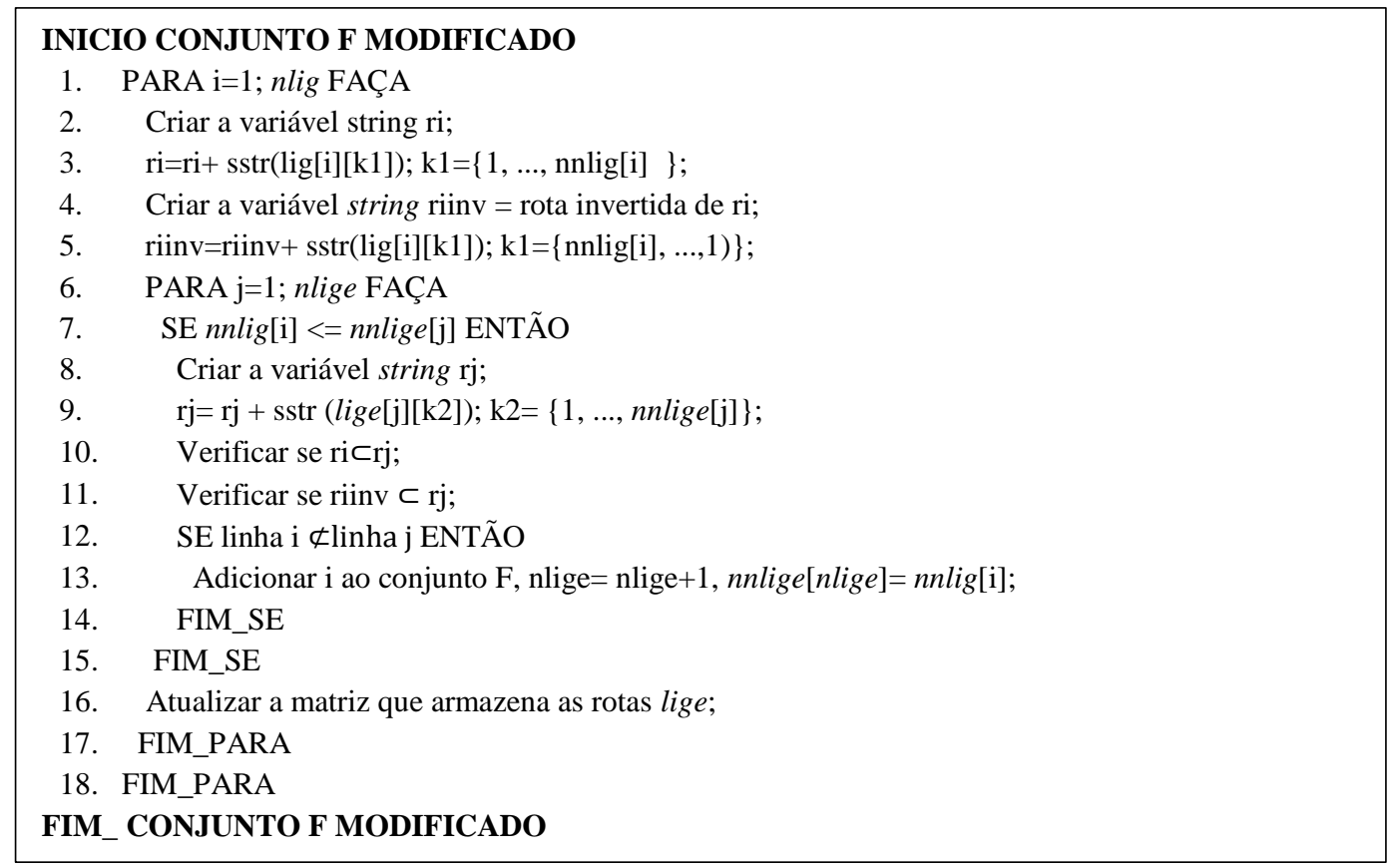

Figura 13. Pseudocódigo da função que gera o conjunto de rotas candidatas F modificado.

\section{2.2}

\section{Geração de uma rede inicial conectada}

É feito o cálculo da demanda potencial da rota $\lambda\left(\mathrm{U}_{2}\right)$, determinada através da somatória das demandas entre os pares de centroides de origem e destino i e j dentro da linha ג, dado pela fórmula (4.1);

$$
\mathrm{U}_{\lambda}=\sum_{\mathrm{ij} \in \lambda} D_{i j} \quad \forall \lambda \in \mathrm{F}
$$

Inicialmente é selecionada a rota i que apresente maior demanda potencial mon[i], para formar parte do conjunto de rotas que definem a rede conectada, armazenando esses valores de demanda na variável inteira rang. A cada inclusão de rota na rede atualizam-se as demandas potenciais das rotas restantes do conjunto de rotas candidatas. 
Uma modificação importante no método refere-se ao critério para a escolha da próxima rota a ser incluída na rede conectada. No método proposto por Aquino, (1980), apresentado na figura 13, continuava-se incluindo as rotas em ordem de maior demanda, como descrito a partir da linha 1 até a linha 16. Na versão modificada mantem-se o objetivo do método que é criar uma rede conectada com os mais longos caminhos mínimos. No entanto, após a primeira rota com maior demanda, a próxima rota a inserir seria aquela que tivesse pelo menos um nó centroide em comum com a rede já criada e o máximo de centroides ainda não conectados. Isso garante a criação de uma rede conectada de forma mais rápida, atendendo, com este critério de seleção, tanto aos interesses das empresas quanto dos clientes, pois seriam rotas de maior nível de rentabilidade. Importante lembrar que a rentabilidade da rota está dada pela demanda total na rota/comprimento da rota. Na figura 14, apresenta-se esta modificação.

Outra modificação importante no programa trata a função que conecta a rede (RECONEC). No programa original havia muitas repetições no código, o que tornava a rotina muito longa e difícil de interpretar. Aquelas partes repetidas, foram identificadas e definidas como funções, sendo chamadas quando necessário e consequentemente fazendo esta rotina mais curta e inteligível. 


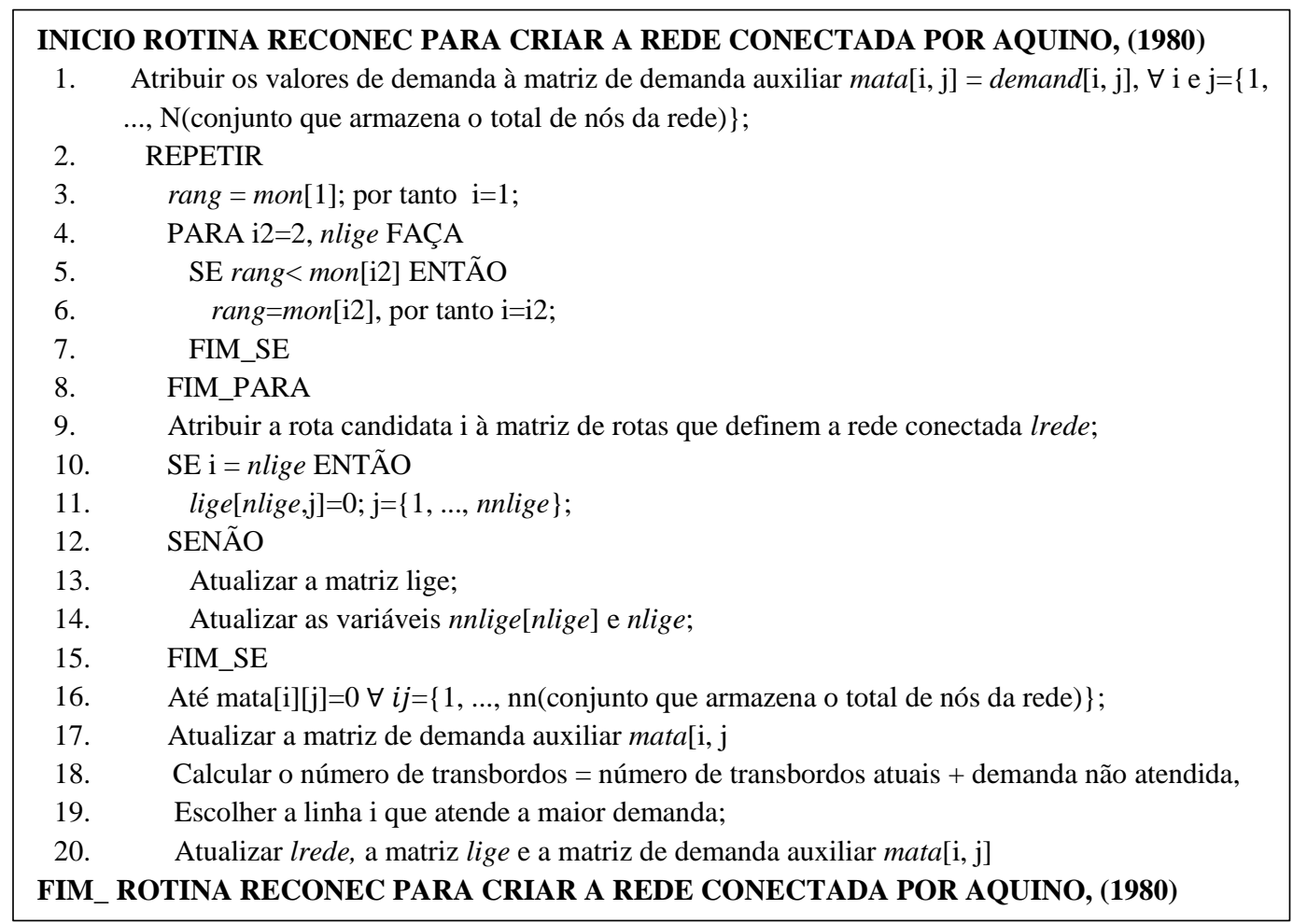

Figura 14. Pseudocódigo da função que cria a rede conectada por Aquino,(1980).

\section{INICIO ROTINA RECONEC PARA CRIAR A REDE CONECTADA MODIFICADO}

1. Atribuir os valores de demanda à matriz de demanda auxiliar $\operatorname{mata}[\mathrm{i}, \mathrm{j}]=\operatorname{demand}[\mathrm{i}, \mathrm{j}], \forall \mathrm{i} \mathrm{e}$ $\mathrm{j}=\{1, \ldots, \mathrm{N}$ (conjunto que armazena o total de nós da rede) $\}$;

2. Escolher a rota de maior demanda;

3. REPETIR

4. Procurar a próxima rota a ser inserida na rede a conectar;

5. Criar um conjunto redengp de todos os centroides na matriz que armazena as linhas que definem a rede conectada lrede;

6. Escolher a rota i com maior número de centroides ainda não conectados

7. $\quad$ PARA $12=1$, nlige FAÇA

8. Criar um conjunto ligengp de centroides;

9. Criar o conjunto inter interseção entre os conjuntos redengp e ligengp;

10. Calcular o número nngp de elementos em redengp-inter;

11. A rota i2 de maior nngp será a rota i escolhida;

12. FIM PARA

13. Inserir a rota i em lrede;

14. Retirar a rota i de lige;

15. Atualizar a matriz auxiliar de demanda mata;

16. ATÉ todos os centroides estejam conectados na rede;

17. $\{\ldots\}$

FIM_ROTINA RECONEC PARA CRIAR A REDE CONECTADA MODIFICADO

Figura 15.Pseudocódigo da função que cria a rede conectada 


\section{2.3}

\section{Definição de um conjunto de rotas em ordem de minimização de transbordos}

Uma vez determinadas as rotas que definem a rede conectada. É calculado o número total de transbordos seguindo a rotina descrita na figura 4, especificamente na linha 9 e como é referenciado também na linha 26 á 31 na figura 15 da rotina RECONEC. A partir daí seleciona-se assim um conjunto de rotas dentre as rotas candidatas que reduzam o número de transbordos (NT) ao longo da rede, até que NT=0.

O número de transbordos resultantes é calculado através da seguinte expressão:

$\mathrm{NT}=\sum D_{i j}-\sum U_{\lambda^{*}} ; \mathrm{ij} \in N^{2} \mathrm{e} \lambda^{*} \in$ conjunto de rotas já inseridas na rede (4.3)

Onde:

NT: Número de transbordos;

$D_{\mathrm{ij}}$ : Demanda entre ij;

$U_{\lambda}$ : Demanda potencial atendida dentro da linha $\lambda$;

Para esta análise também foram feitas melhorias importantes. Segundo o método proposto por Aquino, (1980), seriam escolhidas como rotas candidatas as rotas que reduzem ao máximo o número de transbordos, conforme as linhas 10 e 11 do pseudocódigo referido a figura 4. Para atingir este objetivo foram declaradas, na versão aqui proposta, duas novas funções que permitem identificar todos os pares O-D atendidos apenas através de transbordos. Isto tem o intuito de identificar que rotas ainda não inseridas na rede atendem ao maior número de pares O-D ainda não servidos diretamente. Ou seja, só serão incluídas as rotas que contribuem para reduzir gradativamente os transbordos até chegar a zero. Com isto, as rotas candidatas são 
incluídas em ordem de redução de transbordos, possibilitando a atualização da rede criada a modo de minimizar ao máximo possível o número de transbordos, atendendo assim ao segundo objetivo do problema. Na figura 16 é apresentada a função que cria o conjunto de rotas que conectadas minimizam o número de transbordos na rede.

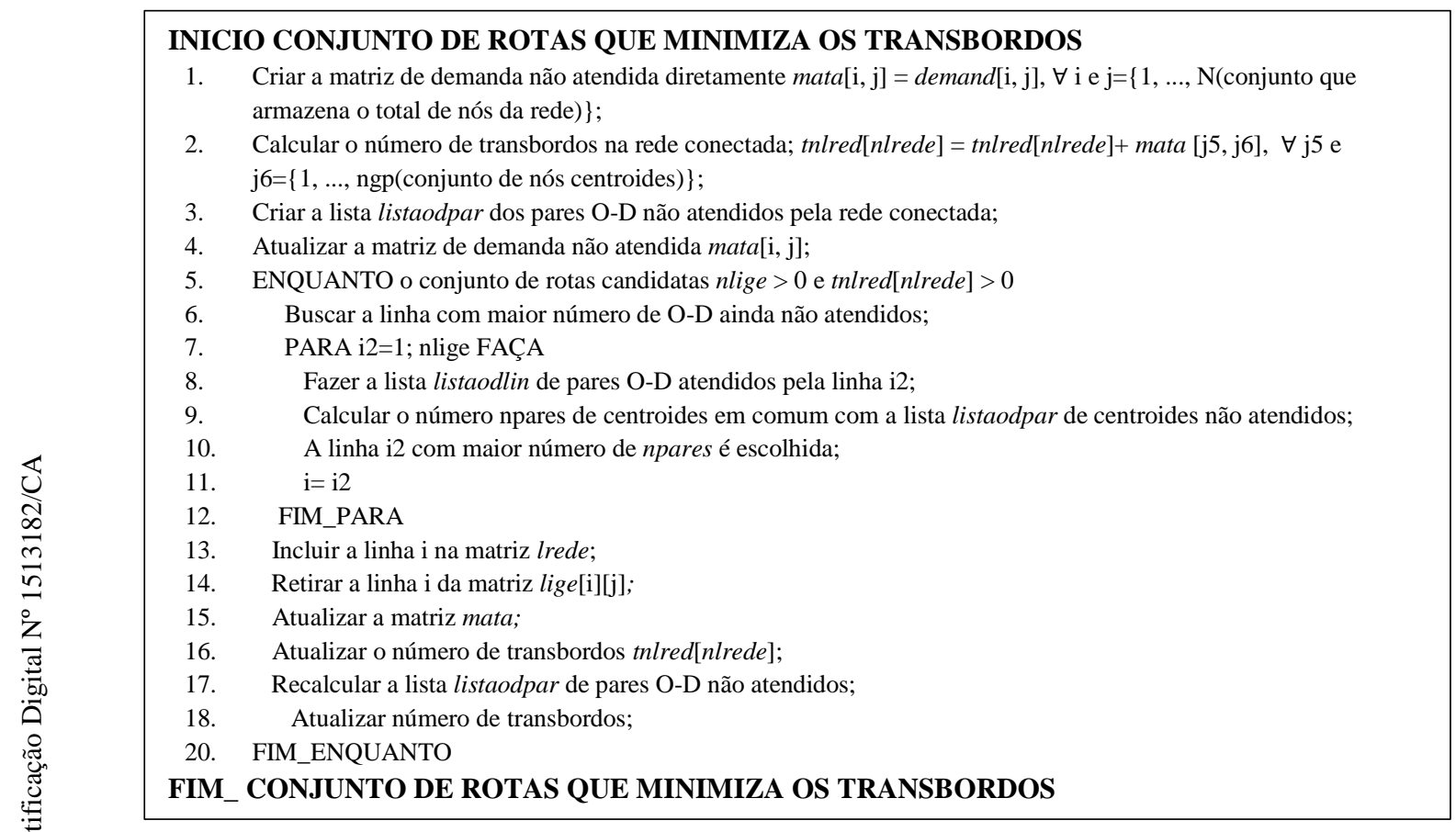

Figura 16. Psedudocodigo da função de rotas que minimiza os transbordos.

\section{2.4}

\section{Avaliação das rotas candidatas}

Nesta fase serão calculados vários indicadores de rotas. Permitindo à empresa prestadora do serviço e ao órgão de planejamento, conhecer o nível de desempenho de cada uma destas rotas.

No método proposto por Aquino, (1980) essa avaliação era feita para todas as rotas candidatas, contidas no conjunto F. Tendo em conta que essa análise nesse momento não era usada e que ele pode ser mais útil para as rotas que minimizam 
número de transbordo. Esta fase foi adiada, para finalmente realizar a avaliação do conjunto de rotas que minimizam o número de transbordo na rede.

Para cada rota candidata $\lambda$, são calculados os seguintes parâmetros:

1) Comprimento da rota $\left(l_{\lambda}\right)$;

2) Tempo de viagem de terminal a terminal (TEMP $\left.P_{2}\right)$;

3) Demanda potencial $\left(U_{x}\right)$;

$$
\mathrm{U} \lambda=\sum D_{i j} \quad ; \mathrm{ij} \in \lambda(4.2)
$$

4) Identificação e carga do trecho mais carregado ( $\mathrm{TMaC}, \mathrm{Ca} . \mathrm{TMaC}$ );

5) Identificação e carga do trecho menos carregado (TMeC, Ca.TMeC);

6) Carga média por trecho (Ca.Med.);

7) Usuários por quilómetros $\left(\mathrm{VKM}_{2}\right)$;

$$
\mathrm{VKM}_{\lambda}=\sum_{\mathrm{ij} \in \lambda} D_{i j} * T_{i j}^{\lambda} * V_{i j}
$$

Onde: $T_{i j}^{\lambda}$ : tempo de viagem entre i e j sobre a rota;

$V_{i j}$ : velocidade no caminho $\mathrm{ij}$.

8) Carga por quilômetro $\left(\mathrm{CPK}_{\star}\right)$;

$$
\mathrm{CPK}=V K M_{\lambda} / l_{\lambda}
$$

9) Distância média percorrida por usuário $\left(\mathrm{DMO}_{\star}\right)$

$$
\mathrm{DMO}=V K M_{\lambda} / U_{\lambda}
$$

10) Índice de rentabilidade $\left(\mathrm{VSK}_{i}\right)$

$$
\mathrm{VSK}_{\lambda}=U_{\lambda} / l_{\lambda}
$$

11) Número de ônibus (NUMBUS ${ }_{\varkappa}$ ) (ver seção 3.5)

$$
\operatorname{NUMBUS}_{\lambda}=\left\{2 * 1_{\lambda} *\left|\left(C_{\lambda} /(\mathrm{t} * \mathrm{CAP})\right)+1\right| /\left(\mathrm{VM}_{\lambda} * \text { delta }\right)\right\}
$$

12) Carga transportada por ônibus (CTBUS $\left.S_{2}\right)$ pode ser analisado como um índice de rentabilidade. 


$$
\mathrm{CTBUS}_{\lambda}=U_{\lambda} / N U M B U S_{\lambda}
$$

13) Desvio total da rota em relação ao caminho mínimo (DESVIO $)_{\lambda}$

$$
\mathrm{DESVIO}_{\lambda}=\sum_{i, j \in \lambda} D_{i j} *\left(T_{i j}-t_{i j}\right)
$$

Onde: $t_{i j}$ : tempo mínimo de viagem entre i e j. Supondo que os usuários são conduzidos pelo caminho mínimo de uma rota direta. 


\section{5.}

\section{Análise dos resultados}

Tendo em conta as modificações feitas, descritas no capítulo anterior, é apresentado a continuação o fluxograma do programa principal modificado, na figura 17, mediante o qual foram obtidos os resultados que serão analisados ao longo do presente capítulo. Além disso é apresentado o pseudocódigo do programa principal modificado no anexo 2.

\section{1}

\section{Dados usados na aplicação do algoritmo modificado}

$\mathrm{Na}$ presente seção será desenvolvido um exemplo de aplicação da presente estratégia de solução, onde é mostrado detalhadamente a implementação de cada uma das fases antes descritas.

Com o intuito de observar os resultados obtidos na aplicação do algoritmo modificado, foi usada a mesma rede do trabalho de Aquino, (1980); rede teórica de tamanho real, composta de um total de:

- 45 nós, entre eles: 18 são centroides e 27 são interseções viárias;

- 51 arcos;

No exemplo original, Aquino, (1980) trabalha com 7 centroides artificiais ligados a 4 nós não artificiais. Esse fato era tratado no programa de forma um tanto confusa. Para esta pesquisa o exemplo foi adaptado, sendo que as demandas destes centroides artificiais são inicialmente atribuídas aos nós da rede ligados a eles. Estes são convertidos em centroides, economizando assim várias análises por causa dos nós artificiais. Na figura 17 é apresentada a estrutura da rede de teste usada. 


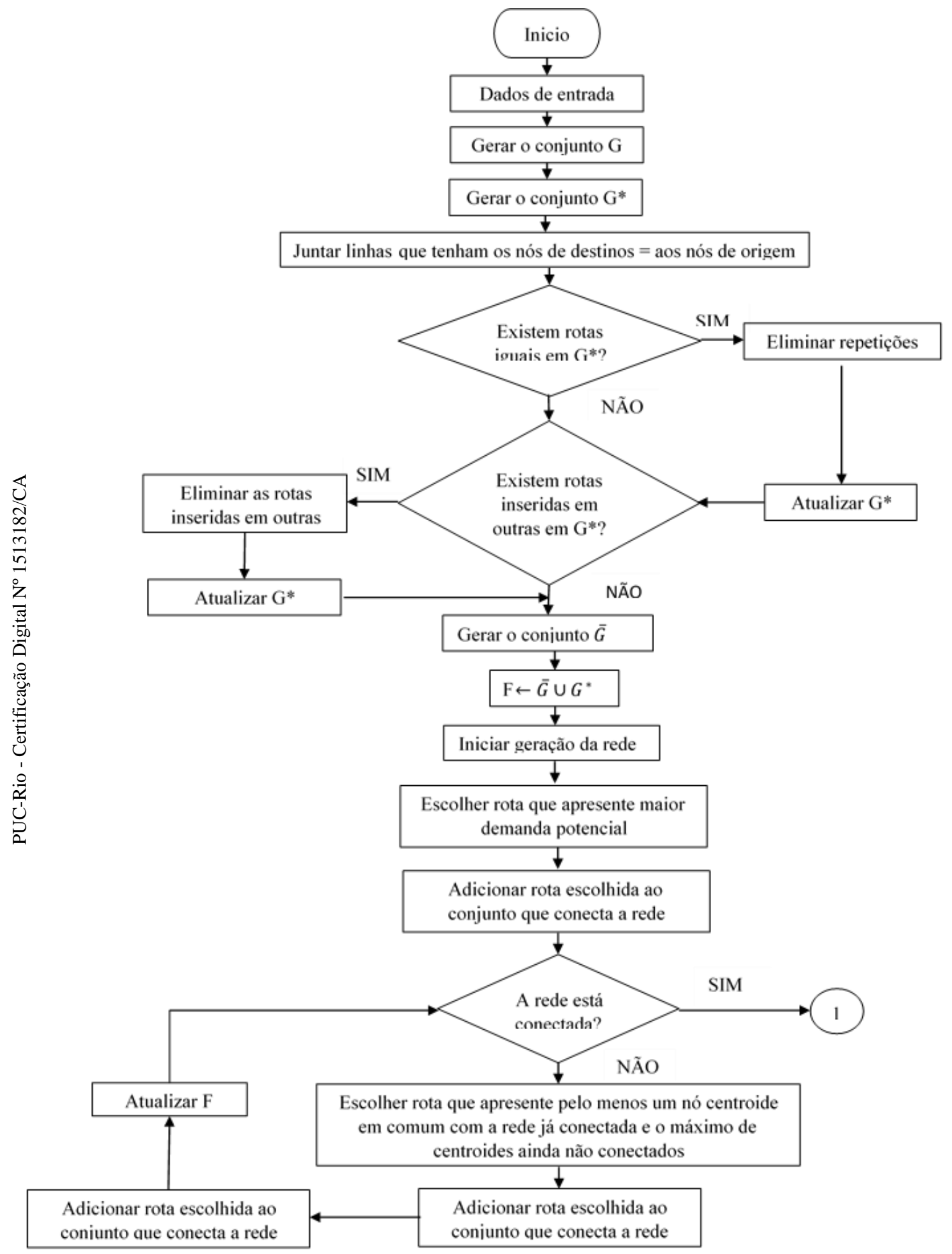




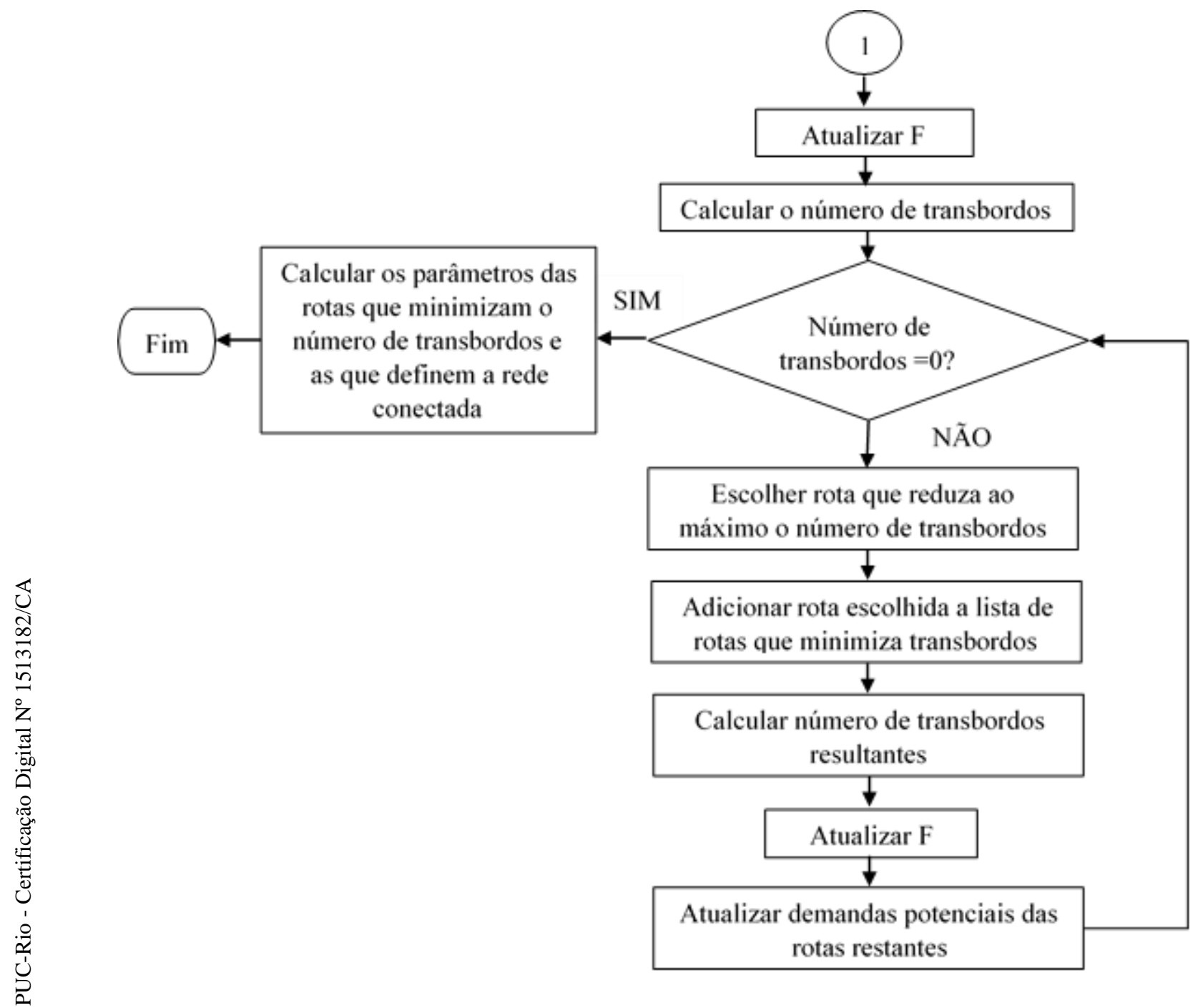

Figura 157. Fluxograma da função principal modificada. 


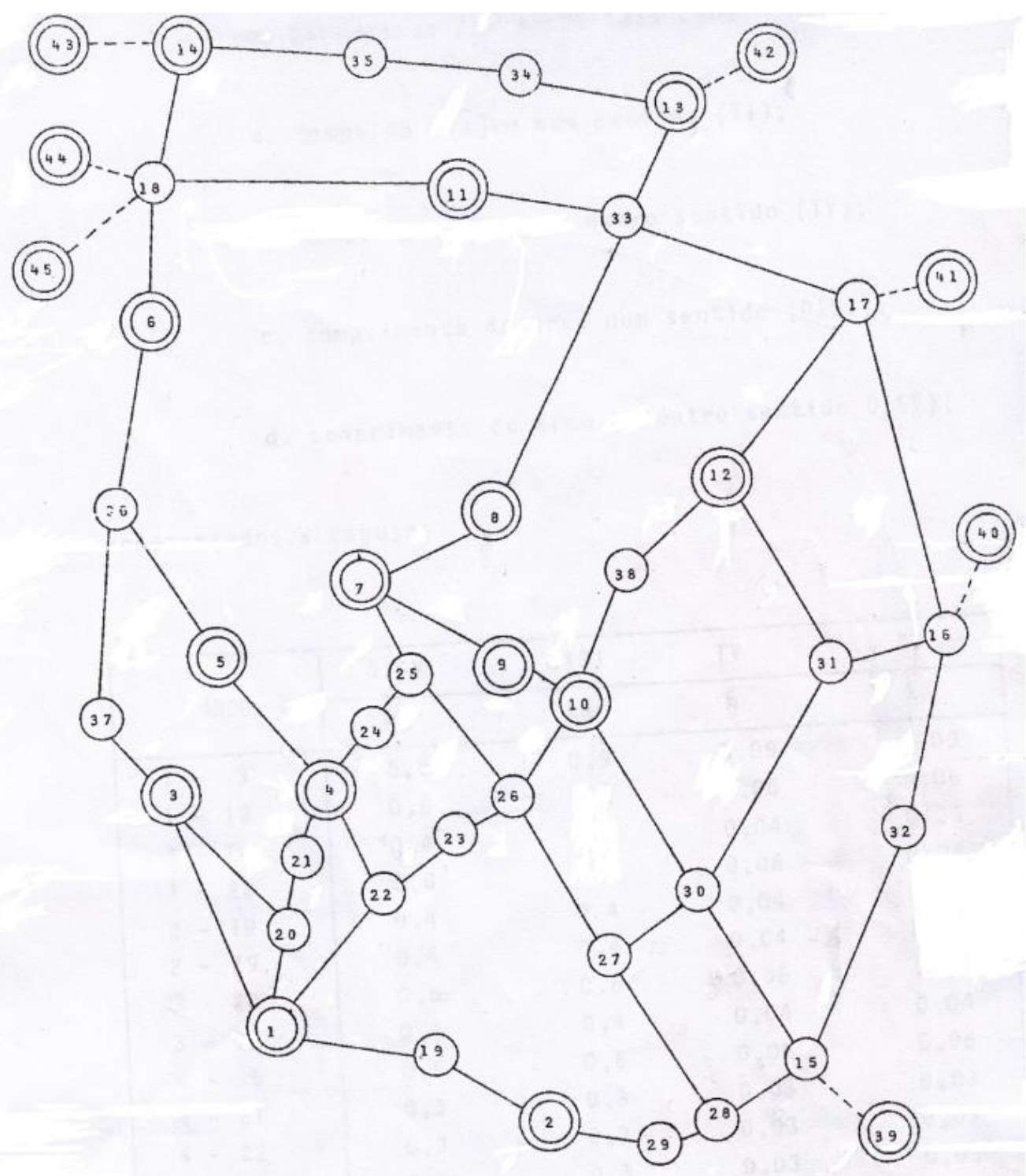

Figura 18. Rede de teste

Na Tabela 2 é apresentada a matriz Origem-Destino, representadas por unidades de carga. Cada unidade de carga equivale a 50 passageiros. Para o período de tempo de 
uma hora. Aqui apresenta-se o triangulo superior da matriz, mas esta será considerada como simétrica.

Tabela 2. Matriz de demanda Origem-Destino.

\begin{tabular}{|c|c|c|c|c|c|c|c|c|c|c|c|c|c|c|c|c|c|c|}
\hline & $\mathbf{1}$ & $\mathbf{2}$ & $\mathbf{3}$ & $\mathbf{4}$ & $\mathbf{5}$ & $\mathbf{6}$ & $\mathbf{7}$ & $\mathbf{8}$ & $\mathbf{9}$ & $\mathbf{1 0}$ & $\mathbf{1 1}$ & $\mathbf{1 2}$ & $\mathbf{1 3}$ & $\mathbf{1 4}$ & $\mathbf{1 5}$ & $\mathbf{1 6}$ & $\mathbf{1 7}$ & $\mathbf{1 8}$ \\
\hline $\mathbf{1}$ & $\mathbf{0}$ & 1 & 1 & 1 & 1 & 2 & 1 & 3 & 1 & 2 & 4 & 4 & 5 & 7 & 9 & 8 & 9 & 16 \\
\hline $\mathbf{2}$ & & $\mathbf{0}$ & 0,5 & 0,5 & 0,5 & 1 & 0,5 & 1 & 0,5 & 1 & 1 & 1 & 0,5 & 2 & 1 & 1 & 1 & 3 \\
\hline $\mathbf{3}$ & & & $\mathbf{0}$ & 0,6 & 0,8 & 1 & 0,5 & 0,8 & 1 & 3 & 2 & 2 & 7 & 6 & 8 & 9 & 7 & 12 \\
\hline $\mathbf{4}$ & & & & $\mathbf{0}$ & 0,5 & 0,5 & 0,5 & 1 & 0,5 & 1 & 3 & 2 & 3 & 6 & 5 & 2 & 6 & 11 \\
\hline $\mathbf{5}$ & & & & & $\mathbf{0}$ & 0,5 & 1 & 1 & 0,2 & 1 & 2 & 3 & 4 & 5 & 6 & 4 & 5 & 14 \\
\hline $\mathbf{6}$ & & & & & & $\mathbf{0}$ & 0,3 & 0,1 & 1 & 0,8 & 0,3 & 2 & 1 & 0,5 & 0,2 & 0,2 & 0,3 & 2,1 \\
\hline $\mathbf{7}$ & & & & & & & $\mathbf{0}$ & 0 & 0 & 0,5 & 0,3 & 0,5 & 0,8 & 1 & 1 & 0,8 & 2 & 6 \\
\hline $\mathbf{8}$ & & & & & & & & $\mathbf{0}$ & 0,3 & 0,1 & 0,1 & 0,2 & 1 & 2 & 2 & 1 & 3 & 6 \\
\hline $\mathbf{9}$ & & & & & & & & & $\mathbf{0}$ & 0 & 1 & 1 & 2 & 2 & 3 & 1 & 4 & 9 \\
\hline $\mathbf{1 0}$ & & & & & & & & & & $\mathbf{0}$ & 0,5 & 1 & 3 & 3 & 5 & 6 & 5 & 11 \\
\hline $\mathbf{1 1}$ & & & & & & & & & & & $\mathbf{0}$ & 1 & 1 & 1 & 1 & 0,3 & 0,1 & 0,5 \\
\hline $\mathbf{1 2}$ & & & & & & & & & & & & $\mathbf{0}$ & 0,5 & 0,3 & 1 & 0,2 & 0,1 & 0,3 \\
\hline $\mathbf{1 3}$ & & & & & & & & & & & & & $\mathbf{0}$ & 0,2 & 0,1 & 0,1 & 0,2 & 6,2 \\
\hline $\mathbf{1 4}$ & & & & & & & & & & & & & & $\mathbf{0}$ & 1 & 1 & 1 & 0,9 \\
\hline $\mathbf{1 5}$ & & & & & & & & & & & & & & & $\mathbf{0}$ & 1 & 1 & 4 \\
\hline $\mathbf{1 6}$ & & & & & & & & & & & & & & & & $\mathbf{0}$ & 1 & 1,7 \\
\hline $\mathbf{1 7}$ & & & & & & & & & & & & & & & & & $\mathbf{0}$ & 4,3 \\
\hline $\mathbf{1 8}$ & & & & & & & & & & & & & & & & & & $\mathbf{0}$ \\
\hline
\end{tabular}

A demanda total na rede é de 963,4 unidades de carga. O número de passageiros permitido por ônibus é igual a uma unidade de carga.

As distancias e os tempos de viagem de ida e de volta nos arcos, são apresentadas na Tabela 3 . 
Tabela 3.Valores de distância e tempos de viagem de ida (I) e volta (V) nos arcos.

\begin{tabular}{|c|c|c|c|c|}
\hline \begin{tabular}{|l|} 
Arco \\
\end{tabular} & Dist. I.(km) & Dist. V.(km) & Temp. I. (h) & Temp. V. (h) \\
\hline \begin{tabular}{|l|}
$1--3$ \\
\end{tabular} & 0,9 & 0,9 & 0,09 & 0,09 \\
\hline $1--19$ & 0,6 & 0,6 & 0,06 & 0,06 \\
\hline $1--20$ & 0,4 & 0,4 & 0,04 & 0,04 \\
\hline $1--22$ & 0,6 & 0,6 & 0,06 & 0,06 \\
\hline $2--19$ & 0,4 & 0,4 & 0,04 & 0,04 \\
\hline $2--29$ & 0,4 & 0,4 & 0,04 & 0,04 \\
\hline $3--20$ & 0,6 & 0,6 & 0,06 & 0,06 \\
\hline $3--37$ & 0,4 & 0,4 & 0,04 & 0,04 \\
\hline $4--5$ & 0,6 & 0,6 & 0,06 & 0,06 \\
\hline $4--21$ & 0,3 & 0,3 & 0,03 & 0,03 \\
\hline $4--22$ & 0,3 & 0,3 & 0,03 & 0,03 \\
\hline $4--24$ & 0,3 & 0,3 & 0,03 & 0,03 \\
\hline $5--36$ & 0,7 & 0,7 & 0,07 & 0,07 \\
\hline 6--18 & 0,5 & 0,5 & 0,025 & 0,025 \\
\hline $6--36$ & 0,6 & 0,6 & 0,03 & 0,03 \\
\hline $7--8$ & 0,4 & 0,4 & 0,04 & 0,04 \\
\hline $7--9$ & 0,5 & 0,5 & 0,05 & 0,05 \\
\hline $7--25$ & 0,4 & 0,4 & 0,04 & 0,04 \\
\hline $8--33$ & 1,2 & 1,2 & 0,06 & 0,06 \\
\hline $9--10$ & 0,2 & 0,2 & 0,02 & 0,2 \\
\hline $10--26$ & 0,5 & 0,5 & 0,05 & 0,05 \\
\hline $10--30$ & 0,8 & 0,8 & 0,08 & 0,08 \\
\hline $10--38$ & 0,5 & 0,5 & 0,025 & 0,025 \\
\hline $11--18$ & 1,2 & 1,2 & 0,03 & 0,03 \\
\hline $11--33$ & 0,5 & 0,5 & 0,0125 & 0,0125 \\
\hline $12--17$ & 0,8 & 0,8 & 0,04 & 0,04 \\
\hline $12--31$ & 0,7 & 0,7 & 0,035 & 0,035 \\
\hline $12--38$ & 0,5 & 0,5 & 0,025 & 0,025 \\
\hline $13--33$ & 0,7 & 0,7 & 0,035 & 0,035 \\
\hline $13--34$ & 0,6 & 0,6 & 0,03 & 0,03 \\
\hline $14--18$ & 1 & 1 & 0,05 & 0,05 \\
\hline $14--35$ & 0,7 & 0,7 & 0,035 & 0,035 \\
\hline $15--28$ & 0,4 & 0,4 & 0,04 & 0,04 \\
\hline $15--30$ & 0,7 & 0,7 & 0,07 & 0,07 \\
\hline $15--32$ & 0,8 & 0,8 & 0,04 & 0,04 \\
\hline $16--17$ & 1,3 & 1,3 & 0,0325 & 0,0325 \\
\hline $16--31$ & 0,8 & 0,8 & 0,04 & 0,04 \\
\hline $16--32$ & 1 & 1 & 0,05 & 0,05 \\
\hline $17--33$ & 0,9 & 0,9 & 0,0225 & 0,0225 \\
\hline $20--21$ & 0,3 & 0,3 & 0,03 & 0,03 \\
\hline $22--23$ & 0,3 & 0,3 & 0,03 & 0,03 \\
\hline $23--26$ & 0,2 & 0,2 & 0,02 & 0,02 \\
\hline $24--25$ & 0,2 & 0,2 & 0,02 & 0,02 \\
\hline $25--26$ & 0,6 & 0,6 & 0,06 & 0,06 \\
\hline $26--27$ & 0,7 & 0,7 & 0,07 & 0,07 \\
\hline $27--28$ & 0,7 & 0,7 & 0,07 & 0,07 \\
\hline $27--30$ & 0,4 & 0,4 & 0,04 & 0,04 \\
\hline $28--29$ & 0,2 & 0,2 & 0,02 & 0,02 \\
\hline $30--31$ & 0,9 & 0,9 & 0,045 & 0,045 \\
\hline $34--35$ & 0,5 & 0,5 & 0,025 & 0,025 \\
\hline $36--37$ & 0,8 & 0,8 & 0,08 & 0,08 \\
\hline
\end{tabular}

\section{2}

\section{Geração do conjunto de rotas candidatas}

Uma vez feita a leitura dos parâmetros e inicializadas as variáveis, foi obtido o primeiro conjunto $\mathrm{G}$ de rotas candidatas, através da aplicação do algoritmo de Dijkstra. 
Tabela 4.Conjunto de rotas do geradas para o conjunto G. Obtidas pelo algoritmo de Floyd-Warshall e pelo Algoritmo Dijkstra.

\begin{tabular}{|c|c|c|c|c|}
\hline No. & Rotas obtidas pelo Algoritmo Floyd-Warshall & Número de nós & Rotas obtidas pelo Algoritmo Dijkstra & Número de nós \\
\hline 1 & $1-22-4-24-25-7-8$ & 7 & $1-22-23-26-10-9$ & 6 \\
\hline 2 & $1-22-23-26-10-9$ & 6 & $1-22-4-24-25-7-8-33-11$ & 9 \\
\hline 3 & $1-22-23-26-10-38-12-17-33-11$ & 10 & $1-22-23-26-27-30-31-12$ & 8 \\
\hline 4 & $1-22-23-26-10-38-12-17-33-13$ & 10 & $1-22-4-24-25-7-8-33-13$ & 9 \\
\hline 5 & $1-3-37-36-6-18-14$ & 7 & $1-3-37-36-6-18-14$ & 7 \\
\hline 6 & $1-22-23-26-10-38-12-17-16$ & 9 & $1-19-2-29-28-15-32-16$ & 8 \\
\hline 7 & $2-19-1-22-4-5$ & 6 & $1-22-4-24-25-7-8-33-17$ & 9 \\
\hline 8 & $2-29-28-15-32-16-17-33-11-18-6$ & 11 & $2-19-1-22-4-5$ & 6 \\
\hline 9 & $2-19-1-22-4-24-25-7$ & 6 & $2-29-28-15-32-16-17-33-11-18-6$ & 11 \\
\hline 10 & $2-29-28-15-32-16-17-33-8$ & 9 & $2-19-1-22-4-24-25-7$ & 8 \\
\hline 11 & $2-29-28-27-26-10-9$ & 7 & $2-29-28-15-32-16-17-33-8$ & 9 \\
\hline 12 & $2-29-28-27-30-31-12$ & 7 & $2-29-28-27-30-10-9$ & 7 \\
\hline 13 & $2-29-28-15-32-16-17-33-13$ & 9 & $2-29-28-27-30-31-12$ & 7 \\
\hline 14 & $2-29-28-15-32-16-17-33-11-18-14$ & 11 & $2-29-28-15-32-16-17-33-13$ & 9 \\
\hline 15 & $3-20-21-4-5$ & 5 & $2-29-28-15-32-16-17-33-11-18-14$ & 11 \\
\hline 16 & $3-20-21-4-24-25-7-8$ & 8 & $3-20-21-4-5$ & 5 \\
\hline 17 & $3-20-21-4-24-25-7-9$ & 8 & $3-20-21-4-24-25-7-8$ & 8 \\
\hline 18 & $3-1-22-23-26-10$ & 6 & $3-20-21-4-24-25-7-9$ & 8 \\
\hline 19 & $3-37-36-6-18-11-33-17-12$ & 9 & $3-1-22-23-26-10$ & 6 \\
\hline 20 & $3-37-36-6-18-11-33-13$ & 8 & $3-37-36-6-18-11-33-17-12$ & 9 \\
\hline 21 & $3-1-19-2-29-28-15$ & 7 & $3-37-36-6-18-11-33-13$ & 8 \\
\hline 22 & $3-37-36-6-18-11-33-17-16$ & 9 & $3-1-19-2-29-28-15$ & 7 \\
\hline 23 & $4-24-25-7-8-33-11$ & 7 & $3-37-36-6-18-11-33-17-16$ & 9 \\
\hline 24 & $4-22-23-26-10-38-12$ & 7 & $4-24-25-7-8-33-17-12$ & 8 \\
\hline 25 & $4-24-25-7-8-33-13$ & 7 & $4-5-36-6-18-14$ & 6 \\
\hline 26 & $4-5-36-6-18-14$ & 6 & $4-22-23-26-27-28-15$ & 7 \\
\hline 27 & $4-22-23-26-27-28-15$ & 7 & $4-24-25-7-8-33-17-16$ & 8 \\
\hline 28 & $4-24-25-7-8-33-17-16$ & 8 & $5-4-24-25-7-8$ & 6 \\
\hline 29 & $5-4-24-25-7-8$ & 6 & $5-4-24-25-7-9$ & 6 \\
\hline 30 & $5-4-24-25-7-9$ & 6 & $5-4-22-23-26-10$ & 6 \\
\hline 31 & $5-4-22-23-26-10$ & 6 & $5-36-6-18-11-33-17-12$ & 8 \\
\hline 32 & $5-36-6-18-11-33-17-12$ & 8 & $5-36-6-18-11-33-13$ & 7 \\
\hline 33 & $5-36-6-18-11-33-13$ & 7 & $5-36-6-18-11-33-17-16-32-15$ & 10 \\
\hline 34 & $5-36-6-18-11-33-17-16-32-15$ & 10 & $6-18-11-33-8-7-9-10$ & 8 \\
\hline 35 & $6-18-11-33-8-7$ & 6 & $7-9-10-30-15$ & 5 \\
\hline 36 & $6-18-11-33-17-12-38-10-9$ & 9 & $9-10-30-31-12$ & 5 \\
\hline 37 & $7-9-10-38-12$ & 5 & $9-10-30-31-16$ & 5 \\
\hline 38 & $7-8-33-11-18-14$ & 6 & $10-9-7-8-33-13$ & 6 \\
\hline 39 & $7-9-10-30-15$ & 5 & $10-9-7-8-33-11-18-14$ & 8 \\
\hline 40 & $8-7-9-10$ & 4 & $10-9-7-8-33-17$ & 6 \\
\hline 41 & $8-33-17-12$ & 4 & $12-17-33-13$ & 4 \\
\hline 42 & $9-10-38-12-17-33-13$ & 7 & $12-17-33-11-18-14$ & 6 \\
\hline 43 & $9-10-38-12-17-33-11-18-14$ & 9 & $12-17-16-32-15$ & 5 \\
\hline 44 & $9-10-38-12-17-16$ & 6 & $12-17-16$ & 3 \\
\hline 45 & $13-34-35-14$ & 4 & $13-34-35-14$ & 4 \\
\hline
\end{tabular}

Segundo a comparação feita entre os conjuntos de rotas geradas a partir do algoritmo de Floyd -Warshal e pelo algoritmo de Dijkstra, apresentados na Tabela 4, pode ser observado que foram geradas igual número de rotas pelos dois algoritmos 
aplicados. De forma geral, as rotas criadas entre os dois algoritmos não têm grandes diferenças nas trajetórias que seguem nem nos números de nós de cada uma delas. O maior diferencial achado é a criação de rotas a partir dos nós centroides de origem 10 e 12 no conjunto obtido pelo Algoritmo de Dijkstra, que pode ser observado linhas 38 a 44 desse conjunto na Tabela acima. No entanto, essas diferenças não criam problema algum ao longo do desenvolvimento do programa.

Após a geração deste primeiro conjunto, para cada um dos caminhos pertencentes ao conjunto $\mathrm{G}$, são buscados caminhos próximos aos mínimos que possuam os mesmos nós terminais. Seus comprimentos deverão ser menores ou iguais a $(1+\mu)$ vezes ao cumprimento da rota original, sendo definindo o parâmetro da estratégia de resolução $\mu=1,3$.

Como mostrado na Tabela 5 a seguir, é possível comparar os conjuntos de rotas $\mathrm{G}^{*}$ obtidos mediante os métodos, original e modificado; foram obtidas menor número de rotas pelo novo método aplicado. De forma geral, as rotas geradas entre os dois métodos não apresentam grandes diferenças, valendo destacar a criação de rotas um pouco mais longas pelo método modificado, que foi possível pela função que une rotas complementares. 
Tabela 5.Conjunto de rotas do geradas para o conjunto G*. Segundo o método original e o modificado.

\begin{tabular}{|c|c|c|c|c|}
\hline No. & Rotas geradas para 0 conjunto $\mathrm{G}^{*}$ originalmente & Número de nós| & Rotas geradas para 0 conjunto $\mathrm{G}^{*}$ modificad & Número de nós \\
\hline 1 & $1-22-23-26-10-9-7-8$ & 8 & $1-22-4-24-25-7-8-33-11$ & 9 \\
\hline 2 & $1-19-2-29-28-15-32-16-17-33-13$ & 11 & $1-22-23-26-27-30-31-12-17-33-13$ & 11 \\
\hline 3 & $2-29-28-15-32-16-17-33-8-7$ & 10 & $1-22-4-24-25-7-8-33-13$ & 9 \\
\hline 4 & $2-29-28-27-26-10-9-7$ & 8 & $1-19-2-29-28-15-32-16$ & 8 \\
\hline 5 & $2-19-1-22-4-24-25-7-8$ & 9 & $1-22-4-24-25-7-8-33-17$ & 9 \\
\hline 6 & $2-19-1-22-23-26-10-9$ & 8 & $2-19-1-22-4-5-36-6-18-11-33-17-12$ & 13 \\
\hline 7 & $2-19-1-22-4-24-25-7-9$ & 9 & $2-19-1-22-4-24-25-7-9-10-30-15$ & 12 \\
\hline 8 & $2-29-28-15-30-31-12-38-10-9$ & 10 & $2-19-1-22-4-24-25-7-8$ & 9 \\
\hline 9 & $2-29-28-15-30-10-9$ & 7 & $2-19-1-22-23-26-10-9-7-8-33-17-12$ & 13 \\
\hline 10 & $2-19-1-22-23-26-10-38-12$ & 9 & $2-29-28-27-30-31-12-17-33-13$ & 10 \\
\hline 11 & $2-29-28-27-26-10-38-12$ & 8 & $2-29-28-15-32-16-17-33-13$ & 9 \\
\hline 12 & $2-29-28-15-32-16-17-12$ & 8 & $2-19-1-3-37-36-6-18-14$ & 9 \\
\hline 13 & $2-29-28-15-30-31-12-17-33-13$ & 10 & $3-20-21-4-5-36-6-18-11-33-17-12$ & 12 \\
\hline 14 & $2-19-1-3-37-36-6-18-14$ & 9 & $3-1-22-4-24-25-7-8$ & 8 \\
\hline 15 & $2-19-1-22-4-5-36-6-18-14$ & 10 & $3-1-22-23-26-10-9-7-8-33-17-12$ & 12 \\
\hline 16 & $2-29-28-15-30-31-12-17-33-11-18-14$ & 12 & $3-1-22-23-26-10-9-7-8-33-13$ & 11 \\
\hline 17 & $3-1-22-4-5$ & 5 & $3-37-36-6-18-11-33-17-12$ & 9 \\
\hline 18 & $3-1-22-4-24-25-7-8$ & 8 & $3-37-36-6-18-11-33-13$ & 8 \\
\hline 19 & $3-1-22-23-26-10-38-12$ & 8 & $3-1-19-2-29-28-15$ & 7 \\
\hline 20 & $3-20-21-4-22-23-26-10-38-12$ & 10 & $3-37-36-6-18-11-33-17-16$ & 9 \\
\hline 21 & $3-20-21-4-24-25-7-9-10-38-12$ & 11 & $4-24-25-7-8-33-17-12$ & 8 \\
\hline 22 & $4-5-36-6-18-11-33-17-16$ & 9 & $4-5-36-6-18-14$ & 6 \\
\hline 23 & $5-4-22-23-26-10-9$ & 7 & $4-24-25-7-8-33-17-16$ & 8 \\
\hline 24 & $5-4-22-23-26-10-38-12$ & 8 & $5-4-24-25-7-8$ & 6 \\
\hline 25 & $5-36-6-18-14-35-34-13$ & 8 & $5-4-24-25-7-9$ & 6 \\
\hline 26 & $5-4-22-1-19-2-29-28-15$ & 9 & $5-36-6-18-11-33-13$ & 7 \\
\hline 27 & $5-4-22-23-26-27-28-15$ & 8 & $5-4-22-1-19-2-29-28-15$ & 9 \\
\hline 28 & $5-4-24-25-7-9-10-30-15$ & 9 & $6-36-5-4-22-23-26-10-9-7-8-33-13$ & 13 \\
\hline 29 & $5-4-24-25-7-8-33-17-16-32-15$ & 11 & $9-7-8-33-17-16$ & 6 \\
\hline 30 & $5-4-22-23-26-10-30-15$ & 8 & $10-9-7-8-33-11-18-14$ & 8 \\
\hline 31 & $6-18-11-33-8-7-9$ & 7 & $12-17-33-11-18-14$ & 6 \\
\hline 32 & $7-8-33-13-34-35-14$ & 7 & $12-17-16-32-15$ & 5 \\
\hline 33 & $9-7-8-33-13$ & 5 & $13-33-11-18-14$ & 5 \\
\hline 34 & $9-7-8-33-11-18-14$ & 7 & & \\
\hline 35 & $9-10-38-12-17-33-13-34-35-14$ & 10 & & \\
\hline
\end{tabular}

Tendo esses conjuntos, é gerado, finalmente o conjunto de rotas candidatas, denominado F. Este conjunto estará formado pela união do conjunto $\mathrm{G}^{*} \mathrm{e}$ as rotas não repetidas nesse conjunto pertencentes a $\mathrm{G}$, ou seja, $\bar{G}=\mathrm{G}^{*}-\mathrm{G}$, por tanto, $\mathrm{F}=\mathrm{G} * \mathrm{U} \bar{G}$. A 
comparação dos resultados do procedimento de Aquino e o proposto neste trabalho é mostrada na Tabela 6.

Todas as modificações feitas até aqui permitiram criar um conjunto menor de rotas candidatas. Algumas rotas têm trajetórias mais longas (maior número de nós na rota). No novo conjunto $\mathrm{F}$ foram inseridas rotas com origem nos nós centroides 10, 12 e 13.

Dispor de um conjunto de rotas candidatas menor facilita ao planejador na hora da escolha das rotas a inserir na rede. Além de tudo a criação de rotas mais longas que também atendem o caminho mínimo pode favorecer na hora de conectar à rede com menor quantidade de rotas. 
Tabela 6. Conjunto de rotas do geradas para o conjunto F. Segundo o método original e o modificado.

\begin{tabular}{|c|c|c|c|c|}
\hline No. & Rotas geradas para o conjunto $\mathrm{F}$ originalmente & Número de nós & Rotas geradas para o conjunto $\mathrm{F}$ modificado & Número de nós \\
\hline 1 & $1-22-23-26-10-9-7-8$ & 8 & $1-22-4-24-25-7-8-33-11$ & 9 \\
\hline 2 & $1-19-2-29-28-15-32-16-17-33-13$ & 11 & $1-22-23-26-27-30-31-12-17-33-13$ & 11 \\
\hline 3 & $2-29-28-15-32-16-17-33-8-7$ & 10 & $1-22-4-24-25-7-8-33-13$ & 9 \\
\hline 4 & $2-29-28-27-26-10-9-7$ & 8 & $1-19-2-29-28-15-32-16$ & 8 \\
\hline 5 & $2-19-1-22-4-24-25-7-8$ & 9 & $1-22-4-24-25-7-8-33-17$ & 9 \\
\hline 6 & $2-19-1-22-23-26-10-9$ & 8 & $2-19-1-22-4-5-36-6-18-11-33-17-12$ & 13 \\
\hline 7 & $2-19-1-22-4-24-25-7-9$ & 9 & $2-19-1-22-4-24-25-7-9-10-30-15$ & 12 \\
\hline 8 & $2-29-28-15-30-31-12-38-10-9$ & 10 & $2-19-1-22-4-24-25-7-8$ & 9 \\
\hline 9 & $2-29-28-15-30-10-9$ & 7 & $2-19-1-22-23-26-10-9-7-8-33-17-12$ & 13 \\
\hline 10 & $2-19-1-22-23-26-10-38-12$ & 9 & $2-29-28-27-30-31-12-17-33-13$ & 10 \\
\hline 11 & $2-29-28-27-26-10-38-12$ & 8 & $2-29-28-15-32-16-17-33-13$ & 9 \\
\hline 12 & 2-29-28-15-32-16-17-12 & 8 & $2-19-1-3-37-36-6-18-14$ & 9 \\
\hline 13 & $2-29-28-15-30-31-12-17-33-13$ & 10 & $3-20-21-4-5-36-6-18-11-33-17-12$ & 12 \\
\hline 14 & $2-19-1-3-37-36-6-18-14$ & 9 & $3-1-22-4-24-25-7-8$ & 8 \\
\hline 15 & $2-19-1-22-4-5-36-6-18-14$ & 10 & $3-1-22-23-26-10-9-7-8-33-17-12$ & 12 \\
\hline 16 & $2-29-28-15-30-31-12-17-33-11-18-14$ & 12 & $3-1-22-23-26-10-9-7-8-33-13$ & 11 \\
\hline 17 & $3-1-22-4-5$ & 5 & $3-37-36-6-18-11-33-17-12$ & 9 \\
\hline 18 & $3-1-22-4-24-25-7-8$ & 8 & $3-37-36-6-18-11-33-13$ & 8 \\
\hline 19 & $3-1-22-23-26-10-38-12$ & 8 & $3-1-19-2-29-28-15$ & 7 \\
\hline 20 & $3-20-21-4-22-23-26-10-38-12$ & 10 & $3-37-36-6-18-11-33-17-16$ & 9 \\
\hline 21 & $3-20-21-4-24-25-7-9-10-38-12$ & 11 & $4-24-25-7-8-33-17-12$ & 8 \\
\hline 22 & $4-5-36-6-18-11-33-17-16$ & 9 & $4-5-36-6-18-14$ & 6 \\
\hline 23 & $5-4-22-23-26-10-9$ & 7 & $4-24-25-7-8-33-17-16$ & 8 \\
\hline 24 & $5-4-22-23-26-10-38-12$ & 8 & $5-4-24-25-7-8$ & 6 \\
\hline 25 & 5-36-6-18-14-35-34-13 & 8 & $5-4-24-25-7-9$ & 6 \\
\hline 26 & $5-4-22-1-19-2-29-28-15$ & 9 & $5-36-6-18-11-33-13$ & 7 \\
\hline 27 & $5-4-22-23-26-27-28-15$ & 8 & $5-4-22-1-19-2-29-28-15$ & 9 \\
\hline 28 & $5-4-24-25-7-9-10-30-15$ & 9 & $6-36-5-4-22-23-26-10-9-7-8-33-13$ & 13 \\
\hline 29 & $5-4-24-25-7-8-33-17-16-32-15$ & 11 & $9-7-8-33-17-16$ & 6 \\
\hline 30 & $5-4-22-23-26-10-30-15$ & 8 & $10-9-7-8-33-11-18-14$ & 8 \\
\hline 31 & $6-18-11-33-8-7-9$ & 7 & $12-17-33-11-18-14$ & 6 \\
\hline 32 & $7-8-33-13-34-35-14$ & 7 & $12-17-16-32-15$ & 5 \\
\hline 33 & $9-7-8-33-13$ & 5 & $13-33-11-18-14$ & 5 \\
\hline 34 & $9-7-8-33-11-18-14$ & 7 & $2-29-28-15-32-16-17-33-11-18-6$ & 11 \\
\hline 35 & $9-10-38-12-17-33-13-34-35-14$ & 10 & $2-29-28-15-32-16-17-33-8$ & 9 \\
\hline 36 & $1-22-23-26-10-38-12-17-33-11$ & 10 & $2-29-28-27-30-10-9$ & 7 \\
\hline 37 & $1-22-23-26-10-38-12-17-33-13$ & 10 & $2-29-28-15-32-16-17-33-11-18-14$ & 11 \\
\hline 38 & $1-22-23-26-10-38-12-17-16$ & 9 & $3-20-21-4-24-25-7-8$ & 8 \\
\hline 39 & $2-29-28-15-32-16-17-33-11-18-6$ & 11 & $3-20-21-4-24-25-7-9$ & 8 \\
\hline 40 & $2-29-28-15-32-16-17-33-11-18-14$ & 11 & $4-22-23-26-27-28-15$ & 7 \\
\hline 41 & $3-20-21-4-5$ & 5 & $5-36-6-18-11-33-17-16-32-15$ & 10 \\
\hline 42 & $3-20-21-4-24-25-7-8$ & 8 & $6-18-11-33-8-7-9-10$ & 8 \\
\hline 43 & $3-37-36-6-18-11-33-17-12$ & 9 & $9-10-30-31-12$ & 5 \\
\hline 44 & $3-37-36-6-18-11-33-13$ & 8 & $9-10-30-31-16$ & 5 \\
\hline 45 & $3-1-19-2-29-28-15$ & 7 & $13-34-35-14$ & 4 \\
\hline 46 & $3-37-36-6-18-11-33-17-16$ & 9 & & \\
\hline 47 & $4-24-25-7-8-33-11$ & 7 & & \\
\hline 48 & $4-24-25-7-8-33-13$ & 7 & & \\
\hline 49 & $5-36-6-18-11-33-17-12$ & 8 & & \\
\hline 50 & $5-36-6-18-11-33-13$ & 7 & & \\
\hline 51 & $5-36-6-18-11-33-17-16-32-15$ & 10 & & \\
\hline 52 & $6-18-11-33-17-12-38-10-9$ & 9 & & \\
\hline 53 & $8-33-17-12$ & 4 & & \\
\hline 54 & $9-10-38-12-17-33-11-18-14$ & 9 & & \\
\hline 55 & $9-10-38-12-17-16$ & 6 & & \\
\hline
\end{tabular}




\section{3}

\section{Geração de uma rede inicial conectada}

No procedimento modificado as rotas a serem conectadas seriam primeiramente a de maior demanda potencial e a partir daí as que tenham pelo menos um nó centroide em comum com as conectadas e que possuam maior quantidade de nos centroides ainda não conectados. Foi obtido o seguinte conjunto de rotas que definem a rede conectada, apresentado na Tabela 7.

Tabela 7. Conjunto de rotas que definem a rede conectada. Segundo o método original e o modificado.

\begin{tabular}{|c|c|c|c|c|}
\hline No. & $\begin{array}{c}\text { Conjunto de rotas que } \\
\text { definem a rede conectada } \\
\text { (algoritmo original) }\end{array}$ & $\begin{array}{c}\text { Número de } \\
\text { trans bordos }\end{array}$ & $\begin{array}{c}\text { Conjunto de rotas que definem } \\
\text { a rede conectada (algoritmo } \\
\text { modificado) }\end{array}$ & $\begin{array}{l}\text { Número de } \\
\text { trans bordos }\end{array}$ \\
\hline 1 & $2-19-1-22-4-5-36-6-18-14$ & 0 & $2-19-1-22-4-5-36-6-18-11-33-17-12$ & 0 \\
\hline 2 & $9-10-38-12-17-33-11-18-14$ & 0 & $3-1-22-23-26-10-9-7-8-33-13$ & 0 \\
\hline 3 & $1-19-2-29-28-15-32-16-17-33-13$ & 0 & $2-29-28-15-32-16-17-33-11-18-14$ & 547 \\
\hline 4 & $3-37-36-6-18-11-33-17-16$ & 0 & & \\
\hline 5 & $9-7-8-33-11-18-14$ & 419 & & \\
\hline
\end{tabular}

A rede é conectada, a partir do método modificado, com um menor número de rotas. Isto foi possível pela modificação do critério de escolha das rotas que conectam à rede anteriormente descrita e foi muito influenciado também pelo conjunto de rotas candidatas gerado, que possui menor número rotas com maior número de nós por linha. Embora a conexão da rede toda, pelo método modificado, seja atingida com um número maior de transbordos, comparado com a obtida por Aquino, (1980), atendendo maiormente, com isto, aos interesses da empresa. A figura 19 representa a trajetória das rotas que definem a rede conectada para o método original e na figura 20 a trajetória das criadas pelo método modificado. 


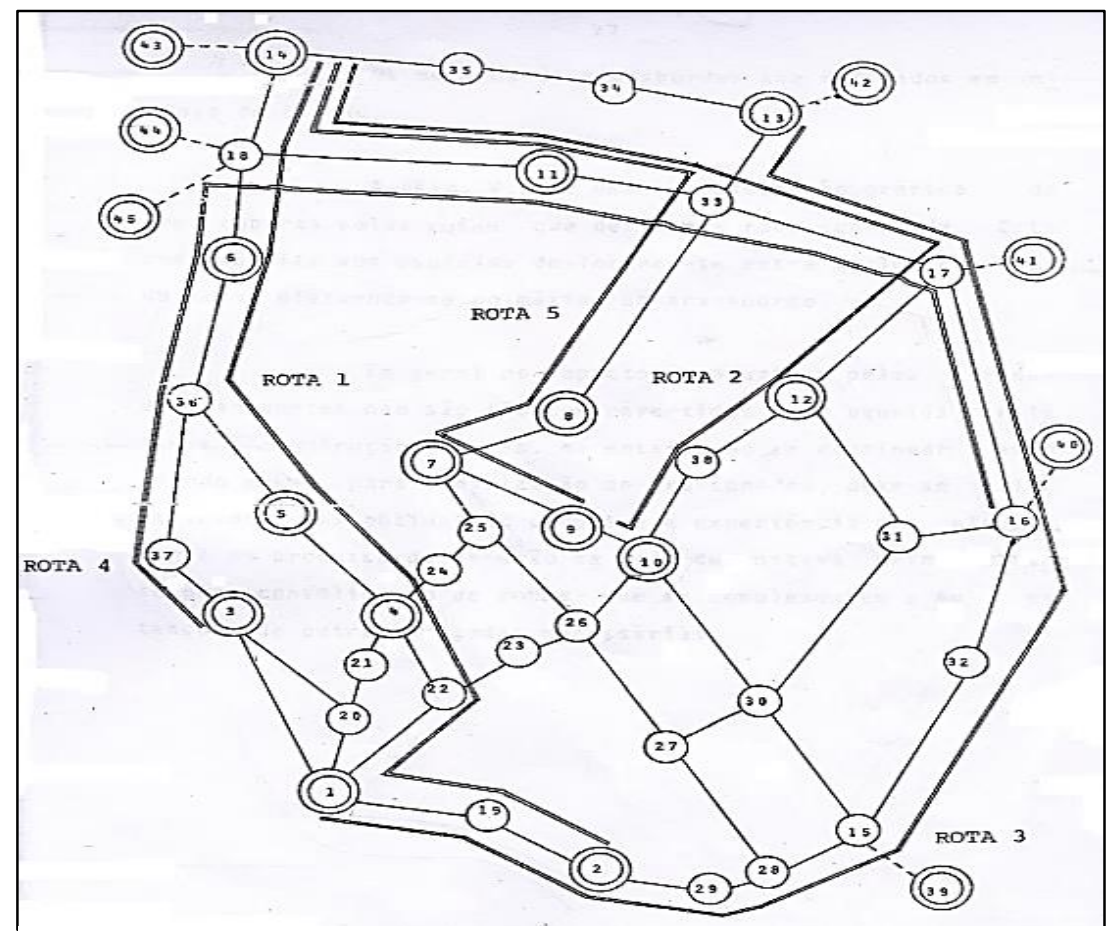

Figura 19.Trajetória das rotas que definem a rede conectada.

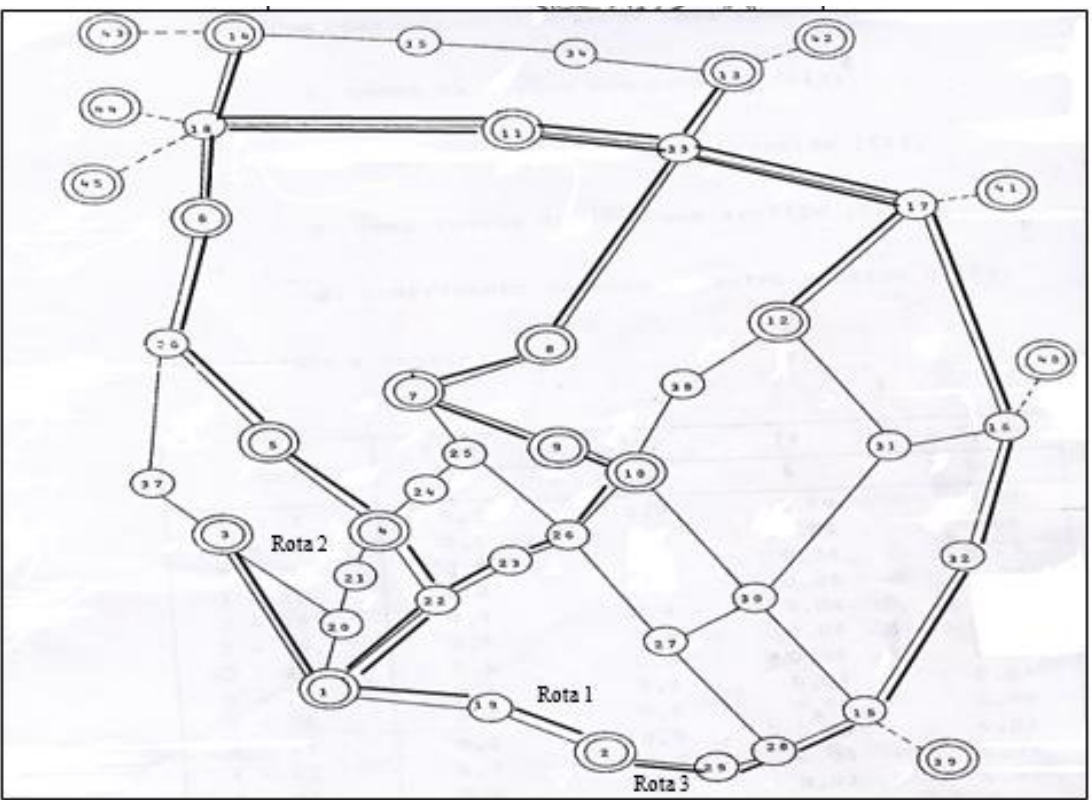

Figura 20.Trajetória das rotas que definem a rede conectada pelo 


\section{3.1}

\section{Definição de um conjunto de rotas em ordem de minimização de transbordos}

A partir do conjunto de rotas, que conectam à rede toda, é gerado um conjunto de rotas que adicionadas a esse conjunto vão contribuir à minimização do transbordo na rede. A continuação, na Tabela 8, é apresentado este conjunto de rotas em ordem de minimização de transbordos.

Para este conjunto foi gerado um menor número de rotas pelo método modificado, que permitiram finalmente, zerar o número de transbordos na rede. $\mathrm{O}$ que esteve influenciado pelas mesmas causas antes descritas para os outros conjuntos. 
Tabela 8. Conjunto de rotas candidatas em ordem de minimização de transbordos.

Segundo o método original e o modificado.

\begin{tabular}{|c|c|c|c|c|}
\hline No. & $\begin{array}{c}\text { Conjunto de rotas candidatas } \\
\text { em ordem de minimização de } \\
\text { trans bordos (algoritmo } \\
\text { original) }\end{array}$ & $\begin{array}{l}\text { Número de } \\
\text { transbordos }\end{array}$ & $\begin{array}{c}\text { Conjunto de rotas candidatas em } \\
\text { ordem de minimização de } \\
\text { trans bordos (algoritmo } \\
\text { modificado) }\end{array}$ & $\begin{array}{l}\text { Número de } \\
\text { transbordos }\end{array}$ \\
\hline 1 & $5-4-24-25-7-8-33-17-16-32-15$ & 337 & $6-36-5-4-22-23-26-10-9-7-8-33-13$ & 485 \\
\hline 2 & $3-37-36-6-18-11-33-13$ & 286 & $2-19-1-22-23-26-10-9-7-8-33-17-12$ & 445 \\
\hline 3 & $9-10-38-12-17-33-13-34-35-14$ & 247 & $10-9-7-8-33-11-18-14$ & 336 \\
\hline 4 & $4-24-25-7-8-33-14$ & 214 & $3-20-21-4-5-36-6-18-11-33-17-12$ & 285 \\
\hline 5 & $2-19-1-3-37-36-6-18-14$ & 183 & $2-19-1-22-4-24-25-7-9-10-30-15$ & 239 \\
\hline 6 & $5-36-6-18-11-33-13$ & 157 & $5-36-6-18-11-33-17-16-32-15$ & 218 \\
\hline 7 & $1-22-23-26-10-38-12-17-16$ & 132 & $2-29-28-15-32-16-17-33-13$ & 214 \\
\hline 8 & $3-20-21-4-24-25-7-9-10-38-12$ & 109 & $2-19-1-3-37-36-6-18-14$ & 152 \\
\hline 9 & $2-29-28-15-30-31-12-38-10-9$ & 86 & $4-24-25-7-8-33-17-16$ & 145 \\
\hline 10 & $2-29-28-15-32-16-17-33-11-18-14$ & 66 & $13-33-11-18-14$ & 129 \\
\hline 11 & $3-1-19-2-29-28-15$ & 50 & $4-5-36-6-18-14$ & 73 \\
\hline 12 & $2-19-1-22-4-24-25-7-8$ & 39 & $12-17-16-32-15$ & 71 \\
\hline 13 & $5-36-6-18-11-33-17-12$ & 25 & $9-10-30-31-16$ & 57 \\
\hline 14 & $1-22-23-26-10-38-12-17-33-11$ & 21 & $3-37-36-6-18-11-33-17-16$ & 39 \\
\hline 15 & $4-24-25-7-8-33-11$ & 15 & $1-22-23-26-27-30-31-12-17-33-13$ & 37 \\
\hline 16 & $6-18-11-33-17-12-38-10-9$ & 11 & $1-19-2-29-28-15-32-16$ & 21 \\
\hline 17 & $5-4-24-25-7-9-10-30-15$ & 9 & $3-1-19-2-29-28-15$ & 5 \\
\hline 18 & $1-22-23-26-10-9-7-8$ & 7 & $12-17-33-11-18-14$ & 4 \\
\hline 19 & $9-10-38-12-17-16$ & 5 & $2-29-28-15-32-16-17-33-8$ & 0 \\
\hline 20 & $3-20-21-4-24-25-7-8$ & 3 & & \\
\hline 21 & $3-20-21-4-5$ & 2 & & \\
\hline 22 & $6-18-11-33-8-7-9$ & 0,8 & & \\
\hline 23 & $8-33-17-12$ & 0,4 & & \\
\hline 24 & 5-36-6-18-11-33-17-16-32-15 & 0 & & \\
\hline
\end{tabular}

\section{3.2}

\section{Avaliação das rotas que minimizam os transbordos na rede}

Outra da modificação feita, foi avaliar o desempenho do conjunto final de rotas que minimizam o número de transbordos a partir do cálculo dos diferentes indicadores. Diferentemente do método original que calcula estes indicadores para o conjunto de rotas candidatas $\mathrm{F}$, esta mudança foi feita tendo em conta que o maior interesse do planejador é avaliar o desempenho das rotas finais que respondem aos objetivos do problema e não das rotas candidatas. 
Na Tabela 9, são agrupados os indicadores que permitem avaliar as rotas que conectam à rede e minimizam o número de transbordos. Como pode ser observado na tabela antes referenciada, as rotas deste conjunto têm um comprimento (ג) médio de $6.132 \mathrm{~km}$, para um comprimento mínimo de $3.5 \mathrm{~km}$ e máximo de $9.3 \mathrm{~km}$. O tempo de viagem (TEMPג) em média é de 0.61 horas, variando na faixa de 0.34 horas e 0.8 horas. A demanda potencial (Uג) atendida por estas rotas é, em média, de 77 unidades de carga, atendendo como mínimo 8,6 unidades por rota e como máximo 209 unidades. A carga média por trecho para cada rota (Ca.Med.) varia num intervalo entre 6 e 98 unidades, tendo uma média de 46 unidades por rota. O número de unidades por quilômetros (VKM^) é, em média de 323 unidades /km, atendendo como mínimo 34 passageiros/ km e como máximo 709 unidades / km; este valor está influenciado pelo tempo de viagem que possui cada uma das rotas e pela velocidade do veículo, além da demanda entre os pares de centroides atendidos na rota. Esse conjunto de rotas tem, em média um índice de rentabilidade (VSKx) de 13 unidades $/ \mathrm{km}$, variando na faixa de 2 a 31 unidades $/ \mathrm{km}$, esse índice varia segundo a variação da demanda e o comprimento da rota, aumentando à medida que aumenta a demanda potencial, mantendo o comprimento da rota constante e diminuindo à medida que aumenta o comprimento, mantendo a demanda potencial da rota constante. O número de ônibus por rota (NUMBUSג) é em média de 65 ônibus, variando entre 5 e 155 ônibus por rota. O desvio total que a rota impõe aos passageiros em relação ao caminho mínimo (DESVIOג) é em média de -1,22, variando numa faixa entre -9.76 e 5.38; esse valor está determinado pela somatória da demanda entre os pares de centroides vezes o tempo de viagem entre estes pares de centroides e seu tempo mínimo, alcançando valore negativos caso o tempo mínimo de viagem seja maior do que os tempos de viagem programados entre estes pares de nós.

Foi feita uma comparação do desempenho das rotas obtidas por Aquino (1980) e do desempenho das rotas obtidas a partir da modificação do método, exposta na Tabela 10. Nesta análise é possível observar que as rotas mínimas obtidas pelo método 
modificado têm um maior comprimento, sendo que na construção delas, devido as modificações antes descritas, foi possível a união de maior número de centroides pelos caminhos mínimos. Isso possibilitou que na maioria dos casos a demanda potencial atendida fosse maior pelo método modificado. Na tabela 10 as linhas não devem ser comparadas individualmente entre si. Aqui se observa o desempenho geral de cada solução. No Anexo 2 são expostos os indicadores correspondentes as rotas candidatas do conjunto F do método proposto por Aquino (1980).

Por último para a aplicação ao problema de tamanho real, o tempo computacional utilizado foi de 11,143 segundos. No método de Aquino, (1980) o tempo foi de 5 minutos. Tendo em conta que as maquinas e os compiladores usados entre estas duas aplicações foram diferentes, sendo uma das causas que influiu na minimização do tempo computacional. 
Tabela 9. Indicadores que avaliam o conjunto de rotas que minimizam o número de transbordos na rede.

\begin{tabular}{|c|c|c|c|c|c|c|c|c|c|c|c|c|c|c|c|}
\hline No. & $\mathrm{l}_{:}(\mathrm{km})$ & TEMP $_{\dot{\alpha}(\mathrm{h})}$ & $\mathrm{U}_{\mathrm{z} \text { (unid.) }}$ & $\mathrm{TMaC}$ & Ca.TMaC (unid.) & TMeC & Ca.TMeC (unid.) & Ca.Med. (unid.) & VKM $_{2(\text { unid*km) }}$ & $\mathrm{CPK}_{\mathrm{n} \text { (unid/km) }}$ & $\mathrm{DMO}_{\mathrm{r}(\mathrm{km})}$ & VSK $_{\text {: (unid./km) }}$ & NUMBUS $_{\text {; unid.) }}$ & CTBUS $_{\text {( (unid.) }}$ & DESVIO, \\
\hline 1 & 7,2 & 0,65 & 209 & 8 & 179,4 & 8 & 14,8 & 97,05 & 447,44 & 62,14 & 2,14 & 29,0278 & 144 & 1,45 & $-6,41$ \\
\hline 2 & 6,6 & 0,73 & 136 & 8 & 110 & 10 & 29,8 & 90,84 & 594,8 & 90,12 & 4,37 & 20,6061 & 66 & 2,06 & $-0,1$ \\
\hline 3 & 5,7 & 0,63 & 60 & 6 & 63,6 & 10 & 16,2 & 30,92 & 280,68 & 49,24 & 4,68 & 10,5263 & 40 & 1,5 & $-2,95$ \\
\hline 4 & 7,9 & 0,75 & 114,2 & 12 & 92,6 & 2 & 9,4 & 62,05 & 491,98 & 62,28 & 4,31 & 14,4557 & 74 & 1,54 & 4,85 \\
\hline 5 & 9 & 0,67 & 87,4 & 9 & 65,8 & 2 & 12 & 46,18 & 427,94 & 47,55 & 4,9 & 9,7111 & 59 & 1,48 & $-1,82$ \\
\hline 6 & 9,3 & 0,62 & 116,8 & 8 & 179,4 & 2 & 18 & 81,51 & 708,92 & 76,23 & 6,07 & 12,5591 & 98 & 1,19 & $-9,76$ \\
\hline 7 & 8,4 & 0,8 & 167,8 & 7 & 147,4 & 2 & 9 & 82,87 & 492,78 & 58,66 & 2,94 & 19,9762 & 155 & 1,08 & 5,38 \\
\hline 8 & 8,2 & 0,68 & 70 & 11 & 48 & 2 & 6 & 37,64 & 247,5 & 30,18 & 3,54 & 8,5366 & 41 & 1,71 & 3,73 \\
\hline 9 & 9,1 & 0,71 & 99 & 3 & 68,2 & 2 & 12 & 50,13 & 457,54 & 50,28 & 4,62 & 10,8791 & 79 & 1,25 & $-2,16$ \\
\hline 10 & 4 & 0,72 & 15,8 & 5 & 11,2 & 8 & 3,8 & 8,3 & 33,32 & 8,33 & 2,11 & 3,95 & 5 & 3,16 & 1,05 \\
\hline 11 & 4,9 & 0,68 & 148 & 6 & 134 & 8 & 3,8 & 90,13 & 222,24 & 45,36 & 1,5 & 30,2041 & 95 & 1,56 & $-3,25$ \\
\hline 12 & 5,7 & 0,57 & 34,6 & 6 & 134 & 7 & 9,6 & 21,34 & 266,6 & 46,77 & 7,71 & 6,0702 & 110 & 0,31 & $-4,33$ \\
\hline 13 & 4,9 & 0,47 & 20,8 & 7 & 147,4 & 4 & 4,8 & 13,1 & 297,96 & 60,81 & 14,33 & 4,2449 & 60 & 0,35 & 0,85 \\
\hline 14 & 3,9 & 0,44 & 118 & 4 & 113,2 & 1 & 5,8 & 88,4 & 186,94 & 47,93 & 1,58 & 30,2564 & 44 & 2,68 & $-4,69$ \\
\hline 15 & 7,1 & 0,55 & 8,6 & 8 & 79,4 & 1 & 2,6 & 5,25 & 385,88 & 54,35 & 44,87 & 1,2113 & 56 & 0,15 & 0,44 \\
\hline 17 & 4,8 & 0,56 & 83,6 & 4 & 65,8 & 8 & 10,8 & 52,3 & 200,34 & 41,74 & 2,4 & 17,4167 & 45 & 1,86 & $-1,82$ \\
\hline 18 & 3,5 & 0,62 & 56 & 4 & 67,8 & 10 & 29,8 & 48,52 & 211,32 & 60,38 & 3,77 & 16 & 59 & 0,95 & $-0,91$ \\
\hline 19 & 4,5 & 0,6 & 42 & 5 & 38 & 1 & 19 & 32,29 & 165,8 & 36,84 & 3,95 & 9,33 & 20 & 2,1 & 2,03 \\
\hline 20 & 4,4 & 0,55 & 41 & 4 & 65,8 & 1 & 19 & 33,5 & 195,86 & 44,51 & 4,78 & 9,3182 & 48 & 0,85 & $-0,46$ \\
\hline 21 & 5,2 & 0,34 & 20 & 6 & 27,4 & 1 & 4 & 11,28 & 84,94 & 16,33 & 4,25 & 3,8462 & 12 & 1,67 & $-0,9$ \\
\hline 22 & 3,8 & 0,52 & 26 & 4 & 113,2 & 3 & 8 & 11,75 & 187,48 & 49,34 & 7,21 & 6,8421 & 54 & 0,48 & $-4,07$ \\
\hline Média & 6,132 & 0,6090909 & 76,7545 & 6,5 & 93,70909091 & 4,2727 & 11,37272727 & 45,74318182 & 322,3863636 & 50,61454545 & 7,82045455 & 12,59213182 & 64,22727273 & 1,348636364 & $-1,221818$ \\
\hline Limite Superior & 3,5 & 0,34 & 8,6 & 3 & 11,2 & 1 & 2 & 5,25 & 33,32 & 8,33 & 1,5 & 1,2113 & 5 & 0,15 & $-9,76$ \\
\hline Limite inferior & 9,3 & 0,8 & 209 & 12 & 179,4 & 10 & 29,8 & 97,05 & 708,92 & 90,12 & 44,87 & 30,2564 & 155 & 3,16 & 5,38 \\
\hline
\end{tabular}


Tabela 10. Comparação entre o desempenho das rotas criadas pelo método Aquino (1980) e o modificado

\begin{tabular}{|c|r|c|r|l|}
\hline No. & $\begin{array}{c}\text { la } \\
\text { Aquino } \\
\text { (km) }\end{array}$ & $\begin{array}{l}\text { la } \\
\text { modificado } \\
\text { (km) }\end{array}$ & $\begin{array}{l}\text { Uz } \\
\text { Aquino } \\
\text { (unid.) }\end{array}$ & $\begin{array}{l}\text { U: } \\
\text { modificado } \\
\text { (unid.) }\end{array}$ \\
\hline $\mathbf{1}$ & 5,3 & 7,2 & 208,2 & 209 \\
\hline $\mathbf{2}$ & 5,6 & 6,6 & 119,2 & 136 \\
\hline $\mathbf{3}$ & 6,7 & 5,7 & 111,8 & 60 \\
\hline $\mathbf{4}$ & 6,2 & 7,9 & 83,6 & 114,2 \\
\hline $\mathbf{5}$ & 4,8 & 9 & 84,8 & 87,4 \\
\hline $\mathbf{6}$ & 7,1 & 9,3 & 89,6 & 116,8 \\
\hline $\mathbf{7}$ & 4,7 & 8,4 & 86,2 & 167,8 \\
\hline $\mathbf{8}$ & 5,4 & 8,2 & 98,8 & 70 \\
\hline $\mathbf{9}$ & 3,2 & 9,1 & 36,6 & 99 \\
\hline $\mathbf{1 0}$ & 5,2 & 4 & 150,2 & 15,8 \\
\hline $\mathbf{1 1}$ & 4,2 & 4,9 & 79,2 & 148 \\
\hline $\mathbf{1 2}$ & 4,7 & 5,7 & 72,6 & 34,6 \\
\hline $\mathbf{1 3}$ & 3,8 & 4,9 & 28,2 & 20,8 \\
\hline $\mathbf{1 4}$ & 4,5 & 3,9 & 29 & 118 \\
\hline $\mathbf{1 5}$ & 7,7 & 7,1 & 70,2 & 8,6 \\
\hline $\mathbf{1 6}$ & 2,9 & 6,8 & 41 & 14 \\
\hline $\mathbf{1 7}$ & 3,2 & 4,8 & 19 & 83,6 \\
\hline $\mathbf{1 8}$ & 5,2 & 3,5 & 71 & 56 \\
\hline $\mathbf{1 9}$ & 4 & 4,5 & 53,4 & 42 \\
\hline $\mathbf{2 0}$ & 3 & 4,4 & 9,8 & 41 \\
\hline $\mathbf{2 1}$ & 5,1 & 5,2 & 90,6 & 20 \\
\hline $\mathbf{2 2}$ & 3,7 & 3,8 & 50,4 & 26 \\
\hline $\mathbf{2 3}$ & 2,7 & & 15,8 & \\
\hline $\mathbf{2 4}$ & 3,3 & & 36,6 & \\
\hline $\mathbf{2 5}$ & 2,5 & & 6,8 & \\
\hline $\mathbf{2 6}$ & 1,8 & & 3,8 & \\
\hline $\mathbf{2 7}$ & 4,3 & & 54 & \\
\hline $\mathbf{2 8}$ & 2,9 & & 6,6 & \\
\hline $\mathbf{2 9}$ & 7,5 & & 99 & \\
\hline & & & & \\
\hline
\end{tabular}


6.

\section{Considerações finais}

Este capítulo irá descrever as conclusões obtidas através do estudo realizado, avaliando se os objetivos do estudo foram alcançados e quais resultados foram encontrados, apresentando, por último, algumas recomendações para potencializar estudos futuros.

\section{1}

\section{Conclusões}

A análise da bibliografia relacionada com o PDRTPU permitiu conhecer as particularidades deste problema além da gama de métodos exatos e heurísticos que existem e tem se aplicado para este problema pela combinação de diferentes variáveis com diferentes funções objetivo.

A formulação e definição dos objetivos do PDRTPU para a presente pesquisa permitiu delimitar melhor o problema, tendo em conta as partes interessadas como o usuário e a empresa operadora do serviço de transporte, além das restrições e particularidades neste caso.

As modificações feitas ao método de Aquino, (1980) uma vez identificadas e tendo compreendido as rotinas das principais estruturas do método possibilitaram a simplificação de alguns aspectos nas principais estruturas, melhorar sua legibilidade, e o desempenho do programa. Com a adição das melhorias descritas nos capítulos anteriores nas estruturas principais foi possível a obtenção de resultados atrativos comparados com os apresentados pelo método original. Com isto foi diminuído o número de rotas que definem a rede conectada de 5 rotas propostas originalmente, para 3 rotas. Também foi minimizado o número de transbordos na rede até zera-los com um menor conjunto de rotas. Originalmente este objetivo foi atingido com um total de 29 
rotas e a partir das melhorias propostas, esse resultado foi obtido com um total de 22 rotas. Realizar uma análise de indicadores de rentabilidade das rotas que minimizam o número de transbordos na rede, permite ao planejador ter uma visão geral do comportamento dessas rotas possibilitando tomar decisões mantendo os requerimentos iniciais e o objetivo de estudo.

O programa do método desenvolvido, numa linguagem moderna, oferece, tanto ao meio acadêmico quanto ao profissional, uma ferramenta de fácil aplicação para dar solução ao PDRTPU. Com isso contribui para o incremento da eficiência do processo de planejamento e, portanto, com a redução de não conformidades do serviço de transporte, resultando em economia dos custos para as empresas prestadoras deste serviço.

\section{2}

\section{Recomendações}

São sugeridos os seguintes estudos associados ao PRDTPU:

- Adaptação do método proposto a casos diferentes, tais como redes orientadas de transporte urbano e redes de transporte interurbano de tamanho real.

- A análise e inserção de outras variáveis como tarifa, tempo de espera, programação da frota.

- Atribuição do carregamento nas linhas;

- Usar métodos de busca local a partir das soluções iniciais obtidas buscando soluções mais robustas do problema e alcançar resultado mais próximos do ótimo. 
7.

\section{Referências bibliográficas}

AQUINO, W. J. S. Uma abordagem do problema de definição de rede interurbana de rotas de ônibus. Dissertação em opção ao título de mestre em Engenharia de Produção. Coordenação do Programa de Pós-Graduação de Engenharia. Universidade Federal do Rio de Janeiro, Rio de Janeiro, Outubro, 1980, pp.1-88.

ARGWAL, J.; MATHEW, T. Transit route network design using parallel genetic algorithm. Journal of Computing in Civil Engineering, Vol.18, 2004, pp.248-256.

AXHAUSEN, K. W.; SMITH, R. L. Evaluation of heuristic transit network optimization algorithms. Transportation Research Record, 976, 1984, pp.7-20.

BAAJ, M.; MAHMASSANI, H. An AI-based approach for transit route system. Journal of Advanced Transportation 25, 1991, pp.187-209.

BAAJ, M.; MAHMASSANI, H. AI-based system representation and search procedures for transit route network design. Transportation Research Record 1358, 1992, pp.67-70.

BAAJ, M.; MAHMASSANI, H. A hybrid route generation heuristic algorithm for the design of transit networks. Transportation Research Part C Vol.3, 1995, pp. 3150 .

BARRA, R. A. O impacto do transbordo em sistemas integrados de transporte coletivo por ônibus: uma análise quantitativa e qualitativa no município de Belo Horizonte. Dissertação apresentada ao curso de Mestrado em Geotécnica e Transportes da Universidade Federal de Minas Gerais, como requisito parcial à 
obtenção do título de Mestre em Geotécnica e Transportes. Minas Gerais, 2011, pp.1149.

BAGLOEE, S. A.; CEDER, A. Transit-network design methodology for actual-size road networks. Transportation Research Part B 45. 2011, pp. 1787-1804.

BEN-AYED, O.; BLAIR, C.E.; BOYCE, D. E. Construction of a Real World Bilevel Linear Program of the Highway Network Design Problem. Faculty working paper No. 1464. College of Commerce and Business Administration, University of Illinois at Urbana- Champaign, June 1988, pp. 1-54.

BIELli, M.; CARAMIA, M.; CAROTENUTO, P. Genetic algorithms in bus network optimization. Transport Research Part C. Vol. 10, 2002, pp.19-34.

BRASIL. Ministério das Cidades. Curso gestão integrada da mobilidade urbana. Módulo II: mobilidade urbana e cidades sustentáveis. Brasília. Nov. 2005.

BYRNE, B. F.; VUCHIC, B. R. Public transportation line position and headway for minimum cost. Proceedings of the Fifth International Symposium on Traffic Flow and Transportation. New York, 1972, pp. 347- 360.

BYRNE, B. F. Public transportation line position and headway for minimum user and system cost in a radial case. Transportation Research, Vol. 9, 1975, pp. 97-102.

BUBA, A. T.; LEE, L. S. Urban Transit Network Design Problems: A Review of Population-based Metaheuristics. Pertanika Journal of Scholarly Research Reviews. Vol. 2, 2016, pp.86-99.

CANTARELlA, G.; VITETTA, A. The multi-criteria road network design problem in an urban area. Transportation. Vol. 33, 2006, pp.567-588. 
CANTARELla, G.; PAVONE, G.; VITETTA, A. Heuristics for urban road network design: Lane layout and signal settings. European Journal of Operational Research 175. 2006, pp.1682-1695.

CEDER, A. Public Transit Planning and Operation: Theory Modeling and Practice. Elsevier, Butterworth-Heinemann, Oxford, UK 2007, pp.1-626.

CEDER, A.; WILSOM, N.H.M. Bus network design. Transportation Research Part B, Vol. 208. No. 4, 1985, pp. 331-344.

CEPEDA, M.; COMINETTI, R.; FLORIAN, M. A frequency-based assignment model for congested transit networks with strict capacity constraints: characterization and computation of equilibria. Transportation Research Part B 40, 2006, pp. 437-459.

CHAKROBORTY, P. Genetic algorithms for optimal urban transit network design. Computer-Aided Civil and Infrastructure Engineering 18, 2003, pp. 184-200. CHAKROBORTY, P.; DWIVEDI, T. Optimal route network design for transit systems using genetic algorithms. Engineering Optimization 34, 2002, pp. 83-100.

CHEW, J.; LEE, L.; SEOW, H. Genetic algorithm for biobjective urban transit routing problem. Journal of Applied Mathematics, 2013, pp. 1- 16.

CHIU, S.H. Bilevel programming for the continuous transport network design problem. Transportation Research, Part B, Vol.39, 2005, pp. 361-383.

CIPRIANI, E.; GORI, S.; PETRELLI, M. A bus network design procedure with elastic demand for large urban areas. Public Transport, Vol.4, 2012, pp.57-76.

CLARENS, G.; HURDLE, V. An operating strategy for a commuter bus system. Transportation Science, Vol.9, 1975, pp. 1-20. 
DAGANZO, C. Structure of competitive transit networks. Transportation Research Part B Vol.44, 2010, pp. 434-446.

DANTZIG, G.B.; HARVEY,R.P.; LANSDOWNE,Z.F.; ROBINSON,D.W.; MAIER,S.F. Formulating and solving the network design problem by decomposition. Transportation Research Part B 13(1), 1979, pp.5-17.

DERRIBLE, S.J.M. The properties and effects of metro network designs. A thesis submitted in conformity with the requirements for the degree of Doctor of Philosophy Graduate Department of Civil Engineering University of Toronto. Toronto, Canada, 2010, pp. 1-220.

DESAUlniers, G., HICKMAN, M. Public transit. Handbooks in Operations Research and Management Science. In: Laporte, G., Barnhart, C., (eds.) Transportation, Vol. 14. Amsterdam, 2007, pp. 69-127.

DIJKSTRA, E.W. A note on two problems in connexion with graphs. Numersiche Mathematik, Vol. 1, pp 269-271. December, 1959.

DUBOIS, D.; BEL, G.; LLIBRE, M. A set of methods in transportation network synthesis and analysis. Journal of Operational Research Society, 39 [9], 1979, pp.797808.

FAN, W., MACHEMEHL, R. a. Optimal transit route network design problem with variable transit demand: a genetic algorithm approach. Journal of Transportation Engineering 132, 2006, pp. 40-51.

FAN, W., MACHEMEHL, R. b. Using a simulated annealing algorithm to solve the transit route network design problem. Journal of Transportation Engineering 132, 2006, pp.122-132. 
FAN, W., MACHEMEHL, R. Tabu search strategies for the public transportation network optimizations with variable transit demand. Computer-Aided Civil and Infrastructure Engineering Vol. 23, 2008, pp.502-520.

FARAHANI, R., MIANDOABCHI, E., SZETO, W., RASHIDI, H. A review of urban transportation network design problems. European Journal of Operational Research 229, 2013, pp.281-302.

FLOYD, R. W. Algorithm 97: Shortest Path. Communications of the ACM5 (6): 345. June, 1962.

FRIESZ, T.L. Transportation network equilibrium, design and aggregation: key developments and research opportunities. Transportation Research Part A 19 (5-6), 1985, pp. 413-427.

GAO, Z.; SUN, H.; SHAN, L.L. A continuous equilibrium network design model and algorithm for transit systems. Transportation Research Part B 38, 2004, pp.235250 .

GUIHAIRE, V. E HAO, J. K. Transit network design and scheduling: A global review. Transportation Research Part A Vol.42. 2008, pp.1251-1273.

GUAN, J., YANG, H., WIRASINGHE, S.C. Simultaneous optimization of transit line configuration and passenger line assignment. Transportation Research Part B Vol.40, 2003, pp. 885-902.

HOBEIKA, A. G.; CHO, C. Equilibration of supply and demand in designing bus routes for small urban areas. Transportation Research Record, Vol.730. 1979, pp.713. 
HOLRYOD, E. The optimum bus service: a theoretical model for a large uniform urban area. In: Edie, L. (Ed.), Proceedings of the Third International Symposium on the Theory of Traffic Flow. Elsevier, 1967, pp. 308-328.

HSU, J.; SURTI, V. H. Decomposition approach to bus network design. Transportation Engineering Journal, 103[4], Julio, 1977, pp.447-459.

HURDLE, V. Minimum cost locations for parallel public transit lines. Transportation Science Vol.7, 1973, 340-350.

IBARRA-ROJAS, O.; LÓPEZ-IRARRAGORRI, F.; RIOS-SOLIS, Y. Multiperiod synchronization bus timetabling. Transportation Research Part B Vol. 77, Abril, 2015, pp. 38-75.

IPEA. Planejamento integrado, organização espacial e mobilidade sustentável no contexto de cidades brasileiras. Ministério das Cidades. Mobilidades e Interações no Desenvolvimento Urbano. Brasília, 2016, pp.81-100.

KARABOGA, D., GORKEMLI, B., OZTURK, C., KARABOGA, N. A comprehensive survey: Artificial Bee Colony (ABC) algorithm and applications. Artificial Intelligence Review. 2012, pp.1-37.

KEPAPTSOGLOU, K.; KARLAFTIS, M. Transit route network design problem: review. Journal of Transportation Engineering 135, 2009, pp.491-505.

KLIER, M. J.; HAASE, K. Urban public transit network optimization with flexible demand. OR Spectrum, Vol. 37, 2015, pp.195-215.

KREMPI, A. P. Explorando recursos de estatística para análise da acessibilidade da cidade de Bauru. Dissertação apresentada ao Departamento de Transporte, da Escala de Engenharia de São Carlos, Universidade de São Paulo, como parte dos 
requisitos para a obtenção do título de Mestre em Engenharia Civil, Área: Transporte. São Paulo, Brasil, 2004, pp. 2-94.

LAMPKIN, W.; SAALMANS, P. D. The design of routes, service frequency and schedules for a municipal bus undertaking: a case study. Operational Research Quarterly, Vol. 18[4], Dec., 1967, pp.375-397.

LAPORTE G. The Vehicle Routing Problem: An overview of exact and approximate algorithms. European Journal of Operational Research Vol.59. 1992, pp.345-358.

LEBLANC, L. J. Transit system network design. Journal of Transport Reserach. Vol. 22B. No.5. 1988, pp. 383-390.

LOWNES, N., MACHEMEHL, R. Exact and heuristic methods for public transit circulator design. Transportation Research Part B Vol.44, 2010, pp.309-318.

LUO, Z.; PANG, J.; RALPH, D. C. Mathematical Programs with Equilibrium Constraints. Cambridge University Press. Cambridge, 1996.

MAGNANTI, T.L.; WONG, R.T. Network design and transportation planning: models and algorithms. Transportation Science Vol. 18(1), 1984, pp. 1-55.

MANDL, C. Evaluation and optimization of urban public transportation network. European Journal of Operational Research 5, 1979, pp.396-404.

MARTINS, C. L.; PATO, M. V. Search strategies for the feeder bus network design problem. European Journal of Operational Research 106, 1998, pp. 425-440.

MARWAH, B.; UMRIGAR, F.; PATNAIK, S. Optimal design of bus routes and frequencies for Ahmedabad. Transportation Research Record Vol.994, 1984, pp.4147. 
MAUTTONE, A., URQUHART, M. A route set construction algorithm for the transit network design problem. Computers \&Operations Research 36, 2009, pp.2440-2449.

MAUTTONE, A.; URQUHART, M. A multiobjective metaheuristic approach for the transit network design problem. Public Transport, Vol. 1, 2009, pp.253-273.

NGAMCHAI, S.; LOVELL, D. J. Optimal Time Transfer in Bus Transit Route Network Design Using a Genetic Algorithm. Journal of Transportation Engineering. Vol. 129(5), 2003, pp.510-521.

NIKOLIC', M.; TEODOROVIC', D. a. Transit network design by bee colony optimization. Expert Systems with Applications, Vol. 40, 2013, pp.5945-5955.

NIKOLIC', M.; TEODOROVIC', D. b. A simultaneous transit network design and frequency setting: computing with bees. Expert Systems with Applications, Vol. 41, 2014, pp.7200-7209.

ORTÚZAR, J., WILLUMSEN, L. Modelling Transport. John Wiley and Sons Ltd., Chichester, England, 2001.

ONG, H.L. et al. Solving the feeder bus network design problem by genetic algorithms and ant colony optimization. Advances in Engineering Software, Vol.37, 2006, pp.351-359.

OUYANG, Y.; NOURBAKHSH, S.; CASSIDY, M. Continuum approximation approach to bus network design under spatially heterogeneous demand. Transportation Research Part B Vol. 68, 2014, pp. 333-344. 
PATTNAIK, S. B.; MOHAN, S.; TOM, V. M. Urban bus transit route network design using genetic algorithm. Journal of Transportation Engineering, Vol.124[4], Agosto, 1998, pp.368-375.

POORZAHEDY, H.; SAFARI, F. An Ant System application to the Bus Network Design Problem: an algorithm and a case study. Public Transport. Vol. 3, 2011, pp.165-187.

RAVEAU, S.; MUÑOZ, J.; DE GRANGE, L. A topological route choice model for metro. Transportation Research Part A, Vol. 45, 2011, pp.138-147.

SALZBORN, F. Optimum bus scheduling. Transportation Science, Vol. 6, 1972, pp.137-148.

SCHMÖCKER, J.; FONZONE, A.; SHIMAMOTO, H.; KURAUCHI, F.; BELL, M. Frequency-based transit assignment considering seat capacities. Transportation Research Part B, Vol.45, 2011, pp. 392-408.

SILMAN, L. A.; BARZILY, Z.; PASSY, U. Planning the route system for urban buses. Computers \& Operations Research 1(2), 1974, pp.201-211.

SZETO, W., JIANG, Y. Hybrid artificial bee colony algorithm for transit network design. Transportation Research Record 2284, 2012, pp.47-56.

SZETO, W.Y.; JABER, X.; O’MAHONY, M. Time-dependent discrete network design frameworks considering land use. Computer-Aided Civil and Infrastructure Engineering 25 (6), 2010, pp.411-426.

TOM, V.M.; MOHAN, S. Transit route network design using frequency coded genetic algorithm. Journal of Transportation Engineering 129 (2), 2003, pp.186-195. 
UNITED NATIONS 2014 a. World Urbanization Prospects: The 2014 Revision. United Nations, New York, NY, USA.

UNITED NATIONS 2014 b. World Urbanization Prospects: The 2014 Revision Population Database, United Nations. Available: http://esa.un.org/unup/. Consultado em: 20, Fevereiro de 2017.

VAN NES, R.; HAMERSLAG, R.; IMMERS, B. Design of public transport networks. Transportation Research Record 1202, 1988, pp. 74-83.

WAN, Q.; LO, H. A mixed integer formulation for multiple-route transit network design. Journal of Mathematical Modelling and Algorithms, Vol.2, 2003, pp. 299-308.

YAN, Y.; LIU, Z.; MENG, Q.; JIANG, Y. Robust optimization model of bus transit network design with stochastic travel time. Journal of Transportation Engineering, Vol. 139, 2013, pp. 625-634.

YANG, Z.; YU, B.; CHENG, C. A parallel ant colony algorithm for bus network optimization. Computer-Aided Civil and Infrastructure Engineering, Vol. 22, 2007, pp. 44-55.

YU, B.; YANG, Z.Z.; JIN, P.H.; WU, S.H.; YAO, B.Z. Transit route network designmaximizing direct and transfer demand density. Transportation Research Part C, Vol. 22, 2012, pp. 58-75. 


\section{8.}

\section{Anexos}

Anexo 1. Pseudocódigo do programa principal do método de Aquino, 1980

\section{INÍCIO PROGRAMA PRINCIPAL;}

1. Inicializar os dados de entrada;

2. Gerar o conjunto G;

3. Gerar o conjunto $\mathrm{G}^{*}$;

4. SE existem rotas iguais em $\mathrm{G}^{*}$ ENTÃO

5. Eliminar as repetições;

6. Atualizar conjunto $\mathrm{G}^{*}$;

7. FIM_SE

8. SE existem rotas inseridas em outras em $\mathrm{G}^{*}$ ENTÃO

9. Eliminar as rotas inseridas em outras;

10. Atualizar conjunto $\mathrm{G}^{*}$;

11. FIM_SE

12. Gerar o conjunto $\bar{G}$;

13. Gerar o conjunto $\mathrm{F} \leftarrow \bar{G} \cup \mathrm{G}^{*}$;

14. Calcular os parâmetros das rotas de F;

15. Iniciar geração da rede;

Escolher rota que apresente maior demanda potencial;

1. Adicionar rota escolhida ao conjunto que conecta à rede;

2. ENQUANTO a rede não está conectada

3. Escolher rota que apresente maior demanda potencial;

4. Adicionar rota escolhida ao conjunto que conecta à rede;

5. Atualizar demandas potenciais das rotas restantes;

6. Atualizar conjunto F;

\section{FIM_ENQUANTO}

8. Atualizar conjunto F;

9. Calcular o número de transbordos;

10. ENQUANTO número de transbordos $\neq 0$

11. Escolher rota que reduza ao máximo o número de transbordos;

12. Adicionar rota escolhida a lista de rotas que minimiza transbordos;

13. Calcular número de transbordos resultantes;

14. Atualizar conjunto $\mathrm{F}$;

15. Atualizar demandas potenciais das rotas restantes;

16. FIM_ENQUANTO 
Anexo 2. Continuação do pseudocódigo modificado da função para a eliminação de repetições no conjunto $\mathrm{G}^{*}$.

$\{$ continuação $\}$
1.SE nw >=1 ENTÃO

2.Verificar que as rotas criadas na iteração atual não sejam iguais as criadas nas iterações anteriores

3.ENTANTO não seja atingido o número máximo de rotas do conjunto $\mathrm{G}^{*}$

4.SE a rota anteriormente criada é igual à da iteração atual;

5.Inicializar a variável que armazena o número de nós nas rotas comparadas, $\mathrm{k} 6=0$;

6.ENTANTO $\mathrm{k} 6<=$ nnlige $[\mathrm{k} 4]$

$7 . \mathrm{k} 6=\mathrm{k} 6+1$;

8.Verificar se as rotas comparadas são diferentes;

9.FIM_ENTANTO

10. SE as rotas comparadas não forem diferentes ENTÃO

11. A linha da última rota criada, repetida com anteriores é zerada na matriz lige;

12. FIM_SE

13. FIM_ENTANTO

14. FIM_SE

15. Definir uma variável inteira que indique a posição da primeira rota criada na iteração atual, $\mathrm{k} 5=$ nlige - nw;

16. ENQUANTO essa variável não atinja o número máximo de rotas no conjunto $\mathrm{G}^{*}, \mathrm{k} 5<$ nlige

17. Avançar a posição da variável, $\mathrm{k} 5=\mathrm{k} 5+1$;

18. SE o primeiro nó na posição da rota $\mathrm{k} 5$ na matriz, lige[k5, 1] = 0 ENTÃO

19. SE a rota k5 não estiver na última posição ENTÃO

20. Atualizar a matriz lige, colocando a rota $\mathrm{k} 5$ na última posição;

21. Atualizar o número de rotas do conjunto nlige;

22. Atualizar a variável $\mathrm{k} 5, \mathrm{k} 5=\mathrm{k} 5-1$;

23. FIM_SE

24. FIM_SE

25. FIM_ENQUANTO

26. FIM_SE

FIM_ELIMINAÇÃO DE REPETIÇÕES NO CONJUNTO G* MODIFICADO 
Anexo 3. Pseudocódigo do programa principal modificado.

\section{INÍCIO PROGRAMA PRINCIPAL;}

1. Inicializar os dados de entrada;

2. Gerar o conjunto G;

3. Gerar o conjunto $\mathrm{G}^{*}$;

4. Juntar linhas que tenham os nós destinos= ao nó de origem;

5. SE existem rotas iguais em $\mathrm{G}^{*}$ ENTÃO

6. Eliminar as repetições;

7. Atualizar conjunto $\mathrm{G}^{*}$;

8. FIM_SE

9. SE existem rotas inseridas em outras em G* ENTÃO

10. Eliminar as rotas inseridas em outras;

11. Atualizar conjunto $\mathrm{G}^{*}$;

12. FIM_SE

13. Gerar o conjunto $\bar{G}$;

14. Gerar o conjunto $\mathrm{F} \leftarrow \bar{G} \cup \mathrm{G}^{*}$;

15. Iniciar geração da rede;

a. Escolher rota que apresente maior demanda potencial;

16. Adicionar rota escolhida ao conjunto que conecta à rede;

17. ENQUANTO a rede não está conectada

18. Escolher rota que apresente pelo menos um nó centroide em comum com a rede já criada e o máximo de centroides ainda não conectados;

19. Adicionar rota escolhida ao conjunto que conecta à rede;

20. Atualizar demandas potenciais das rotas restantes;

21. Atualizar conjunto $\mathrm{F}$;

22. FIM_ENQUANTO

23. Atualizar conjunto F;

24. Calcular o número de transbordos;

25. ENQUANTO número de transbordos $>0$

26. Escolher rota que reduza ao máximo o número de transbordos;

27. Adicionar rota escolhida a lista de rotas que minimiza transbordos;

28. Calcular número de transbordos resultantes;

29. Atualizar conjunto F;

30. Atualizar demandas potenciais das rotas restantes;

31. FIM_ENQUANTO

32. Calcular os parâmetros das rotas que minimizam o número de transbordos;

FIM_PROGRAMA PRINCIPAL 
Anexo 4. Valores dos indicadores para o conjunto $\mathrm{F}$ de rotas candidatas propostas por Aquino, (1980). 
*ROTAS DE "F" E RESPECTI\$OS PARA:IETROS*

RQTA NUUHERT

COMPRI MENTU $=12.30$

CARGA PUTELAGE DE TERUINALA TERHINAI, = $=0.27$

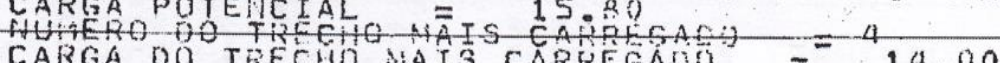

CARGA DO TRECHD MAIS CARKEGADO $=-14.00$

CARGA DO TRECHO WENOS CARREGAADO =

USUARIOS $X$ DUILDWETKOS $=\frac{1}{32} 20$

CAREA PDR ${ }^{X}$ UU

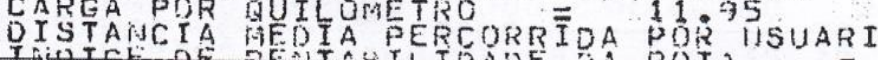

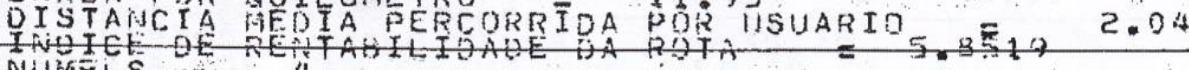

NUMG

UESVID EM RELACAO AO CAMINHO MIMIMO

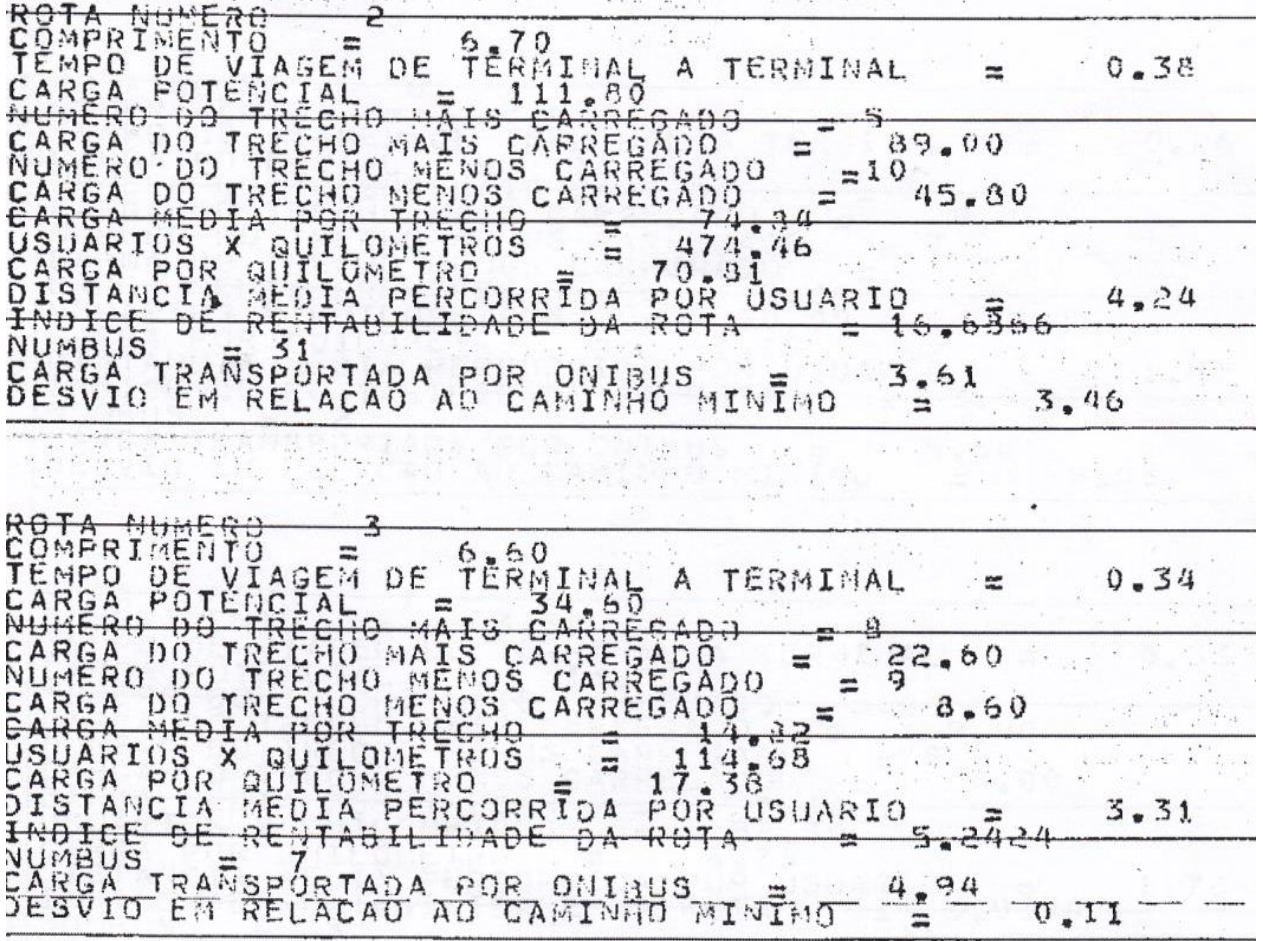




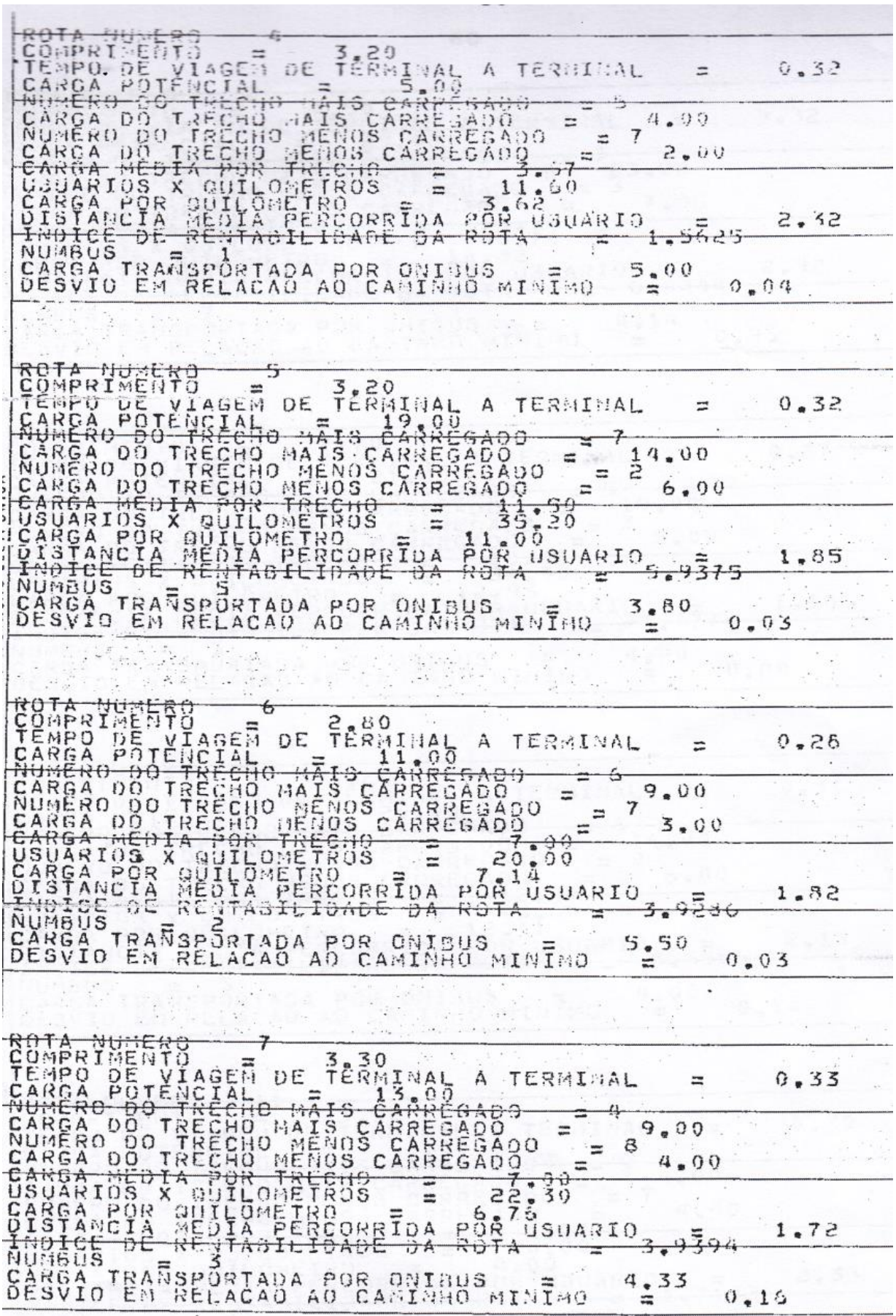




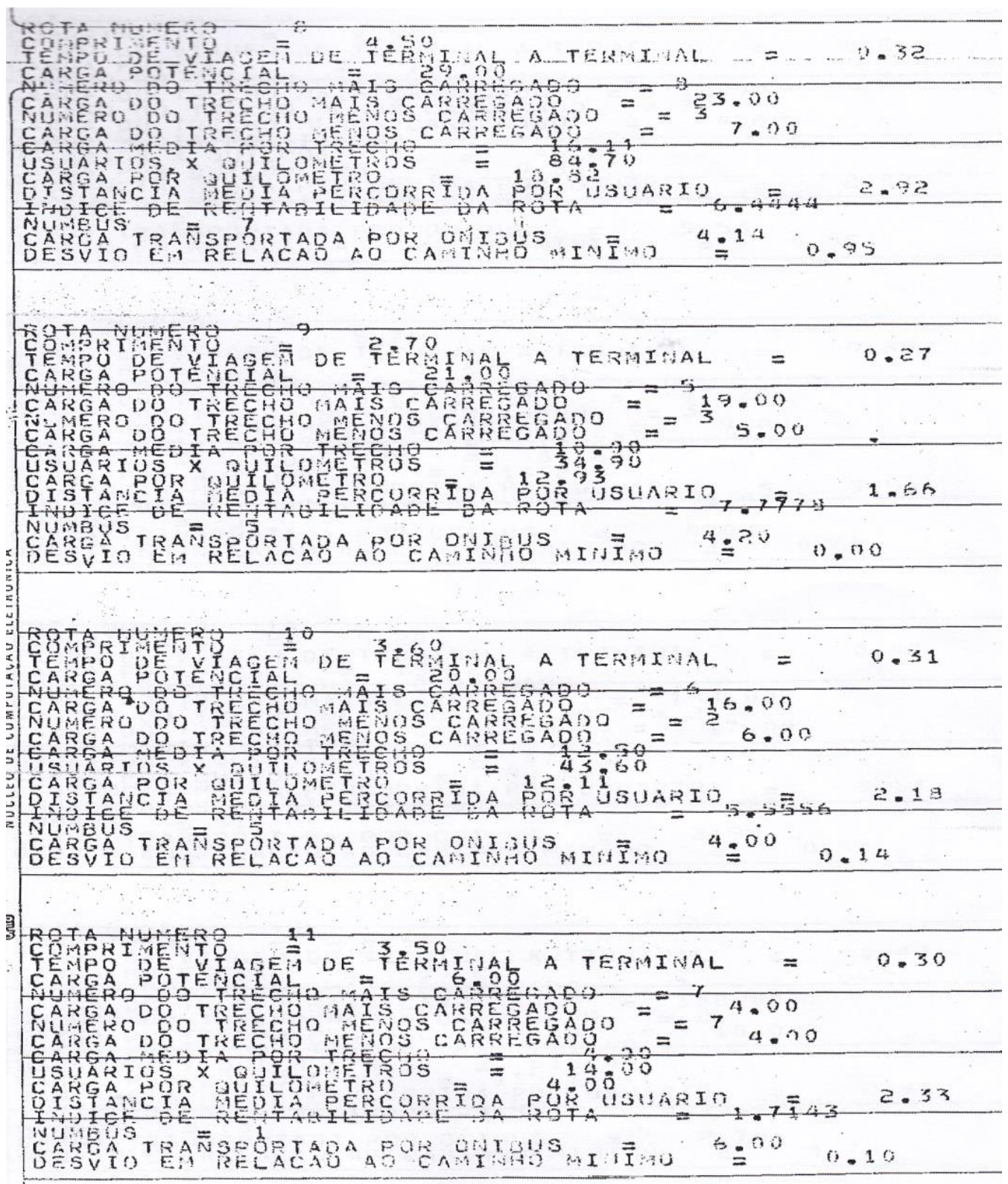




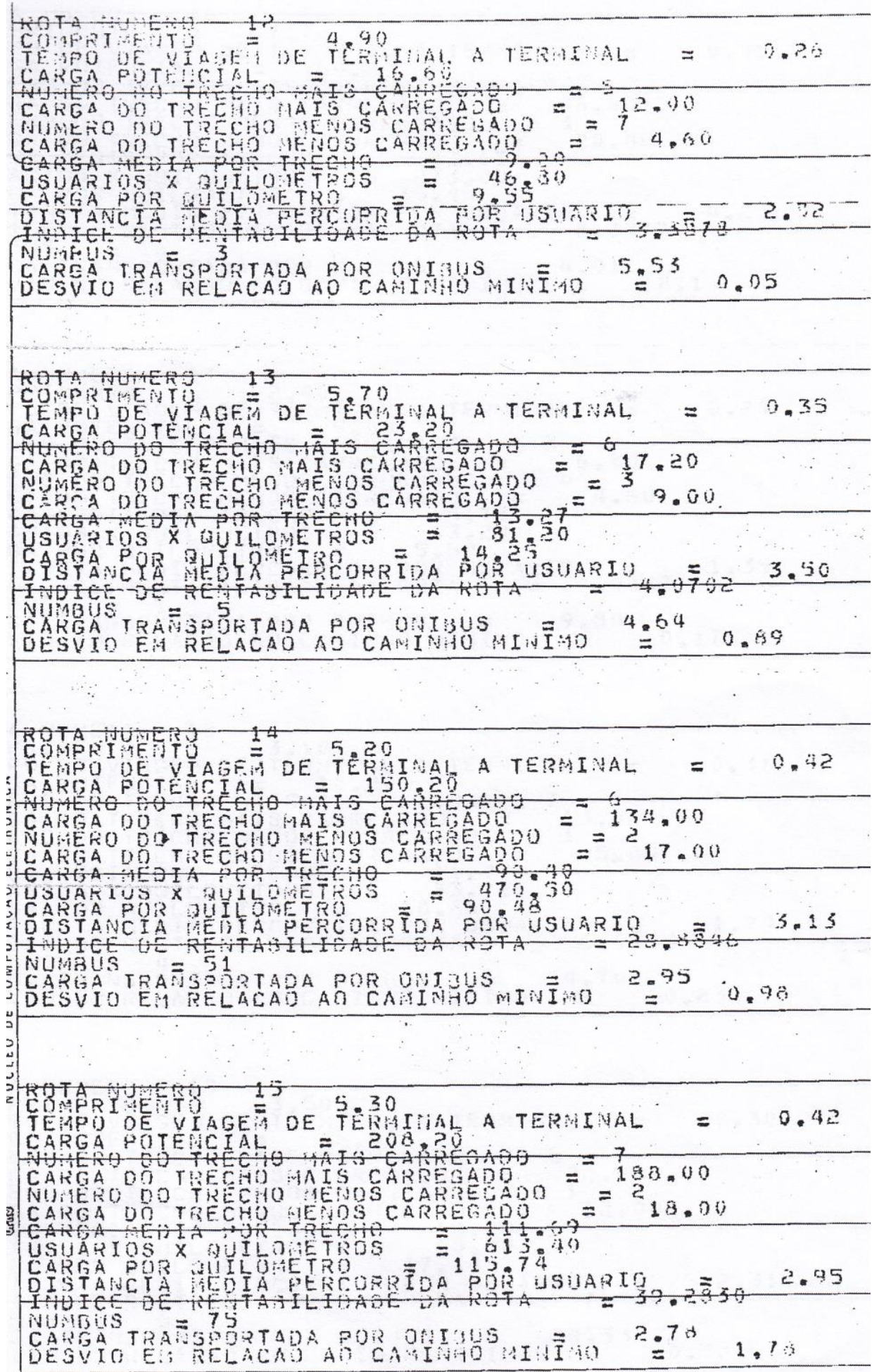




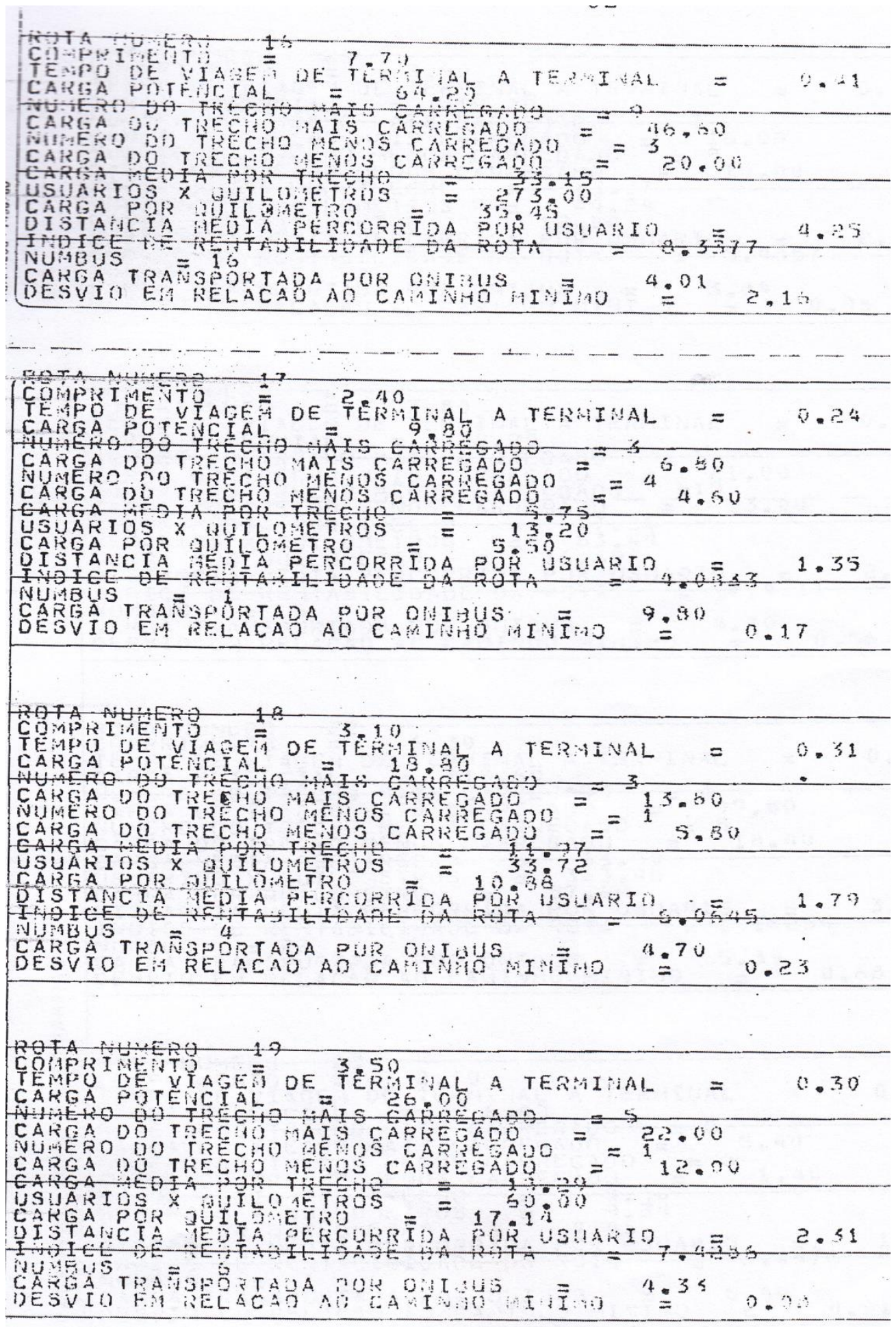




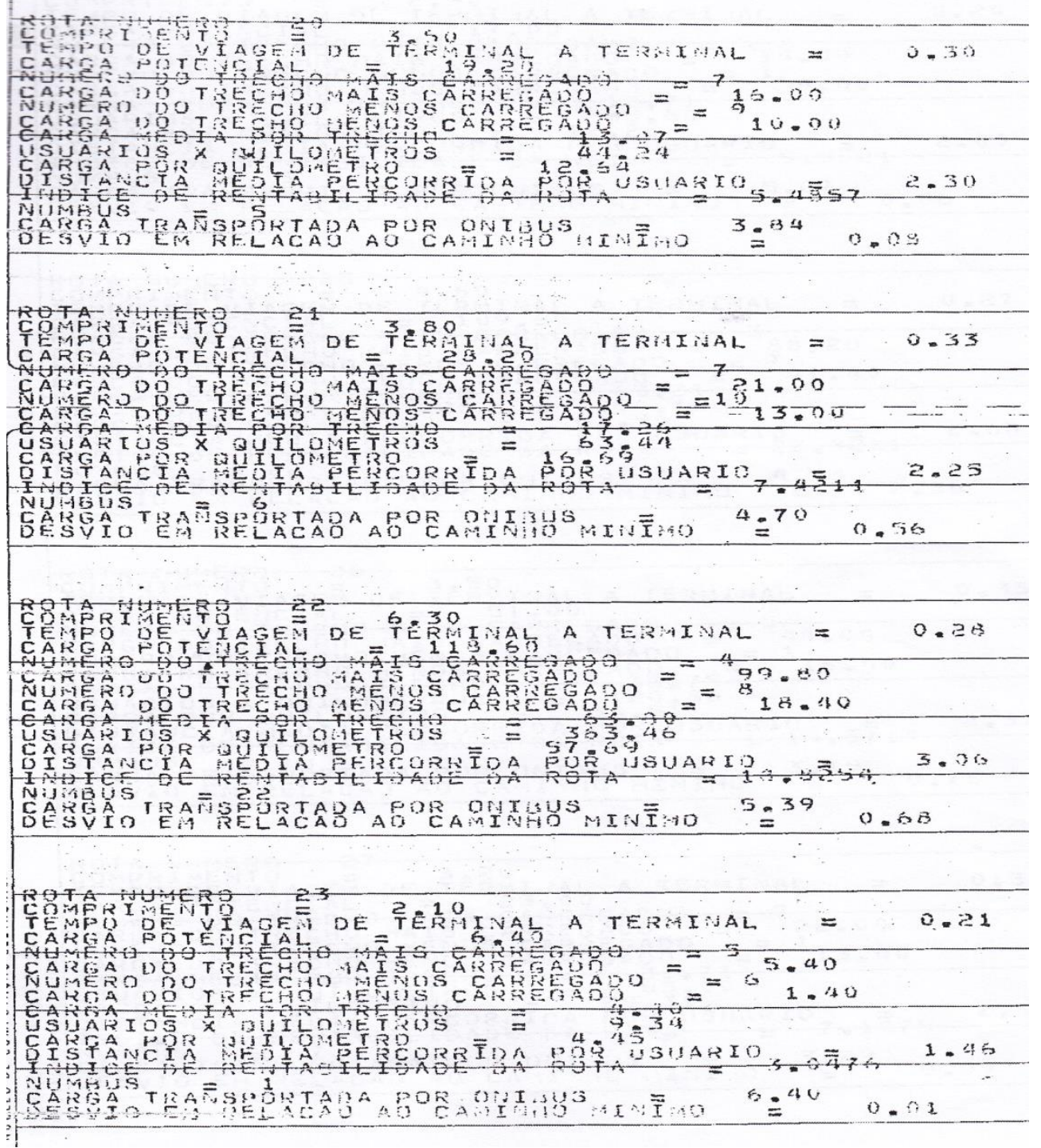



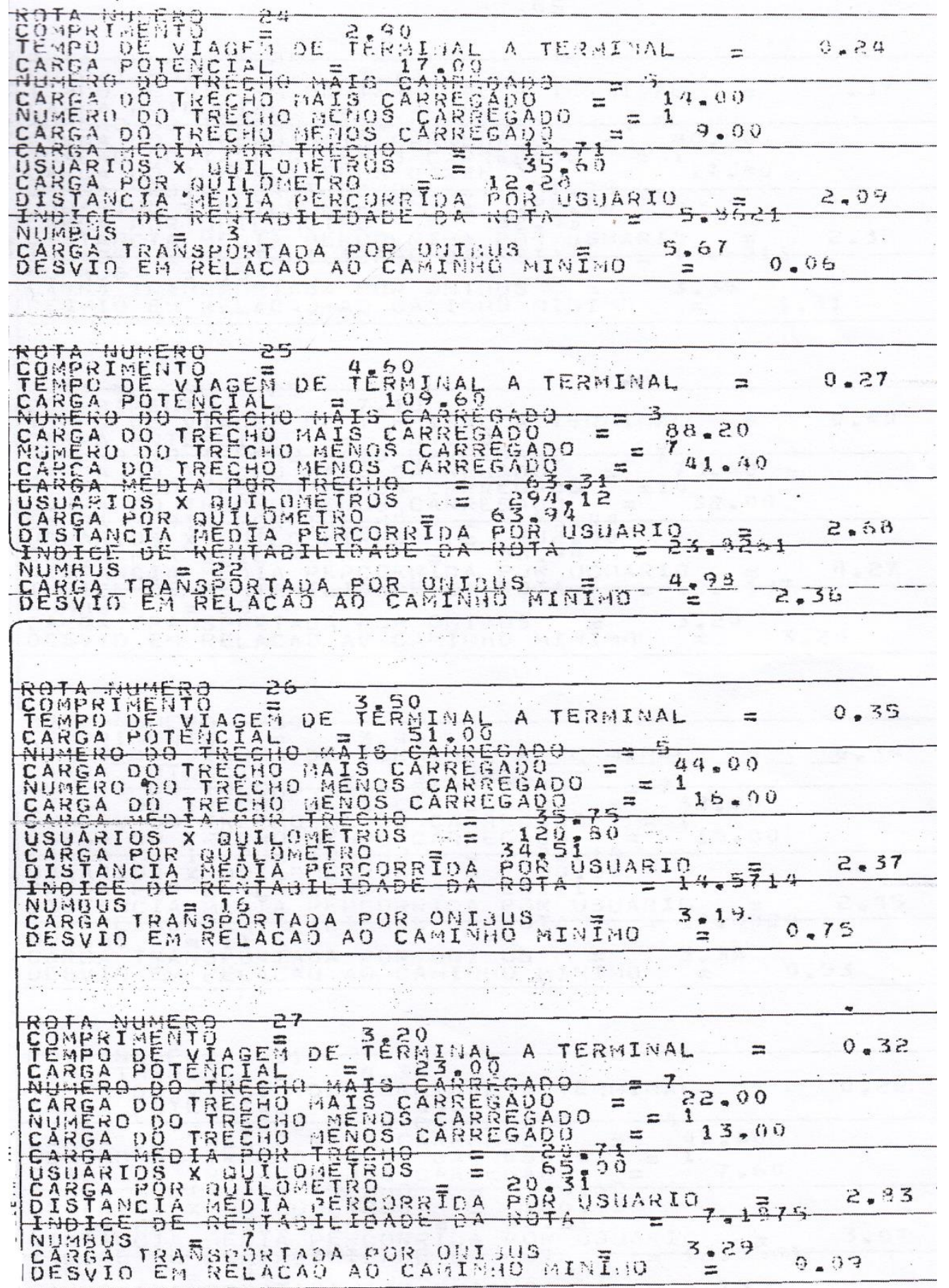

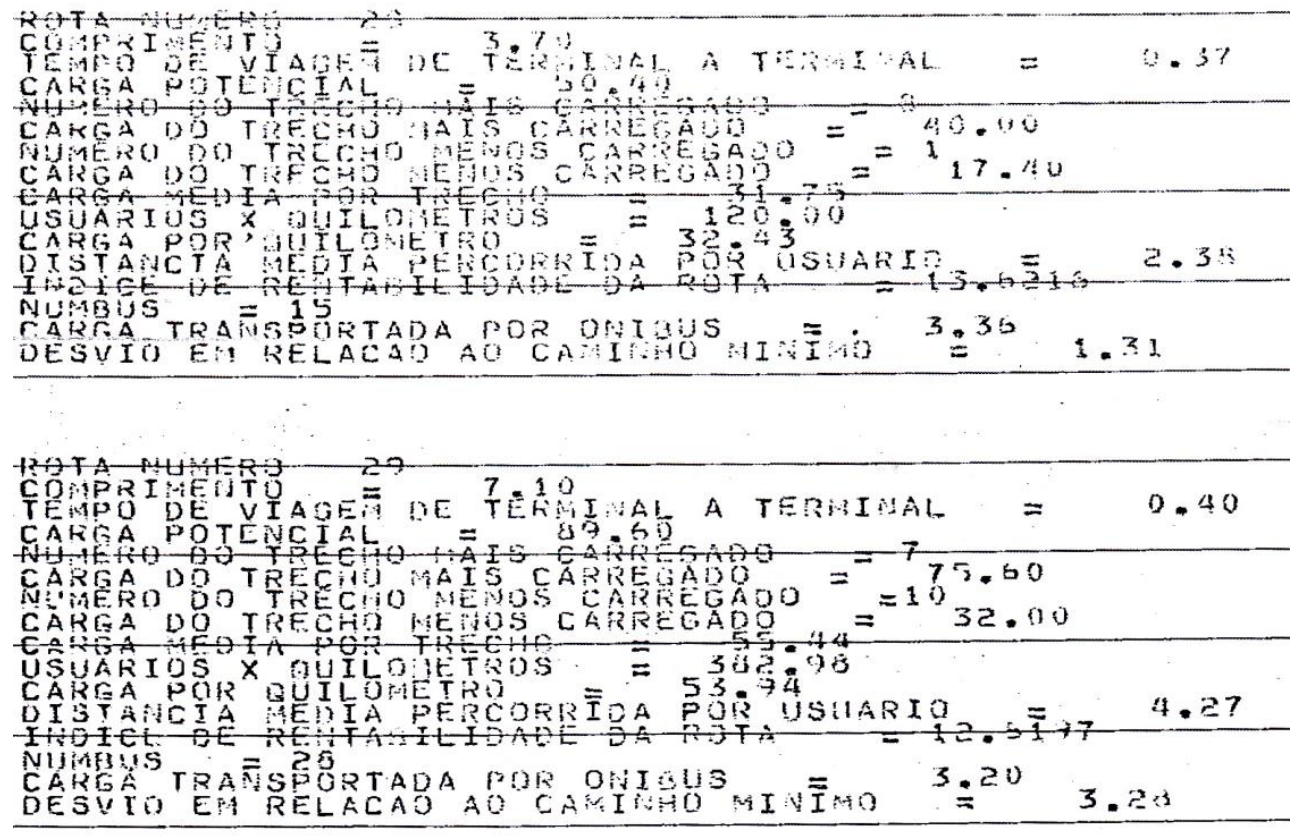

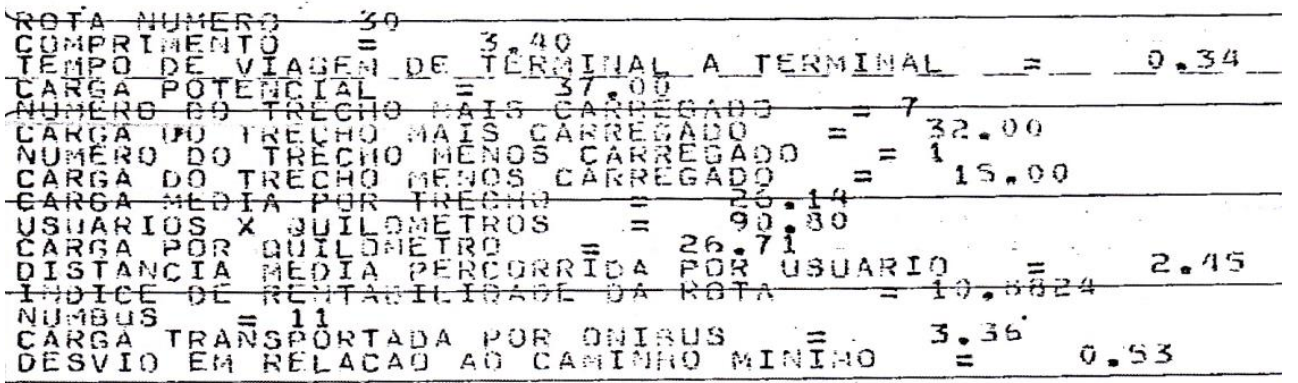

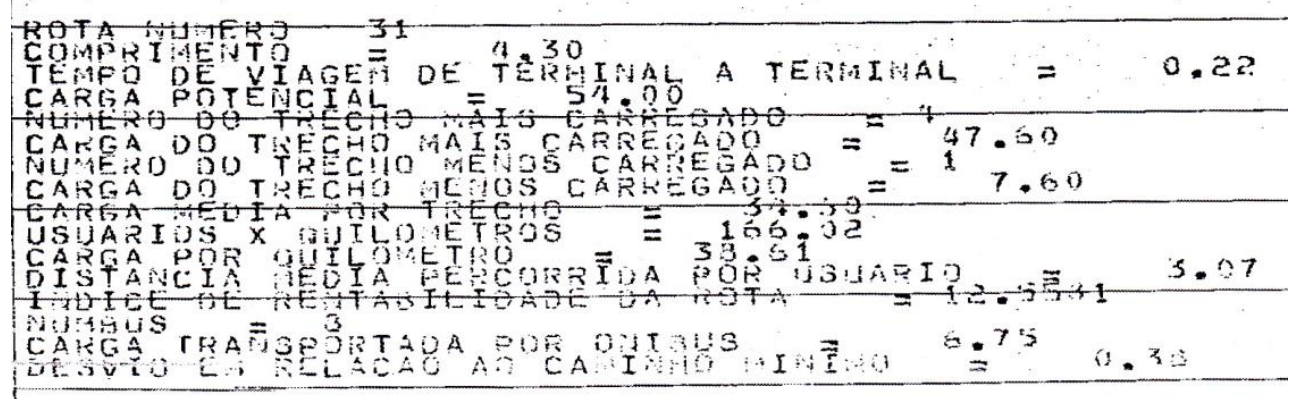




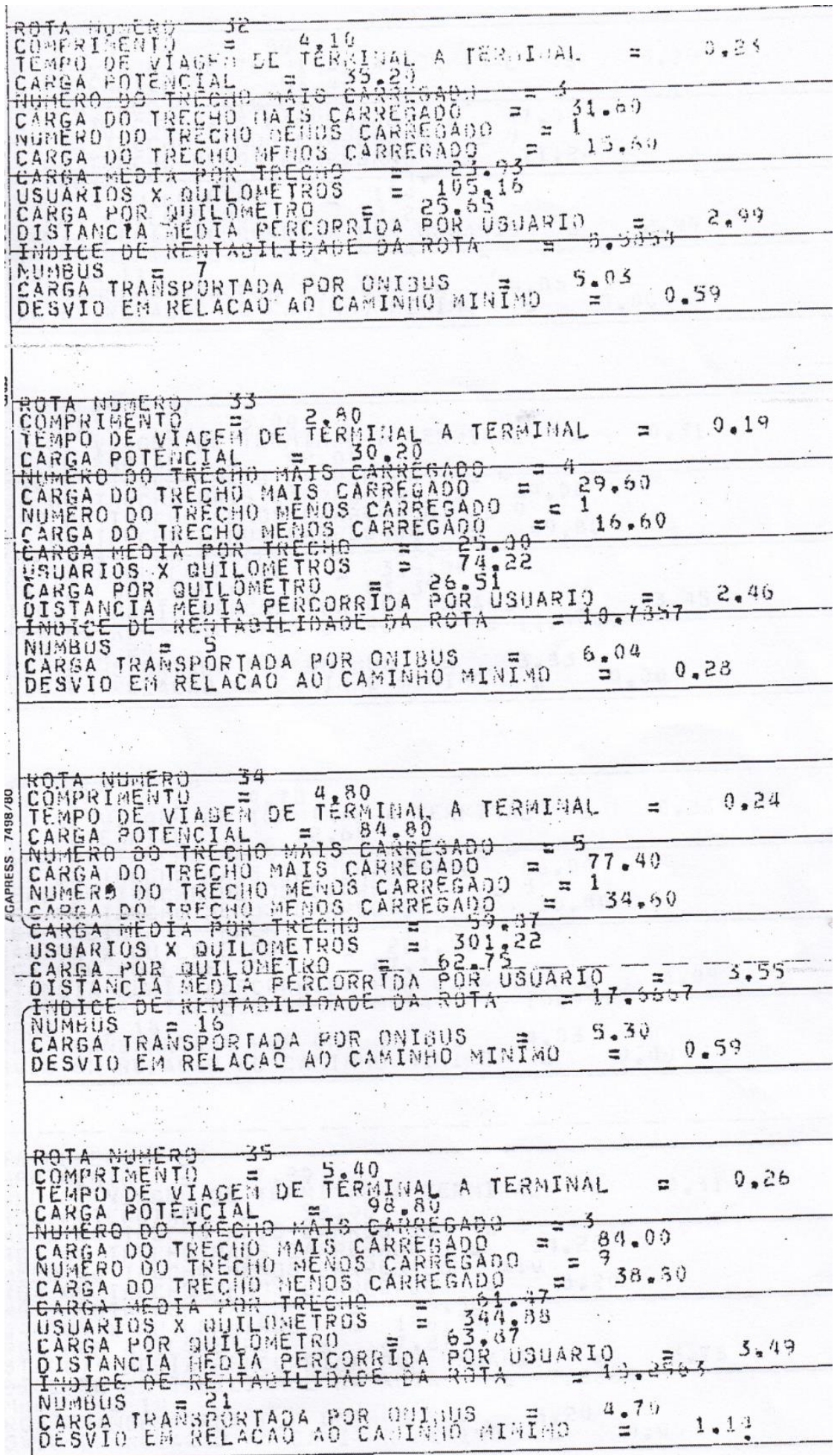




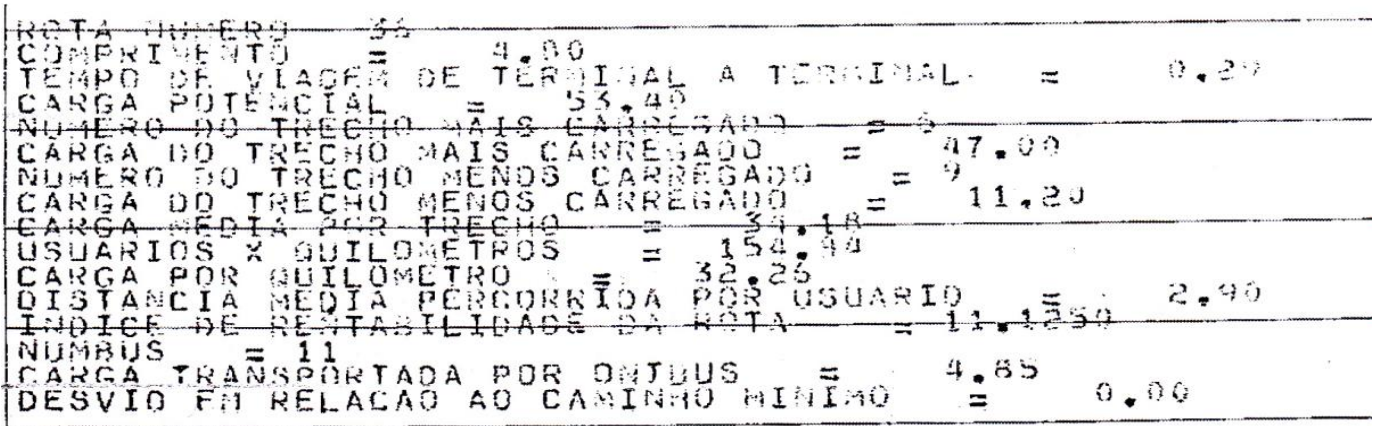

COMFRI ENTTO

CARGA DO TIECHO MAIS CAFRE

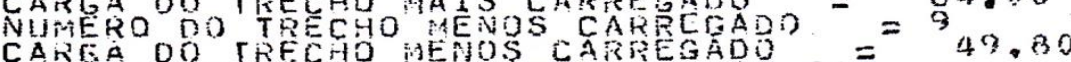

CAREA DO TRFCHD HENOS CABRESADQ

USUARIS X QUILOATROS

CARGA FER MUILOAETRQ

ISTANCIA MEDIA PERCORRIDA POY

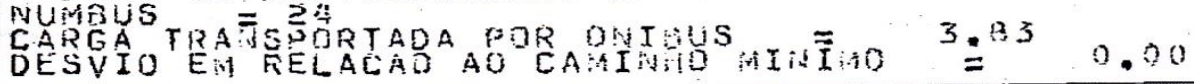

DESVIO EN RELACAB AO CAAINID MIUITO $=0.0$

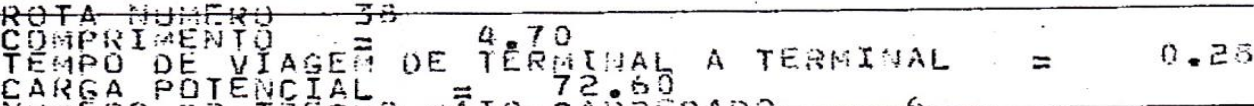

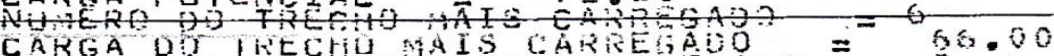

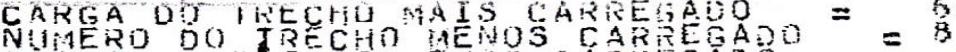

CAREA DO TRECH AONOS CARREGADO $=30.40$

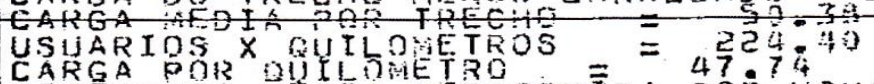

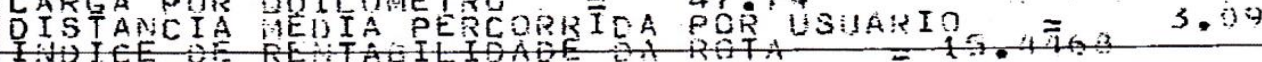

NUYBUS

CARTA TRAMSRRTADA POR OUTOUS

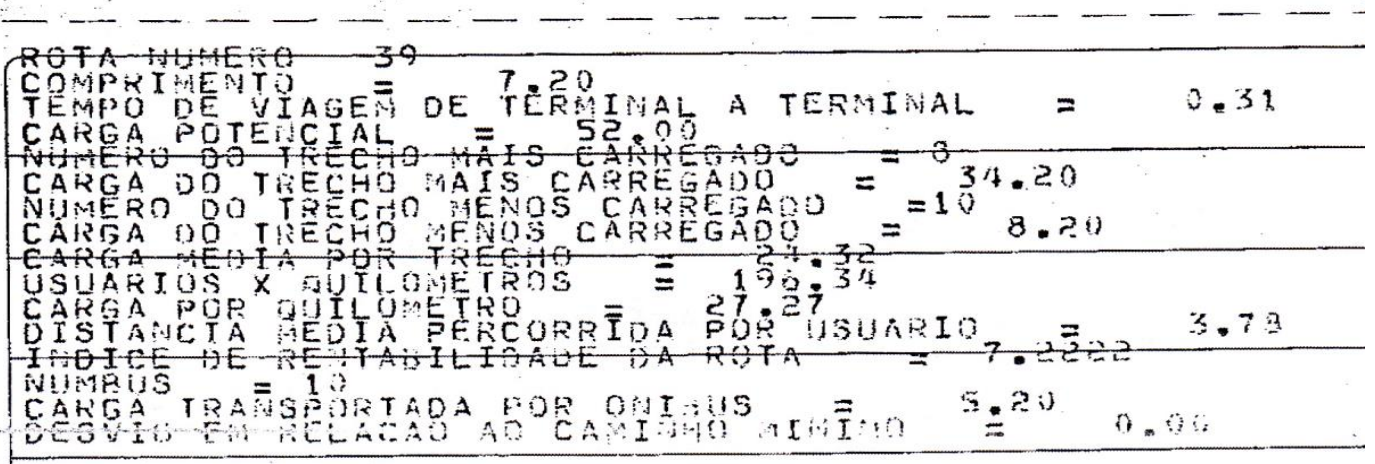




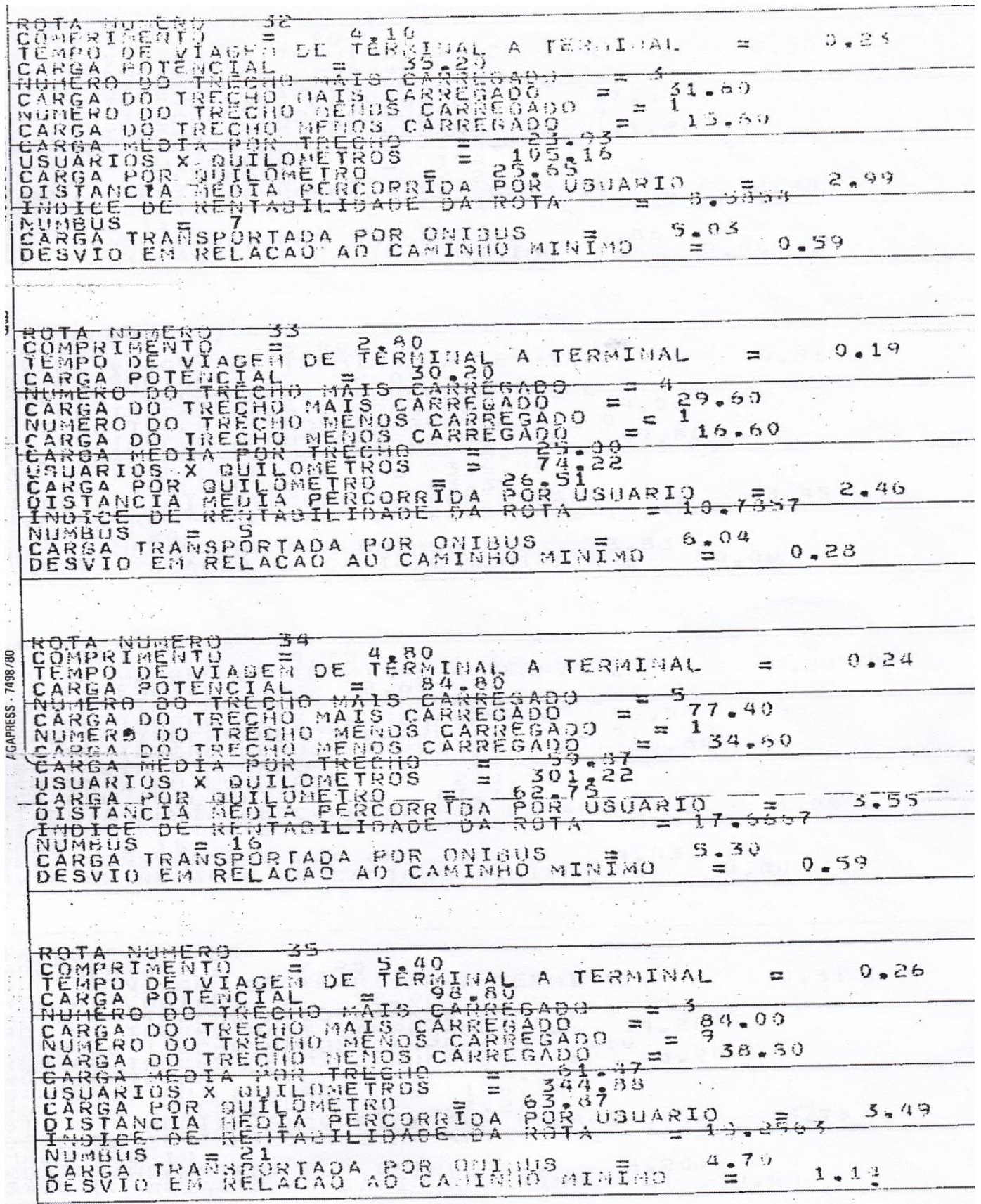



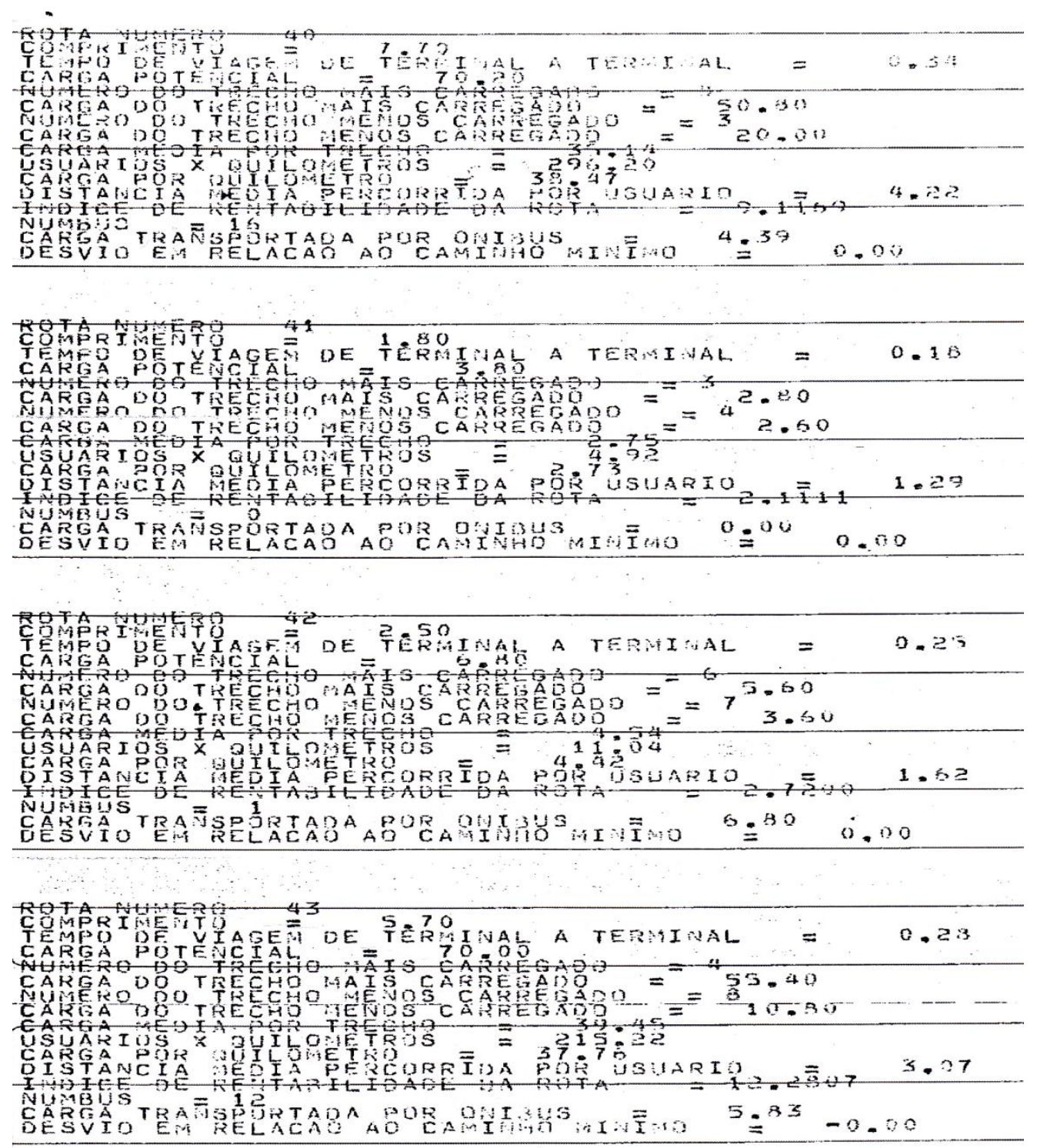

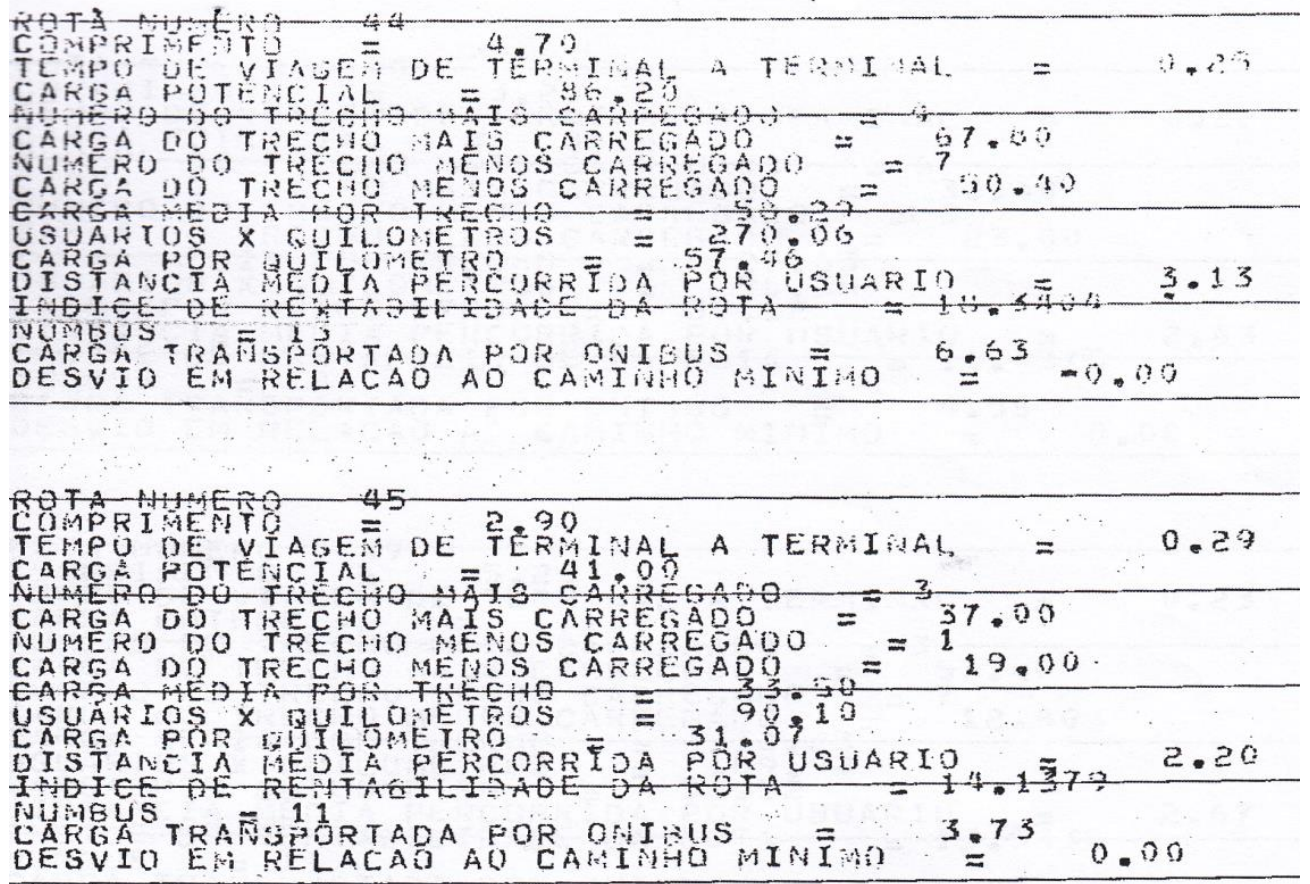


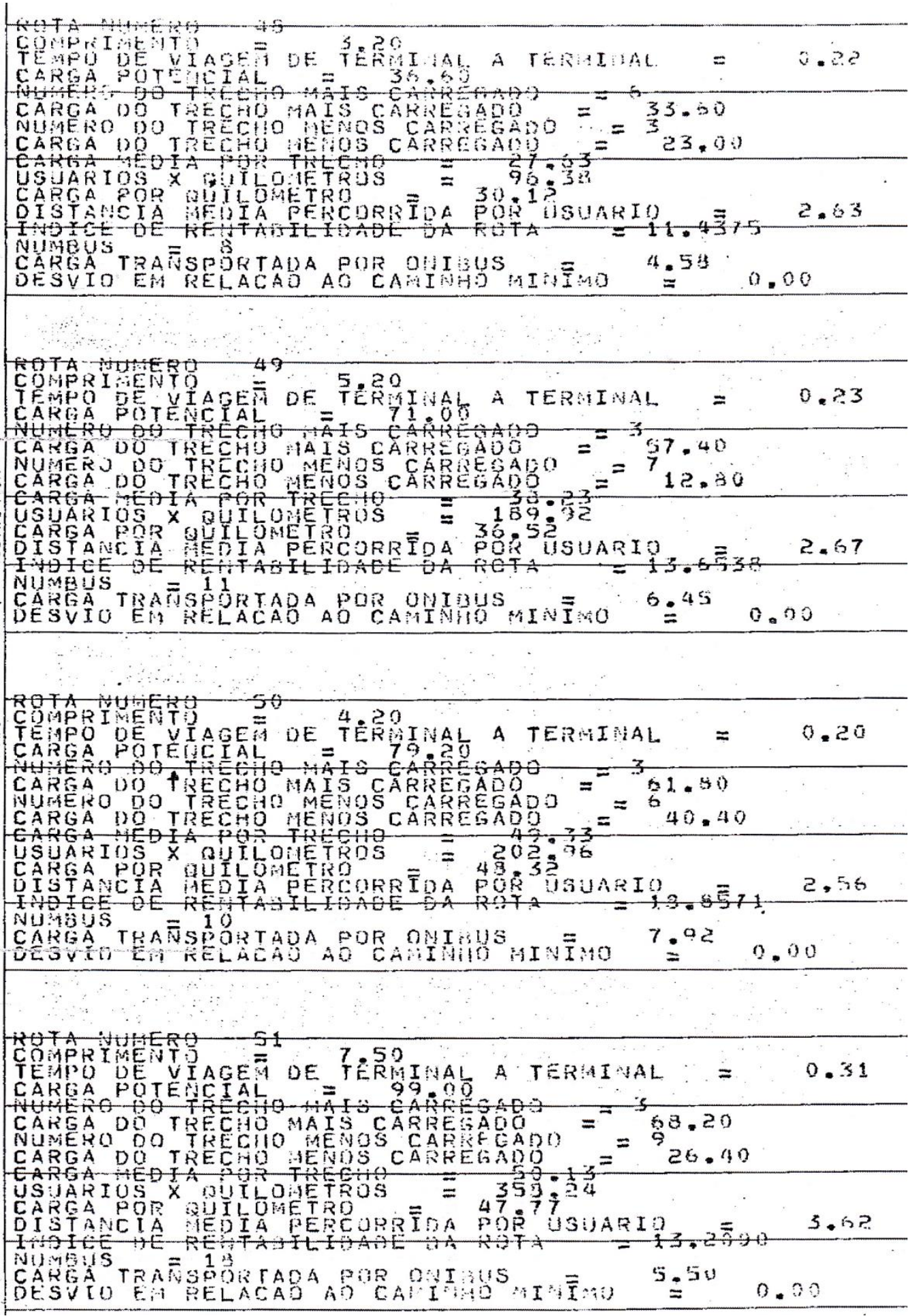




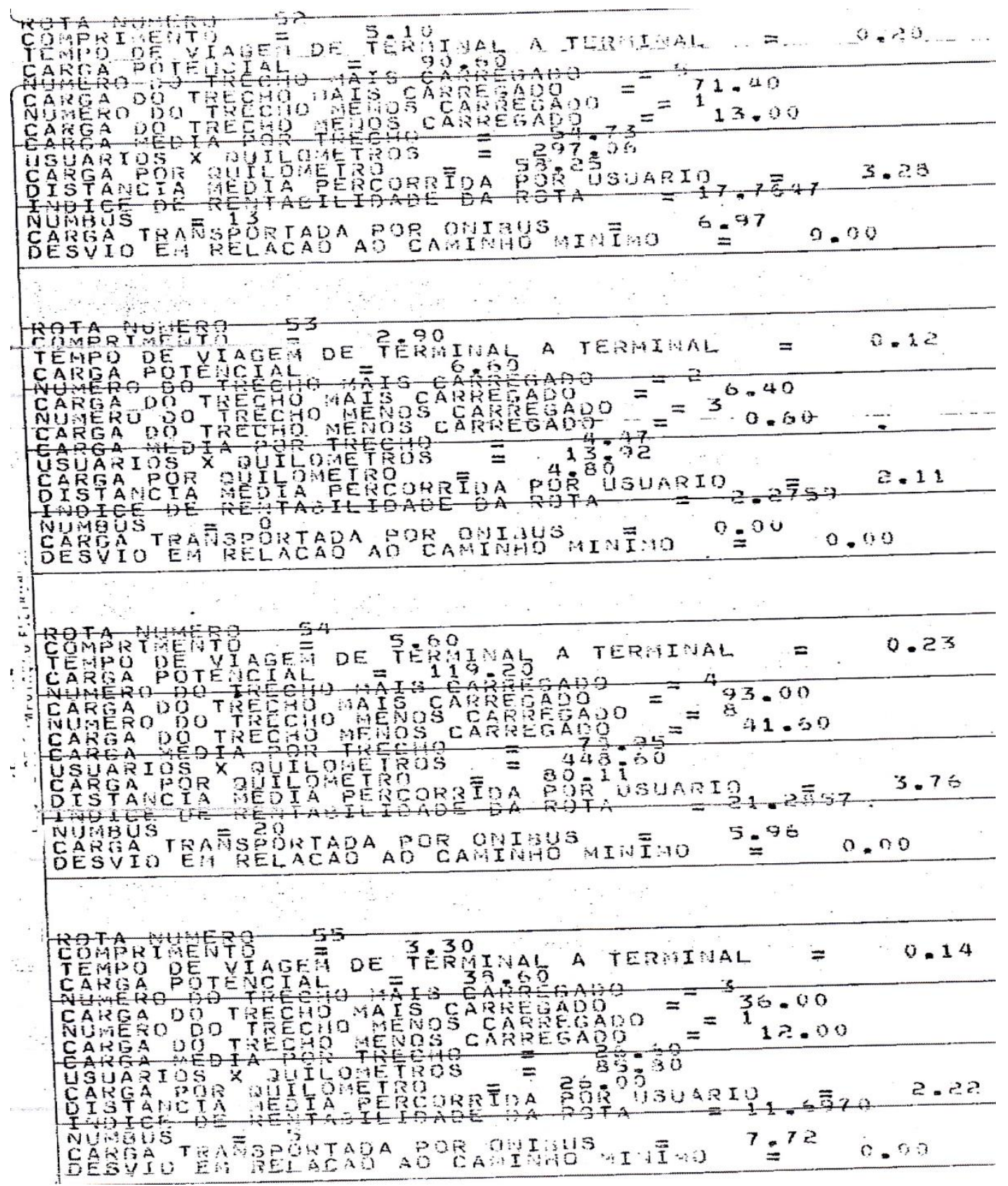

